University of Louisville

ThinkIR: The University of Louisville's Institutional Repository

$12-2010$

\title{
Longitudinal predictors of disciplinary alternative school placement and the risk of subsequent juvenile detention in a cohort of third grade children.
}

Judi Elisa Vanderhaar

University of Louisville

Follow this and additional works at: https://ir.library.louisville.edu/etd

\section{Recommended Citation}

Vanderhaar, Judi Elisa, "Longitudinal predictors of disciplinary alternative school placement and the risk of subsequent juvenile detention in a cohort of third grade children." (2010). Electronic Theses and Dissertations. Paper 1484.

https://doi.org/10.18297/etd/1484

This Doctoral Dissertation is brought to you for free and open access by ThinkIR: The University of Louisville's Institutional Repository. It has been accepted for inclusion in Electronic Theses and Dissertations by an authorized administrator of ThinkIR: The University of Louisville's Institutional Repository. This title appears here courtesy of the author, who has retained all other copyrights. For more information, please contact thinkir@louisville.edu. 
LONGITUDINAL PREDICTORS OF DISCIPLINARY ALTERNATIVE SCHOOL PLACEMENT AND THE RISK OF SUBSEQUENT JUVENILE DETENTION IN A COHORT OF THIRD GRADE CHILDREN

\section{By}

Judi Elisa Vanderhaar

B.S., University of Louisville, 1998

M.A., University of Louisville, 2003

A Dissertation

Submitted to the Faculty of the

Graduate School of the University of Louisville

in Partial Fulfillment of the Requirements

for the Degree of

Doctor of Philosophy

Department of Educational Leadership, Foundations and Human Resource Education College of Education and Human Development

University of Louisville

Louisville, Ky

December 2010 

LONGITUDINAL PREDICTORS OF DISCIPLINARY ALTERNATIVE SCHOOL PLACEMENT AND THE RISK OF SUBSEQUENT JUVENILE DETENTION IN A COHORT OF THIRD GRADE CHILDREN

By

Judi Elisa Vanderhaar

B.S., University of Louisville, 1998

M.A., University of Louisville, 2003

A dissertation approved on

November 30, 2010

By the following Dissertation Committee:

Dissertation Director (Joseph M. Petrosko)

\begin{tabular}{c}
\hline Marco Munoz \\
\hline Sam Stringfield \\
\hline Sue Lasky \\
\hline J. Blaine Hudson
\end{tabular}




\section{DEDICATION}

This dissertation is dedicated to Norman, Brandon, and Tremane, whose early struggle for dignity and hope inspired this work. 


\section{AKNOWLEDGEMENTS}

I would like to first thank my advisor, Dr. Joe Petrosko for standing beside me along my journey through the doctoral program, from entrance to dissertation. His unwavering support, boundless enthusiasm for statistics and willingness to engage in methodological challenges made this study and my success in the program possible. I would also like to thank my phenomenal committee members: Dr. Sam Stringfield, Dr. Sue Lasky, Dr. Marco Munoz, and Dr. Blain Hudson for their time, energy, support, and contributions to this study. In addition, I would like to thank Dr. Stringfield for exuding passion and a sense of urgency in every conversation and lecture, and for providing me an assistantship that helped me grow in knowledge and experience; Dr. Lasky for imparting her rich knowledge and understanding of the socio-cultural lens and her tremendous nurturing support; Blaine Hudson for first introducing me to the critical intersections of history, educational policy, race and inequality; and to Dr. Munoz for being the best mentor one could ever hope for, who leads by his shining example and whose kindness and words of wisdom will always be cherished. A special thanks to Dr. Robert Rodosky for the countless opportunities he has provided for my professional growth over the years and for his invaluable input to this study.

I would not have made it to this point without the unconditional support, friendship and encouragement of my work family: Florence, Deven, Joe, Dena, Bev, 
Ryan, and Marita. Thank you for believing in me and helping to push me towards the finish line. I am also indebted to the Jefferson County Public School Teenage Parent Program (TAPP) and the teachers and staff who provided all the support necessary to set me on this path towards success and who commit their lives to uplifting those students that others render hopeless.

I would like to thank Ryan McCafferty, Mark McCafferty and Beverly Nelson for helping me tackle the difficult task of historical data retrieval and for their knowledge of codes. I also want to acknowledge Judith Singer and John Willett for encouraging and making widely available the resources necessary for educational researchers to carry out survival analysis.

I owe infinite gratitude to my mother and father for their unconditional love and for sticking by me through the most difficult times, always encouraging me to get up and move forward. I am forever grateful for my siblings: Mike, Ann, Margaret, Liz, and Jimmy for their loving moral support and for helping me with the boys when I needed it most. Finally, I would like to acknowledge my primary source of pride and pure joy, my children, Savion and David for their patience throughout this process. Savion, your bright light, boundless love and big smile enrich each day, and your great sense of humor provide many moments of needed laughter during this work. David, your unconditional love, patience, intellect, grace, character, and old soul have deeply enriched the last 18 years of my life and made parenting you a delightful experience. Your depth of thought, curiosity, critical thinking, and similar love for engaging in lively debates expanded and deepened my thinking. I look forward to watching you along your own academic journey. 


\begin{abstract}
LONGITUDINAL PREDICTORS OF DISCIPLINARY ALTERNATIVE SCHOOL PLACEMENT AND THE RISK OF SUBSEQUENT JUVENILE DETENTION IN A COHORT OF THIRD GRADE CHILDREN
\end{abstract}

\author{
Judi Elisa Vanderhaar
}

November 30,2010

\begin{abstract}
Alternative school settings for students who are identified as "disruptive or dangerous" are playing an increasingly prominent role in the world of public education, yet many gaps in the research literature are abound. This dissertation study is an effort to contribute to an understanding of the students placed in these alternative schools, identify longitudinal predictors of placement, and assess the risk of subsequent involvement of the juvenile justice system.
\end{abstract}

The study sample consisted of an entire cohort of third grade children in a large metropolitan school district. Through the use of the methodological technique of discrete-time hazard analysis, time-constant and time-varying predictors of placement between $3^{\text {rd }}$ and $12^{\text {th }}$ grade were examined. The predictor variables used in the study included student demographic, academic and non-academic characteristics that were extracted through the districts large data warehouse. Also under examination in this study was whether, and if so when, students who experienced alternative school placement subsequently experienced a juvenile detention before $12^{\text {th }}$ grade. 
The results of this study indicated that cumulatively, $9 \%$ of the total cohort experienced placement in a disciplinary school by the end of $12^{\text {th }}$ grade. The hazard of placement was greatest in $7^{\text {th }}$ grade. African-American males were disproportionately represented among students placed. The discrete-time hazard models revealed that variables minority, male, free/reduced lunch status, school mobility, EmotionalBehavioral disability, absenteeism, and grade retention were significant predictors of placement through time. Out of school suspension remained the strongest predictor even when controlling for other significant predictors. Over a third of the student placed in alternative school experienced a subsequent juvenile detention. Of those placed in alternative school during elementary, half experienced juvenile detention before the end of $12^{\text {th }}$ grade. Logistic regression results indicated that race and gender were significant predictors of subsequent juvenile detention. Implications for policy, practice and future research are presented in the final chapter. 


\section{TABLE OF CONTENTS}

\section{PAGE}

DEDICATION...............................................................

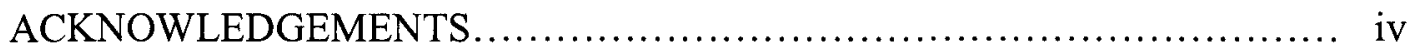

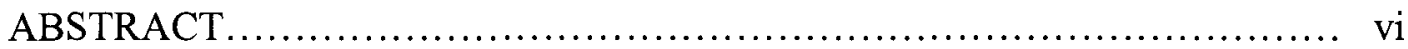

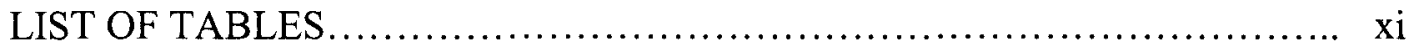

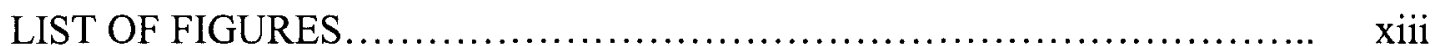

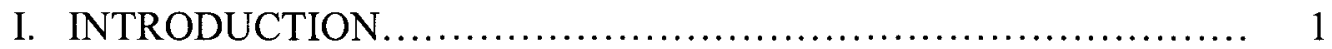

Statement of the Problem....................................... 2

Purpose of the Study........................................... 3

Definition of Terms......................................... 4

Study Limitations and Delimitations........................... 6

Significance of the Study .................................. 8

Researchers Perspective................................. 10

Organization of the Study .................................. 10

II. REVIEW OF LITERATURE...................................... 11

Overview.......................................................... 11

Alternative School Background............................. 12

Alternative School Typology........................... 12

The Evolving Purpose of Alternative Schools............. 13

Growth of Alternative Schools for Disruptive Students. 15

National Trends in ASDS................................ 18

Characteristics of ASDS................................. $\quad 20$

Characteristics of Student Placed in ASDS.............. 22

Alternative School Placement and School Discipline............. 23

Alternative School Placement as a "Last Chance"......... 23

Alternative Schools and the Placement of Students

with "BD"............................................ 24

Delinquency Prevention Programs in Mainstream Schools 25

National and Kentucky State Policies Influencing Placement into

Alternative Schools.............................................. 26

Gun Free Schools Act of $1994 \ldots \ldots \ldots \ldots \ldots \ldots \ldots \ldots \ldots . . \ldots 27$

Zero Tolerance Policies.................................... $\quad 28$

IDEA Amendments of $1997 \ldots \ldots \ldots \ldots \ldots \ldots \ldots \ldots \ldots \ldots . . . \ldots 29$

No Child Left Behind Provisions......................... $\quad 29$ 
Kentucky State Policy Context....................... 30

ASDS and the School-to-Prison Pipeline...................... 32

Individual and Systemic Impact of ASDS ..................... 34

Weakness and Potential............................... 35

Impact of Alternative School Placement on Students....... 36

Alternative School Accountability.......................42

Impact of Alternative Schools on the School System....... 43

Theoretical Framework....................................... 47

Broader Sociological Frameworks................... 47

Two Worldviews: Individual-Event or Systemic-Process... 49

Cumulative Disadvantage Theory ..................... 51

School to prison pipeline thesis.......................... 52

Gaps in Research Literature This Study Will Address............ 53

Statement of the Research Questions........................... 55

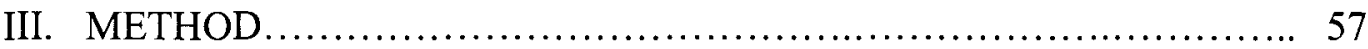

Problem and Purpose.................................... 57

Research questions....................................... 57

Research Design and Rational............................... 58

Site of Study ................................................... 60

Population and Sample...................................... 61

Data Collection and Procedures................................ 62

Study Variables........................................... 63

Analyses................................................... 67

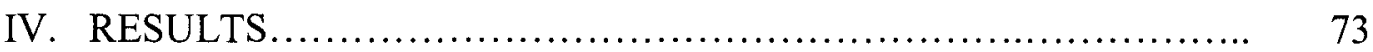

Description of the $3^{\text {rd }}$ grade cohort sample......................... 73

Demographics........................................ 74

Non-Academic Characteristics............................ 76

Academic Characteristics.................................. $\quad 77$

Research Question 1: Placement in disciplinary alternative school...... 77

Descriptive comparison of students placed and the cohort....... 82

Comparison of Demographics....................... 86

Comparison of Non-Academic Characteristics............ 87

Comparison of Academic Characteristics.............. 89

Number of Alternative School Entries...................... $\quad 90$

Research Question 2: Placement in disciplinary alternative school....... 93

Initial Discrete-time Hazard Model: Main effect of Time......... 93

Effects of Demographic Characteristics on risk................ 95

Effects of Non-Academic Characteristics on risk................ 104

Effects of Academic Characteristics on risk.................. 118

Research Question 3: Subsequent Juvenile Detention................... 125

Proportion of students subsequently detained................. 125

Time between placement and detention....................... 127 
Grade of placement and subsequent detention................ 128

Impact of race and gender............................... 131

V. DISCUSSION .................................................. 138

Purpose and significance............................................ 138

Key Findings and Implications.................................. 140

Additional recommendations for policy and practice.................. 148

Limitations of the study.......................................... 149

Directions for future research.................................... 150

Concluding thoughts......................................... 151

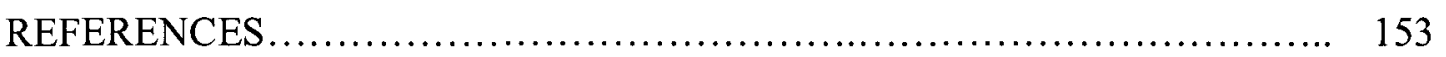

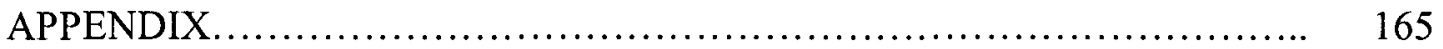

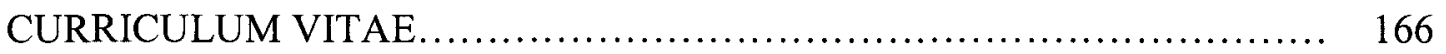




\section{LIST OF TABLES}

\section{TABLE}

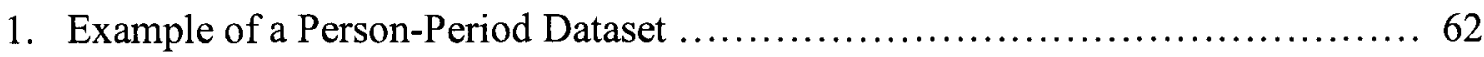

2. Research Questions, Data, Sample, Source, Analysis, and Interpretation Matrix... 72

3. Demographic Characteristics of $3^{\text {rd }}$ Grade Cohort 1997-1998 …................ 75

4. Non-Academic Characteristics of $3^{\text {rd }}$ Grade Cohort 1997-1998_................. 76

5. Academic Characteristics of $3^{\text {rd }}$ Grade Cohort 1997-1998_.................. 77

6. Life Table for the Cohort from 3rd to $12^{\text {th }}$ Grade.............................. 79

7. Demographic Characteristics of Students Placed in Disciplinary Alternative Schools and the Cohort ................................................ 85

8. Demographic Characteristics of Students Placed in Disciplinary Alternative Schools and the Cohort by Level ................................................ 87

9. Non-Academic Characteristics of Alternative Placed Students and Cohort by Level

10. Academic Characteristics of Alternative Placed Students and Cohort by Level... 90

11. Number of Unique Students and Number of Alternative School Entries......... 92

12. Initial Discrete-Time Hazard Model with main effect of TIME Re-expressed Parameter Estimates as Fitted Odds and Fitted Hazard Probabilities....

13. Results of fitting Discrete-Time Hazard models for Predictor Variables Race, Gender and Lunch Status to the Grade of First Placement.......................... 100

14. Results of fitting Discrete-Time Hazard models for Predictor Variables EBD and Suspension to the Grade of First Placement ................................ 108

15. Results of fitting Discrete-Time Hazard models for Predictor Variables Mobility and Absenteeism to the Grade of First Placement 
16. Results of fitting Discrete-Time Hazard models for Predictor Variables Retention and LD to the Grade of First Placement ....................................... 120

17. Results of fitting Discrete-Time Hazard models for Predictor Variables Lunch, Suspension, Mobility and Retention to the Grade of First Placement ............. 124

18. Number of Students Placed in Alternative School and Number and Percent of Students Subsequently Detained

19. Number of Years Between Placement in a Disciplinary Alternative School and Juvenile Detention Between $3^{\text {rd }}-12^{\text {th }}$ Grade

20. Average Number of Years Between Grade Level of Placement and Subsequent Juvenile Detention....

21. Grade of First Alternative School Placement and Subsequent Grade of Juvenile Detention

22. Percent of Students by Race and Gender in Cohort, Alternative Schools and Detained for Students Placed in Elementary School.

23. Percent of Students by Race and Gender in Cohort, Alternative Schools and Detained for Students Placed in Middle School

24. Percent of Students by Race and Gender in Cohort, Alternative Schools and Detained for Students Placed in High School......................................... 135

25. Logistic Regression Predicting Juvenile Detention with Race and Gender ........ 136

26. Summary of Results................................................... 137 


\section{LIST OF FIGURES}

\section{FIGURE}

1. Timeline of policies regarding increased use of disciplinary alternative schools... 32

2. Systemic model of alternative school placement.............................. 51

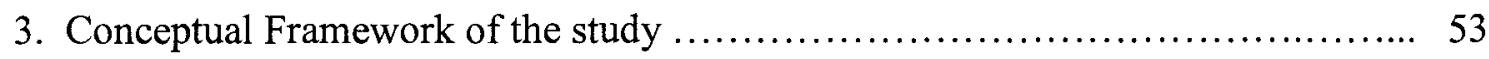

4. Illustration of hazard function for alternative school placement ................. 80

5. Illustration of the survivor function for placement in alternative school.......... 81

6. Number of unique students placed and number of entries into disciplinary alternative

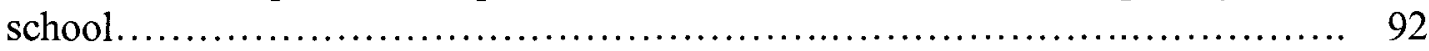

7. Illustration of fitted hazard function for the grade of placement with main effects of time and race. ...... 102

8. Illustration of fitted hazard function for the grade of placement with main effects of

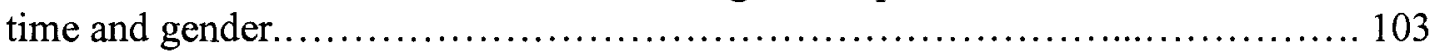

9. Illustration of fitted hazard function for the grade of placement with main effects of time and lunch status................................................. 104

10. Illustration of fitted hazard function for the grade of placement with main effects of time and EBD........................................................ 109

11. Illustration of fitted hazard function for the grade of placement with main effects of time and suspension...................................................... 110

12. Illustration of fitted hazard function for the grade of placement with main effects of time and mobility .................................................... 117

13. Illustration of fitted hazard function for the grade of placement with main effects of time and absenteeism.............................................. 118

14. Illustration of fitted hazard function for the grade of placement with main effects of time and retention. 


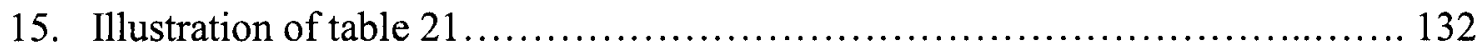

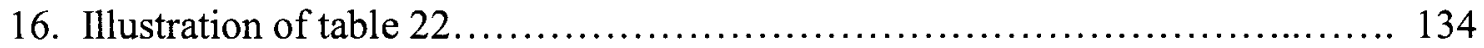

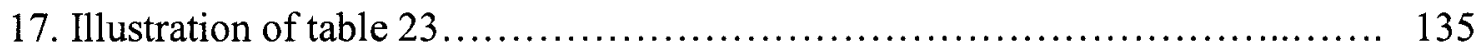




\section{CHAPTER I INTRODUCTION}

The rapid increase in the use of alternative school placement for disruptive or "dangerous" students necessitates a longitudinal examination of the educational and disciplinary predictors of students placed in such schools. Simultaneously, the nation's juvenile detention rate continues to grow. Grounded in conflict theory, this exploratory study represents a unique longitudinal investigation of multiple predictors of student placement in alternative schools for disruptive or "dangerous" behavior within a large urban school system. Currently, there is a significant lack of rigorous empirical investigation into the educational experiences and outcomes of students placed in alternative schools. The chief goal of this dissertation was to contribute to the sparse research literature on youth placed in alternative schools. The secondary goal of this dissertation was to contribute to the emerging "school-to-prison" research by exploring the subsequent juvenile detention of students placed in these schools. These aims were tackled by modeling event occurrence over time through the application of survival analysis to longitudinal data, housed in a large district database. The use of this technique provided an understanding of the time-constant and time-varying predictors of alternative school placement and the duration between placement and subsequent juvenile detention. 


\section{Statement of the Problem}

Alternative school settings for students who are identified as "disruptive or dangerous" are playing an increasingly prominent role in the world of public education. The increase in alternative schools is correlated with the mounting population of disenfranchised students (Kim \& Taylor, 2008). National data reflect an expansion that can be defined as skyrocketing, not steady (Lange \& Sleeten, 2002; Lehr, Soon Tan, \& Ysseldyke, 2009,). In Kentucky, the alternative schools, if aggregated, would be the largest classified school system in Kentucky (Kentucky Youth Advocates, 2008). At the local, state and national level, the demand for alternative schools for "disruptive or dangerous" students outweighs the supply. In fact, a recent National Center for Education Statistics report revealed that the majority of urban school districts reported having to place students on waiting lists due to space and staffing limitations (Lange \& Sleeten, 2002). These districts reported "lack of alternative placements for disruptive students" as the most limiting factor impeding efforts to reduce or prevent crime at school a decrease in violent victimization in schools. There is sparse literature (rooted largely in descriptive self-reported statistics and anecdotal evidence) examining the schooling histories of students enrolled in these schools and very little research documenting the outcomes of students, particularly with respect to involvement of the juvenile justice system.

Though rapid expansion of and reliance on these schools is clear, the body of research is far from parallel to their growth. Similarly, there is an emerging line of literature on the "school-to-prison pipeline" that is in great need of continual investigation. Due to the ever increasing numbers of young people and particularly 
African-American males entering the juvenile justice system, many scholars, practitioners, and social justice advocates note extreme concern and are calling for research that explores the relationship between schooling experiences and entry into the juvenile justice system.

\section{Purpose of the Study}

The purpose of this exploratory study was three fold. The first purpose of the study was to describe how many, and at what grade level students were placed in alternative schools for "disruptive or dangerous" students in a cohort of $3^{\text {rd }}$ grade students. The second purpose of the study was to determine the time-constant and timevarying predictors of alternative school placement. Time-constant predictors are variables that remain stable over time (e.g., ethnicity). Time-varying predictors are those whose values can change over time (e.g., school attendance). While these were the primary purposes of this study, the third purpose was to explore whether, and if so when, students who experienced an alternative placement event subsequently experienced a juvenile detention before $12^{\text {th }}$ grade, and if grade level of placement (e.g., elementary, middle, high) impacts the risk of juvenile detention. Importantly, this study aimed to fill a gaping void in the research literature on disciplinary alternative schools as well as contribute to the budding yet small body of "school to prison pipeline" literature through a rigorous empirical research methodology. The longitudinal nature of the data set allowed changes in students' event histories to be tracked through their education careers.

The research questions investigated in this study were (a) What is the proportion of students who experience a placement in an alternative school event and when are students most likely to experience the placement across a 10 year time span in a cohort of 
$3^{\text {rd }}$ grade children?, (b) What are the empirically based time-constant and time-varying predictors of risk associated with an alternative school placement event in the cohort of 3rd grade children across 10 year time span?, and (c) for the students that experience an alternative placement event, what proportion experience subsequent juvenile detention and when are they most likely to experience that event?

\section{Definition of Terms}

The primary terms used in this study were defined as follows:

\section{Alternative School for Disruptive Students}

The district in the study provides a wide array of alternative schools to serve students with various special circumstances. The district has schools that serve many different student populations including students with severe mental and physical disabilities, students who are hospitalized, students who are pregnant or parenting, students who previously dropped out or aged out of k-12 seeking their GED, and students who struggle academically for various reasons. The alternative schools in this study can be identified as alternative schools for disruptive or dangerous students (ASDS). The primary differences between ASDS and other alternative schools are that (1) placement in ASDS is mandatory via state and/or school board policy (the others are self-selected by students or enrollment through an application process), and (2) students are enrolled due to being (a) in violation of the student code of conduct that requires placement or (b) too disruptive, behaviorally challenged, or dangerous to remain in the regular school setting.

\section{Juvenile Detention}

The district database contains student level information for the entire duration of a student's schooling career within the district. Any time a student is withdrawn from a 
school or enters into a school, a code is entered into the student's record within the district database. When a student is withdrawn from any school for any reason (e.g., residential move, dropout, hospitalization, juvenile detention placement) the school enters the respective withdraw code. Enrollment into a youth detention facility that serves students who were adjudicated or are awaiting adjudication is used to identify students that experience juvenile detention. While the majority of students in the district who are placed in a juvenile justice facility still receive educational services from the district, there are those who have been incarcerated and placed under the court's jurisdiction and do not receive any educational services for a period of time. Only a juvenile detention event that occurs after placement into an ASDS is considered in this study.

\section{Academic Measures}

While individuals possess numerous cognitive factors, many of which cannot be measured simply through academic testing, the proxy for the academic or cognitive factors in this study are limited to those that are measured through standardized academic tests. The test scores used to indicate academic ability over time comes from a norm referenced test -the Comprehensive Tests of Basic Skills (CTBS), which is given to students in grades 3,6 and 9. The CTBS total battery test score and in the CTBS reading score operate as the cognitive factors in this study. The second factor used as a proxy for cognitive ability is the special education status related to learning (Specific Learning Disability). This is a dichotomous variable, with students identified as having a learning disability coded 1 and those not identified coded 0 . 


\section{Non-Academic Measures}

There are a multitude of non-academic factors that impact individuals stemming from psychological, social-behavioral, and environmental realms. The non-academic factors explored in this study are limited to those that are documented within the districts database. In addition to student demographics (e.g., ethnicity, gender), these factors include school absenteeism, retention, school mobility, lunch status (as proxy of poverty), out of school suspension, and the special education status of Emotional Behavioral Disability.

\section{Limitations and Delimitations}

In an effort to describe the bounds of this research, possible threats to the study's validity and to acknowledge the limitations of the research, the study delimitations and limitations are explicated. With respect to delimitations, the variables used in this study were restricted to what the district has collect over the timeframe covered in this research. There is limited and in some cases no availability of data on individual students outside the bounds of what is housed in the district database such as psycho-social and home or other environmental factors. These other factors undoubtedly play a role in the schooling experiences and outcomes of the students in this study; however it is not feasible to explore such variables in this study.

Similarly, the specific impetus for alternative placement has historically not been documented in the district database and remained primarily in individual school records. Specific reasons for juvenile detention are also not documented in the district database and are housed within the juvenile justice data systems. As such, the individual reasons 
for alternative placement and subsequent juvenile detention are beyond the bounds of this study.

Finally, prior research reveals that a large percentage of students in alternative schools do not experience successful transition after placement into the mainstream schools and as such return to alternative schools, in some cases multiple times. This study only examined the first alternative school placement and not multiple exits and entries into alternative schools.

The primary limitation of the study is the study sample of one cohort of $3^{\text {rd }}$ grade students within one large urban school district. This will have implications for restricting generalizability of the findings. Other limitations of this study are rooted in the constraints posed by the data available on the study sample. The realities behind many of the defined variables used in the study are unknown as they simply represent a construct. For example, the lunch status is used as a proxy for poverty and assumes that this status means the same thing for all of the students identified as having a particular lunch status associated with them. Also, the lunch status of students during the elementary years is considered more reliable than in middle of high school. Due to the stigma associated with this status, some secondary students do not want to be identified as receiving free lunch and thus do not even apply for the lunch program.

Additionally, there are several challenges inherent in a large longitudinal student information system that has changed over the time period this study covers. For example, while alternative school placement data is reliable and valid, the withdraw from one school and entry into a juvenile detention facility relies on adequacy and accuracy of the 
data entry and communication between school clerks and the juvenile justice personnel so that can be entered into the students record in a timely manner.

Despite the delimitations and limitations of the research, the researcher believes this study has great significance and implications for education policy and practice.

\section{Significance of the Study}

This dissertation study is important for theoretical, practical, and ethical reasons. In light of the growing placements of students in alternative schools for "disruptive or dangerous" students coupled with the lack of rigorous quantitative research, this study aids in augmenting the sparse body of knowledge on this sector of public education.

This study substantively contributes to the current yet small body of research on students placed in alternative schools and the school-to-prison pipeline. No known previous study investigates the longitudinal schooling experiences of these students, includes students in elementary grade levels, identifies both time-constant and timevarying predictors of alternative school placement, or quantifies subsequent juvenile detention. Nearly all of the "school to prison pipeline" research is qualitative or anecdotal and thus there is a great need for quantitative research on large numbers of students. Increasing the number of rigorous investigations probing these aspects and links adds to the theoretical knowledge base of systems thinking related to schooling experiences, alternative school placements, and subsequent juvenile justice system involvement.

Practically, this study contributes to understanding the individual impact disciplinary alternative schools have on students and as such, school districts may be able to make more informed policy decisions regarding their use. Having a greater awareness of the student predictors of placement can aid in earlier more targeted interventions in the 
mainstream school. This research can help illuminate specific points of intervention within large urban school systems that can help curtail exclusionary discipline and the diminish school to prison pipeline. Also, identifying the schooling histories of students within a school system found to increase the likelihood of alternative school placement may garner attention and thus further investigation. Examining these issues through the lenses of "cumulative disadvantages" or, processes over time, rather than simply onetime events may encourage administrators to view students identified as "disruptive or dangerous" with respect to schooling experiences over time, and school policies and practices, not simply individual student deficits.

Importantly, this research will provide educational researchers (practitioners and academics) explicit guidance regarding the use of existing longitudinal data in large often untapped district data bases to identify systemic issues, predictors and critical intervention points related to various persisting problems in our educational system. Additionally, by applying an advanced methodology to a longitudinal data set, this research will illuminate the need for educational researchers to take advantage of the sophisticated methods- used in other fields- necessary to move our field forward (Willit \& Singer, 2003).

With respect to ethics, it is estimated that 1 in 100 Americans are in prison yet 1 in 10 black males are in prison (Sentencing Project, 2008). The disproportional exclusion, containment, and cumulative disadvantage of some minority youth in our nation's public school system have a real and devastating impact on the youth, their families, their communities, and the integrity of the system itself. In a society that increasingly contains both adults and juveniles within a growing prison industrial 
complex, any attempt to understand processes within institutions that either perpetuate or that can prevent the imprisonment of minority males is an economic, social and ethical imperative.

\section{Researchers Perspective}

Empirical research assumes complete objectivity on the part of the researcher, yet the topic selection and discussion of findings are often framed by the researchers experience and interest. In an effort to be forthright about the lens through which the researcher views this area of study, the researcher's frame of reference on this topic is rooted in real world experiences. The researcher previously worked closely with students as a therapeutic aide in a disciplinary alternative school for elementary and middle school students; as well as well as conducted in-depth evaluations of two of the alternative schools in this study as part of a job duty.

\section{Organization of the Study}

The study is organized into several sections. Preceding an introduction that explicates the framework and purpose of the study, the body of literature on alternative schools for "disruptive" or "dangerous" students is presented in Chapter 2. This includes empirical research and non-empirical literature. The theoretical framework guiding this study is also presented in Chapter 2. This section will conclude with a summary. The study methodology is presented in Chapter 3. This chapter includes details on the primary method of investigation, the data, site of study, data collection, and analyses. The results of all analyses are presented in Chapter 4. Finally, a discussion of the study findings, implications, and directions for future research is put forth in Chapter 5. 


\section{CHAPTER II}

\section{LITERATURE REVIEW}

To contextualize the present study, several relevant areas of literature are reviewed. First, the background of alternative schools in presented. This includes a description of alternative school typologies, changing purposes, the growth and trends of alternative schools and the characteristics of the schools and students who are placed in them. The discussion then turns to alternative placement in the context of school discipline and is followed by an account of key policies influencing the growing use of alternative schools. A brief yet critical review of the emerging school-to-prison pipeline thesis is presented. Next, a review of qualitative and quantitative research on the individual and system-wide impact of alternative schools is presented.

Following, the conceptual and theoretical frameworks that undergird this research

study are explicated. The theoretical component in this section is presented near the end of the chapter, as opposed to the beginning because it helps provide a context for the rational of the approach taken in this study and explicates how the research paradigm differs from previous studies presented throughout the literature review. In the final portion of this review, the author underscores the serious gaps in the research literature, thereby pointing to the need for the current study. After discussing why this research is important, the research questions of the study are presented. 


\section{Alternative School Background: typology, evolving purpose, growth, trends and characteristics}

The emergence of alternative schools runs parallel to the birth of traditional public schools in the United States. In general, alternative schools serve a variety of students for a variety of reasons. While the purpose, nature and participants of alternative schools vary across many dimensions, the consistent growth of alternative schools within the national public educational system is clear. In order to situate the research on alternative schools serving disruptive students, this section will provide a background by describing the basic alternative school types, their evolving purpose, characteristics, and growth.

\section{Alternative School Typology}

In response to the variations and lack of definitive definitions of public alternative school types, Raywid (1994) offered the first widely recognized typology of alternative schools by defining three types. Due to the continuous evolution and changing nature of alternative schools, Lange and Sletten (1995) added to this typology with a fourth distinct type of school.

Type I includes alternative schools of choice for students of all kinds. These schools typically are likened to "magnet" or charter programs with an emphasis on education through innovative or challenging curriculum. Type II alternative schools, the focal point of this study, exists as a "last chance" for students with the purpose of containing and/or reforming disruptive and dangerous students. Type III alternatives are designed to provide a short-term academic remedial setting for students with social and emotional problems (Raywid, 1994). Less typical, yet increasingly emerging in some states, Type IV alternative schools include a blend of type I and Type II schools (Lange \& Sletten, 1995). 
Many alternative schools serve students who failed in some respect in mainstream school settings. What distinguishes Type II schools from all other types is the issue of choice. That is, Type II alternative schools that serve disruptive, dangerous or delinquent students are both punitive and mandatory. Within a school system, the primary function of Type II schools is to keep students in mainstream schools safe. In theory, type II schools are designed to provide a punitive environment so that students will re-think and change the behavior that is considered unacceptable in mainstream schools (Loflin, 2000).

The distinguishing characteristic of choice or lack thereof, has important implications for the outcomes of students attending such schools. Research comparing voluntary alternative schools versus mandatory alternative schools indicates that student improvement is rare in mandatory alternative schools with a punitive purpose (Arnove \& Strout, 1980; Raywid, 1999). Thus, within the wide spectrum of alternative educational programs, alternative schools serving disruptive or delinquent youths are marked by three distinguishing characteristics: (a) students are mandated to attend following an exclusion from their mainstream school, (b) placement is generally temporary, and (c) containment and discipline remain at the center of the schools' purpose.

\section{The Evolving Purpose of Alternative Schools}

In her research on the first decade of public alternative schools, Raywid (1981) found that alternative options for public school students skyrocketed from 100 schools to over 10,000 between the late 1950 's through the early 1960 's. Alternative education was strongly supported by the 1965 Elementary and Secondary Education Act, designed to prevent dropout and academic failure (Kim \& Taylor, 2008). According to Young 
(1990), the impetus for the growth of alternative schools was a result of the wider societal changes that took hold during the civil rights movement. In particular, alternative education sprouted as a movement to empower poor and minority students (Morrison et al., 2001). Most of the alternative schools established during the civil rights movement were different from those of today, because they were structured around a progressive orientation.

Institutions of education reflect society at large and are influenced by the social, economic and political climate. Thus, mirroring changes in the wider political climate from the 1960's throughout the 1980's, alternative schools became less progressive, and operated out of a more narrow and conservative framework (Raywid, 1981; Young, 1990). Beginning in the early 1980's, the Office of Juvenile Justice and Delinquency Prevention began an initiative promoting alternative schools for delinquent students based on the premise that schools could play a significant role in reducing youth crime (Barber, 1980; Cox, 1999).

While in theory, alternative schools exist to advocate and provide optional learning environments for all students, Arnove and Strout (1980) explained that in practice, alternatives most frequently serve two types of students: those who are deemed "gifted" or those identified as "failures" (p.454). For students deemed failures or at risk of failure, two basic subsets of alternative schools emerged: One included alternatives for students experiencing academic difficulty and at risk of dropping out, and the other for students described as dangerous or disruptive. Ironically, though the original purpose of alternative schools for the "at-risk student" was to provide an alternative learning environment for students who had difficulty in the traditional school environment, 
research indicates that they are increasingly being used as an act of punishment, exclusion, and containment for disruptive students (Dunbar, 2001; Lehr, Lanners \& Lange, 2003; Morrison et al., 2001).

In fact, some are calling for the replacement of minor forms of discipline with increasing placement of students to alternative schools (Morrison et al., 2001; Troyan, 2003). After depicting constitutional violations of in school suspension (ISS) as a disciplinary practice in the context of Texas Law, Troyan (2003) advocated for the elimination of ISS in favor of transfers to alternative education programs. Troyan urged for this change based on the following reasons. First, students habitually assigned to ISS are not receiving any true instruction and thus are being denied their right to an education. Second, placement in an alternative program would ensure the students receive instruction in a structured, rehabilitating environment.

In 1996, the American Federation of Teachers (AFT) recommended that districts provide a continuum of alternative school placements. The AFT encouraged the use of both in-school suspension centers and long term alternative settings for disruptive students and students with behavioral disorders. While the AFT promotes the use of preventative strategies and early intervention, a paper presented at the Annual Convention of the council for exceptional children reaffirmed the AFT's position favoring alternative schools (Bader, 1997).

\section{Growth of Alternative Schools for Disruptive Students}

In response to current educational, political, economic and social forces, alternative schools are increasingly playing a more prominent role in the world of public education (Kim \& Taylor, 2008; Lange \& Lehr, 2003a; Lehr, Soon Tan \& Ysseldyke, 
2009). Interestingly, in the mid 1980's, it was projected that alternative schools for disruptive and at-risk students would grow steadily throughout the 1990's (Garrison, 1987). Consistent with the steady increase of alternative schools nation-wide throughout the 1990's, the current number of public alternative schools and enrollment of the at-risk students that fill them is on the rise.

Data from the National Center for Education Statistics (NCES) Common Core of Data (CCD) indicate that alternative schools grew from 2,606 in 1994 to 3,850 in the 1998. Indicative of the recently rapid growth in such schools, a recent NCES study by Kliner, Porch, \& Farris, (2002) identified 10,900 public alternative schools for at-risk students during the 2000-2001 school years. Moreover, this represents a conservative estimate of the number of such schools. Lange and Sletten (2002) estimated that there were over 20,000 alternative schools and programs for at risk students.

Due to the variety of alternative schools and programs for students deemed at risk, these studies did not identify the type II alternative schools specifically for disruptive students. Nevertheless, there is an agreement among researchers who examine issues related to alternative schools and school discipline that placement of disruptive students into alternative schools is a growing popular strategy schools are using to deal with students who are considered behavior problems (Banicky, 2000; Loflin, 2000; Lehr et al., 2003). A 2005 NCES study conducted by DeVoe et al. found that in 2000 , of the $54 \%$ of public schools reporting at least one serious disciplinary action against a student, $18 \%$ removed/transferred students from their mainstream school environment.

A demand for more alternative schools serving disruptive students is clearly growing across the country (Aaron \& Zweig, 2003; Dunbar, 2001; Franklin, 1992; Loflin, 
2000). Reflecting on current suspension and expulsion practices nationwide, some researchers recently forecasted that the use of alternative school placement will continue to rise (Lehr et al., 2003; Morrison et al., 2001). In fact, $83 \%$ of districts with alternative schools reported putting students on waiting lists due to space and staffing limitations (Kliner, Porch, \& Farris, 2002). In the 2003 national school survey on crime and school safety $70 \%$ of urban public schools reported lack of alternative placements for disruptive students as the most limiting factor impeding efforts to reduce or prevent crime at school (NCES, 2007). Paradoxically, a 2003 NCES report on indicators of school crime and safety showed a decrease in violent victimization in schools, from 10 percent to 6 percent between 1995 and 2001(NCES, 2003). Though rapid expansion of and reliance on these schools is very evident, the body of research is far from parallel to their growth.

Theoretically speaking, the increasing use of alternative schools reflects policy makers' "constrained worldview" of students who violate school rules. Constrained worldview is a common expression used by sociologists. This worldview reflects the general orientation of the U.S. criminal justice and legal system that holds individuals are deemed responsible for their behavior. Exceptions are made only for special circumstances (e.g., diminished mental capacity). In contrast to an "unconstrained worldview" that views student misbehavior as a result of social inequalities and special circumstances, the "constrained worldview" conceptualizes that students are responsible for their misbehavior and must accept the consequences. "Due to the dominance of the constrained worldview in the education policy realm, exclusion remains the intervention of choice" (Morrison et al., 2001, p.46). 


\section{National Trends in Alternative Schools for Disruptive Students}

There is no dispute among educational researchers and policy makers that alternative schools for "disruptive/dangerous" students continues to mount significantly across the United States (Lehr, Soon Tan, \& Ysseldyke, 2009). Findings from an indepth National Center of Education Statistics (NCES) study by Kliner, Porch and Farris (2002) reveals the growth of such schools and highlights several important national trends. The trends presented in the study have only accelerated (Kim \& Taylor, 2008). The authors conducted a representative survey to determine school district practices in the use of alternative schools. Issues under examination included availability, enrollment size, entrance/exit criteria, staffing, curriculum, and degree of collaboration with community agencies. Questionnaire data from 1534 school districts during the 20002001 school year revealed that school districts most likely to have alternative schools for at-risk youth were large, located in the Southeast region, have a high minority enrollment, and high concentrations of poverty. Alternative schools were offered at the high school level by $92 \%$ of districts, at the middle school level by $67 \%$ of districts and at the elementary level by $21 \%$ of districts. In many districts, the demand for alternative school placements outweighed the supply. In fact, $83 \%$ of districts with alternative schools reported putting students on waiting lists due to space and staffing limitations.

With respect to entrance and exit criteria, the majority of districts with alternative schools for at-risk youth placed students in the schools because the students physically attacked someone, possessed drugs, were truant, or engaged in disruptive verbal behavior. Of districts with alternative schools, $75 \%$ allowed students to transfer back to a base school while $1 \%$ did not allow transfers. The two key determinants for allowing 
students to transfer back to their base schools were improved student behavior/ attitudes and motivation to return. Key findings in regard to staffing, curricula, and collaboration, revealed that large districts and districts with high minority enrollment and poverty concentration were more likely to report involuntary placement of teachers into alternative schools; $75 \%$ had policies requiring curriculum to meet individual student needs. The types of collaboration most widely reported were with the juvenile justice system ( $84 \%$ ), mental health agencies $(75 \%)$, police departments $(70 \%)$ and child protective services $(69 \%)$.

Due wide variation in the development and implementation of alternative schools at the state, district and school level, it is difficult to make any sweeping generalizations about them. However, in a survey of 48 states regarding alternative school enrollment, funding, curricula and staffing, Lehr et al., (2003) reported several key findings.

With respect to curriculum, while most states required alternative schools to follow state standards, more than a third of states had unclear language regarding the curriculum (Lehr et al., 2003). Enrollment criteria numbers suggest that alternative schools are being used as a setting for suspended and expelled students, as both groups are projected to increase. With respect to funding, most alternative schools rely on state funding, but other widely used sources including local, federal and grant dollars. Findings regarding school staffing indicate that more than half of the states did not have staffing standards for alternative schools in their policy. However, Lehr et al. (2003) disclosed that some states' staffing requirements are covered by a more global policy. Finally, the majority of states did not have clear guidance regarding the education of students with disabilities in alternative school settings (Lehr et al., 2003). This finding 
validates a previous study that assessed the concerns of state directors of special education. Results of the study conducted by Lehr and Lange (2003b) indicated an increasing concern regarding the enrollment procedures and quality of services for special education students enrolled in alternative school settings.

\section{Characteristics of Alternative Schools for Disruptive Students}

While school characteristics differ from state to state and school to school, a small body of research reveals characteristics associated with both positive and negative alternative schools outcomes for participating students. Recent research identifying both positive and negative characteristics of alternative schools mirrors early research on alternative school characteristics found to be effective.

In a field study of school districts considered to be leaders in alternative education (Boston, Philadelphia, Houston, Chicago, Grand Rapids, Louisville, Minneapolis, Los Angeles, San Jose, Berkeley and Seattle), Arnove and Strout (1980) gathered data to determine the origins, functioning and outcomes of alternative schools. Semi-structured interviews were conducted with administrators, teachers, students and parents involved with the alternative schools.

The researchers found several key alternative school characteristics or conditions that were conducive to positive outcomes. These school characteristics included small size, low student teacher ratio, flexible and understanding teachers, individualized instruction, student involvement in decision-making and family/parent participation (Arnove \& Strout, 1980). The positive student outcomes related to these school characteristics include warm interpersonal relations, student success, positive future outlook, empowerment and enhanced self-concept. 
Reviews of research by Hawkins and Wall (1980), Young (1990), and Paglin and Fagler (1997) supported the importance of these school characteristics that contribute to positive student outcomes. Likewise, a research synthesis of recent alternative education programs by Lange and Sleeten (2002) confirmed the existence of similar characteristics found in effective alternative schools.

Despite the positive aspects that early and recent research reveal, Arnove and Strout (1980) also identified several "deleterious practices" and characteristics associated with alternative schools for disruptive students. These included racial isolation, punitive focus, intensified social control of "labeled" students, inadequate resources, lack of accountability, and an unchallenging curriculum. In light of the persisting racial disparities in school discipline (Skiba \& Peterson, 1999), it is not surprising that one of the negative characteristics most frequently cited concerning alternative schools for disruptive students is the racial isolation of Black male students (Arnove \& Strout, 1980; Cox, Davidson \& Bynum, 1995). This is of particular concern in light of the threat to system equity this poses (Hadderman, 2002). In fact, Soleil (2005) argued that such schools may risk charges of discrimination, inequity and civil rights violations due to lack of high standards, clear entrance/exit criteria and right to due process.

In a more recent report, Weissman et al. (2005) noted that national criticisms echo several deficiencies of alternative schools including a lack of coherent purpose, the stigmatizing nature of placement, a chaotic environment due to their transitory nature, disproportionate use for minority students, and lack of youth development activities. These characteristics frequently lead to student drop out and increased involvement with the juvenile justice system. 


\section{Characteristics of Students Placed in Alternative Schools for Disruptive Students}

Research on alternative schools for disruptive students describes the student population as being overwhelmingly minority, male and identified with a special education disability (Dunbar, 2003; Wald and Losen, 2003, Verdugo \& Glenn, 2006). This student population mirrors the population of students that are suspended and expelled from school, as well as incarcerated as juveniles. The majority of researchers have examined high school populations. The second largest number of studies has involved middle school student populations. However, there seems to be an increasing elementary student population that is currently under-researched. In one study, Morrison and D'Incau (1997) found that students who were excluded from school had different education and behavior profiles. Most of the students were at some point served by special education services, had attendance problems and were performing well below average in terms of achievement.

There are often replicated results about the demographic background of students placed in alternatives schools for disruptive/delinquent behavior. For example, most students are Black and male (Arnove \& Strout, 1980; Cox, Davidson \& Bynum, 1995; Wald \& Losen, 2003; Verdugo \& Glenn, 2006). In addition, students engage in risky health behaviors, and other multiple risk behaviors (Grunbaum, Lowry \& Kann , 2001), physical fighting (Escobar-Chaves, Tortolero, Kelder, and Kapadia, 2002) emerge from high-delinquency geographic areas plagued with social disorganization that aids in the transmission of delinquency (Shaw, Zorbaugh, McKay, and Cottrell, 1929), have a highly external locus of control (Miller, Fitch \& Marshall, 2003), and experience high levels of anxiety and depression (Gold \& Mann, 1984; Matson \& Niemien, 1987). 
Within this body of research, no study was found to indicate any research has investigated these types of schools longitudinally. Further, no study was found that examined the schooling experiences of students that included the variables of school mobility, socio-economic status, suspensions, academic achievement, amount of absenteeism, and poverty level of schools students attend, and subsequent juvenile detention.

\section{Alternative School Placement and School Discipline}

Within the wide spectrum that schools have for student discipline, alternative school placement is one of the most severe forms of punishment. This section will situate alternative school placement within the context of school discipline alternatives. The author will discuss alternative placement as a last chance, the placement of behavioral disorder (BD) students in alternative settings, and the national failure of preventative programs in mainstream schools.

\section{Alternative School Placement as a "last chance"}

School discipline takes many forms ranging from verbal discipline within the classroom to the physical exclusion of students from the classroom or school setting. This practice is not limited to the United States public schools. Research conducted in other developed nations (e.g., Canada and Australia) have demonstrated an overall increase in the use of exclusionary discipline practices following adoption of U.S. models. These nations have policies instituting school disciplinary practices that require the physical removal or exclusion of students from a setting include in-school suspension, out of school suspension, alternative school placement and expulsions. (Cassidy, 2005; Imich, 1994). 
In school suspension includes short-term exclusion from the classroom. Out of school suspension is the most widely administered form of exclusionary school discipline in which students are excluded from the school setting for a short term, typically between 1-10 days. Alternative school placement requires the longer-term exclusion of students from their "home" school and is sometimes offered instead of permanent expulsion. Expulsion excludes the student from the entire educational institution or school district.

Thus, with respect to exclusionary school discipline, alternative school placement symbolizes a threshold between short term and permanent exclusion from the educational setting and is viewed in many respects as a "last chance" for mainstream students who are charged with being disruptive or dangerous in their mainstream school. Additionally, alternative school placement is mandated for many special education students identified as having a behavioral disorder (BD) when administrators consider their behavior as "unduly burdensome."

\section{Alternative Schools and the Placement of Students Labeled Behaviorally Disordered}

Within the world of special education, the classification category that continues to create the most controversy and confusion is the emotional or behavioral disorder label (Stephens \& Lakin, 1995). While students with the BD label are typically educated in mainstream schools, an increasing number are being educated in alternative schools. Further, this appears to be a consistent trend across all states in the U.S. (Lehr \& Lange, 2003). Stephens and Lakin (1995) reported that $36 \%$ of all students labeled BD are educated in separate public school facilities. Though the placement of BD students appears to be on the rise, earlier research regarding the classification and placement of children with "emotional/behavioral" found that these students are not provided the 
services that other special education students are entitled to (Kugelmass, 1987). In 2003, the lack of services being provided to emotional/behavioral disorder (EBD) students in alternative settings was a concern expressed by many State Directors of Special Education (Lehr \& Lange, 2003 ).

Stephens and Lankin (1995) further suggested that the labeling and placement of BD students is used as a mechanism to isolate and control students whose behavior is disturbing within the mainstream school environment. This increasing trend indicates a wider pervasive problem of segregation based on race and disability in the educational system as a whole and in special education programs in particular (Blanchett, Mumford \& Beachum, 2005).

\section{Failure of Delinquency Prevention Programs in Mainstream Schools}

Over the past decade, research regarding effectiveness of programs designed to increase school safety and reduce delinquent behavior have been produced at local, state and national levels. A national study sponsored by the National Institute for Justice conducted by Gottfredson et al. (2004) surveyed 848 public and private elementary, middle and high schools in two phases to gather information about their school delinquency prevention programs. School level administrators were asked to complete the surveys. Statistical analyses were performed to test hypotheses about the quality of program implementation based on existing research on the role of implementation in school outcomes. Based on the findings of numerous locally conducted evaluations of program effectiveness, the synthesis of results revealed that while nearly all US public schools currently use a large number and wide variety of delinquency prevention programs, the quality of implementation is poor. Further, the study suggested that while 
the implementation of multiple approaches may increase successful reduction in school delinquent behavior, it may also diminish the quality of the programs because resources are spread too thin.

Interestingly, the single largest cut proposed in the 2007 and 2008 federal budget was the elimination of the Safe and Drug Free Schools and Communities (SDFSC) Program. This program had provided states with \$346 million grant dollars to help "create and maintain drug-free, safe and orderly environment for learning in and around schools" (US Dept of Education, 2008). This proposed elimination was a result of findings through the use of the Bush administrations' Performance Assessment Rating Tool (PART) that the SDFSC program has not demonstrated effectiveness, and grant funds are spread too thinly to support quality interventions. The final budget passed for the 2008 fiscal year included an $11 \%$ cut to the SDFSC program, cutting $\$ 64$ million from the program (Eschool news, 2007).

Some scholars argue that the majority of delinquency prevention programs are doomed to failure due to the nature of their focus. That is, programs centered on "fixing" the "students who misbehave" do not take into account cumulative disadvantage or factors within the school environment itself that can facilitate and perpetuate student misbehavior. Dupper (1995) described many school environments as hostile, especially to at-risk students. Examples of hostile school environments include covert processes such as exposure to teacher sarcasm, low expectations, and failing grades with no offer of additional academic assistance.

\section{Key National and Kentucky State Policies Influencing Alternative Placement for Disruptive Students}


Exclusionary school discipline has existed since the beginning of public education. However, alternative school placement has been increasingly used for both mainstream and special education students. The rising use of alternative school placement of students has been linked to the recent implementation of key federal and state policies. A national examination of state legislation and policy in 2002 (Lehr et al., 2003) suggested that since the late 1990's, there has been consistent growth in state-level organization and legislative/policy on alternative schools for chronically disruptive students. This growth in general is attributed to increased public concern and attention regarding school violence and behavior problems in schools. However, three relatively recent federal legislation/policies in particular are identified as increasing placements of disruptive students into alternative schools: The Gun-Free Schools Act, zero-tolerance policies, the Individuals with Disabilities Act Amendments, and provisions of the No Child Left Behind Act.

\section{Gun-Free Schools Act-1994}

One key federal policy influencing the increasing use of alternative placement as a disciplinary practice is the Gun-Free Schools Act. The act was introduced as the federal response to several random school shootings in the 1990's. Passed into law in 1994, this act required all states receiving federal funds to enact a state law requiring local educational agencies to: (a) expel a student, for no less than one year, who is determined to have brought a weapon to school and, (b) implement a policy requiring referral to the criminal justice or juvenile delinquency system for students who bring weapons to school (Illback \& Sanders, 2000). Though the federal law mandates the expulsion of students for carrying what is determined to be a weapon (a continually expanded definition that has 
included plastic knifes and pencils), each state has the authority to determine whether placement of the expelled student in an alternative educational setting is mandatory or voluntary. According to the Education Commission of the States Report (1999), 29 states did not mandate their local school districts to provide an alternative educational setting for students who are expelled from school. The introduction and passage of the GunFree Schools Act propelled the widespread adoption of zero tolerance policies in public schools.

\section{Zero-tolerance policies}

Zero-tolerance policies guarantee the administration of strict consequences, particularly exclusion from the school setting, when local school rules or laws are violated. While the underlying premise of zero-tolerance school policies lies in the desire to ensure a safe school setting for all students, a growing body of research on the impact of zero-tolerance school policies indicate that the widespread adoptions of such policies has resulted in troubling consequences. These include doubling the number of school suspension and expulsions, exacerbating racial disparities in exclusionary school discipline (Skiba \& Peterson, 1999), and increasing the concentration of at-risk youth in the alternative schools. One important unintended consequence of concentrating "deviant or disruptive" students in one setting is that they may learn deviant behavior from each other (Reeding \& Shalf, 2001; Reinke \& Walker, 2005). Having delinquent companions has been shown to be a significant predictor of school delinquency for both males and females (Joseph, 1995). 


\section{Individuals with Disabilities Act (IDEA) Amendments -1997}

Coupled with the Gun Free Schools Act, increasing interest and enrollment in alternative schools has been stimulated by the 1997 reauthorization of the Individuals with Disabilities Act (IDEA). The IDEA 1997 amendments eased "unduly burdensome requirements" facing administrators and teachers with respect to the discipline of special education students. The new amendments required special education students to be placed in an interim alternative educational setting (IAES) if the student is removed from the school setting (via suspension or expulsion) for more than 10 consecutive days (Reinke \& Walker, 2005). The amendments also dictated that special education students should not be placed in the IAES for more than 45 days as a disciplinary measure. They further required that the alternative educational setting must allow students to receive continued instruction in the general curriculum, receive services related to their individual education plan (IEP), and address the behavior that led to the IAES placement to prevent reoccurrence (IDEA, 1997).

As noted in the previous section, the alternative school placement of BD students is on the rise. A recent national survey of alternative schools estimates that approximately $12 \%$ of students in alternative schools are special education students (Kliner, Porch, \& Farris, 2002). However, findings from a state level study in Minnesota indicated that $19 \%$ of alternative school students were students with disabilities. Of these students, $50 \%$ were identified as having an emotional/behavioral disorder (Lange \& Lehr, 2003 ).

\section{No Child Left Behind (NCLB) provisions}

Some researchers suggest that several provisions of the NCLB legislation combined with the high stakes/high pressures associated with the legislation may also be 
responsible for increased alternative school placement since more students are funneled there (Lange, 2003; Reinke \& Walker, 2005; Thomas, 2003). Though the foundation of NCLB requires all students to meet the same academic standards, the legislation has several provisions related to attendance and school safety that in many respects are relevant for the placement of students into alternative schools.

With respect to attendance provisions, the test scores of students who are not in the same school setting 100 or more days are not counted in the accountability formula. So, low functioning students may be mandated to attend an alternative school, under the guise of behavioral disturbance, for a short period of time in order to discount their test scores. Thomas (2003) reported that the school board of a district in Atlanta, GA, passed a resolution in 2002 as a result of concerns that principals were sending low scoring students to alternative settings during the testing period. The new district resolution requires students to attend alternative schools for three months pre and post testing period.

An important part of the NCLB legislation is the Title V: Safe Schools for the $21^{\text {st }}$ Century. This provision of NCLB is designed to "free students from those that are dangerous" (Nealis, 2003). Under Title $\mathrm{V}$, states will not receive federal funding for related programs unless they adopt zero-tolerance policies for violent or persistently disruptive students. This Title also encourages teachers (empowered by the states) to remove persistently disruptive students from their classrooms. Moreover, under this Title, parents are given the right to transfer their child from schools that are deemed unsafe. Thus, schools are under increasing pressure to remove disruptive students out of the mainstream schools for both accountability and funding purposes. 


\section{Kentucky State Policy Context}

The birth of alternative schools for disruptive youth in Kentucky is rooted in a Senate Bill passed by the 1978 Kentucky state legislature in response to increasing concerns about discipline in schools. This bill authorized the Kentucky State Department of Education to develop a specific program that would aid local schools in addressing problems such as delinquency, absenteeism, and unacceptable behavior. The primary focus of the state program was the development and implementation of alternative schools for disruptive students (Barber, 1980). While passage of this bill led to the development of such schools in Kentucky, legislation passed two decades later is responsible for their growth.

Following the 1998 passage of Kentucky's safe schools legislation, the number of alternative schools geared towards behavioral interventions in Kentucky has dramatically increased. Over 150 alternative schools currently exist in Kentucky (Swarts, 2004). Kentucky defines alternative schools as "a district-operated and district-controlled facility with no definable attendance boundaries that is designed to provide services to at-risk populations with unique needs. Its population composition and characteristics change frequently and are controlled by the school district student assignment practices and policies" (703 KAR 4:080).

The Education Commission of the States Report (1999) stated that in 1998 the state of Kentucky enacted legislation (Ky.Rev.Stat.158.150) that mandated local school boards provide educational services to expelled students in appropriate settings.

However, the legislation also noted that if the school board determines (on the record and supported by clear and convincing evidence) that an expelled student poses a threat to the 
safety of other students or school staff and cannot be placed in a state-funded program, then the requirement to provide an appropriate educational setting does not apply.

A recent Kentucky safe schools data report indicated that in recent years weapon use has declined dramatically. Based on a review of data that districts must provide to the state, the study also found that defiance of authority, fighting, threats, and intimidations resulted in the most severe forms of school discipline. Moreover, alternative placement was the second most common school punishment administered, and suspension was the first (Illback \& Sanders, 2000).
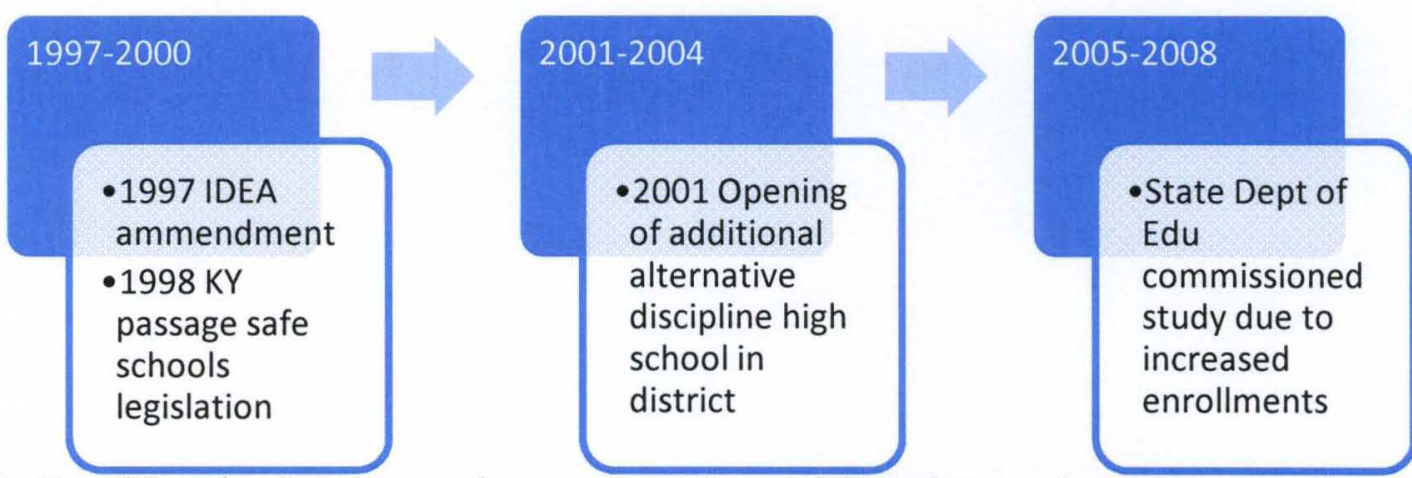

Figure 1. Timeline of policies regarding increased use of disciplinary alternative schools

\section{Alternative Schools for Disruptive Youth and the School-to-Prison Pipeline}

The proliferation of the placement of students in alternative schools for disruptive youth (ASDS) mirrors the increased detention of juveniles. The convergence of such patterns is clearly illustrated in the state of Kentucky. In a 2007 the Kentucky State Board of Education commissioned a study of Kentucky's ASDS in light of their rapid expansion (Kentucky Youth Advocates, 2008). One year later, the national Kids Count Data Book (2008) published by the Annie E Casey Foundation revealed that Kentucky was second highest in the nation for incarcerating juveniles for non-violent offences.

There are increasing attempts to illustrate the institutional link between the public school system and the criminal justice system. Punitive school disciplinary policies, such 
as the zero tolerance standard and school suspensions or expulsions, can be viewed as a first step of what becomes a cumulative pattern of disparity in the treatment of minorities in the criminal justice system. Youth of color are more likely to be suspended, suspended youth are more likely to be involved in the juvenile justice system where minority youth are more likely to be detained at arrest, adjudicated and sentenced to a custodial placement than are white youth (Poe- Yamagata \& Jones ,2000).

Racial disparity is even more pronounced in the juvenile justice system than in the adult system and provides the foundation for further discrimination in the criminal justice system (Weissman, et al, 2005). School disciplinary policies increasingly facilitate greater amounts of interaction between the schools and the juvenile justice system. At virtually every stage of the school disciplinary process, criminal justice tools and personnel are playing play an increasingly prominent role. In fact, school policing is the fastest growing law enforcement field (Pascopella, 2005).

Hirschfield (2008) stated, 'The criminalization of school related disciplinary issues extends into the juvenile court. Data from several jurisdictions indicates a netwidening effect and reflects increased collaboration between schools and the juvenile justice system, which has eroded the traditional boundaries between the two institutions' (p.3)

The population characteristics of students placed in alternative schools mirrors the increasing population of youth in the criminal justice system. Within the criminal/juvenile justice system, there is a wealth of evidence documenting the disproportionate representation of minority youth at every stage of contact within the system -from processing to imprisonment (Huizinga et al., 2000). Probing institutional 
links between the school system and the juvenile justice system is imperative. In one of the first attempts at deconstructing the school-to-prison pipeline, Casaella (2003) presented research that indicated a link between school preventative detention (i.e., detaining and isolating potentially dangerous offenders) and the criminal justice system. This rich qualitative research project documented how male minority students who are angry or engaged in conflicts are treated as if they have a natural propensity to be dangerous thereby justifying their isolation from the mainstream school system.

The urgent need for empirical research on the school to prison pipeline coupled with heavy collaboration with law enforcement in alternative schools highlight an important possible link that, while discussed, remains largely unexplored.

\section{Research on Individual and Systemic Impact of Alternative Schools for Disruptive Students}

While the recent growth of alternative schools for disruptive students is both certain and well documented, research regarding their effectiveness is not (Katsiyannis \& Williams, 1998; Lehr, Lanners, \& Lange, 2003; Morrison et al., 2001). The vast majority of research that has been conducted on such schools is descriptive at best and anecdotal at worst. Rigorous empirical research is gravely lacking. In fact, over nearly three decades of research (1966-1993) on student outcomes produced only 27 reports that use statistical analysis to determine student outcomes such as attitudes, delinquency, and achievement (Cox, 1995). Moreover, this body of research is plagued with weak methodology and inconsistent findings.

In addition to multiple gaps in the research literature, a review of studies on alternative schools for disruptive students reveals long-standing research challenges, dilemmas, and conflicting findings. The following section discusses several important 
facets of alternative school research including: (a) the weaknesses and potential of alternative school research, (b) the impact of alternative school placement on individual student outcomes, (c) research and evaluation of alternative schools for disruptive students, and (d) the relationship between alternative schools and the mainstream schools within a school system. Inconsistencies and gaps within each research component will be highlighted.

\section{Weakness and Potential of Alternative School Research and Evaluation}

The varied nature of the alternative schools, their transient student populations, and the politically sensitive issues surrounding these schools pose many difficulties for research and evaluation. In addition to being scattered, varied, nonsystematic, and state or program specific (Lange \& Sletten, 2002) alternative school research is frequently criticized for lack of rigor and limited generalizability (Cox, 1995). More specifically, studies on alternative schools for disruptive students frequently lack control or comparison groups, fail to have randomly drawn samples from populations, and lack follow up data on students (Hawkins \& Wall, 1980). Unfortunately, some of the methodological weaknesses mentioned are inherently difficult to overcome due to small sample sizes, data quality issues, large attrition rates, and ethical dilemmas posed by the randomization process.

In spite of various weaknesses that continue to plague alternative school research and evaluation efforts, some researchers suggest that alternative schools for disruptive students can serve as "rigorous testing grounds" for educational reforms that focus on preventing disruption and delinquency in mainstream educational settings (Cox et al., 1995; Hawkins \& Wall 1980; Young 1990). Additionally, they also have the potential to 
shed light on school practices found to be effective for Black male youth (Dunbar, 2003).

In other words, characteristics that are found to be successful with students exhibiting disruptive behavior could then be incorporated within the larger school system. In this respect, alternative schools for disruptive youth might no longer be needed if well grounded prevention efforts took hold within the mainstream school system, thereby eliminating the need for containing/rehabilitating students outside of the mainstream school setting.

\section{Impact of Alternative School Placement on Students}

Though there has been research on various outcomes of at-risk students who attend alternative schools; this research has been conducted using a broad definition of atrisk students who have attended a wide variety of alternative schools. There is limited research on the outcomes of students who have been mandated to attend alternative schools as a result of behavior at variance with rules on school discipline. The following is a review of the small body of research on the outcomes of students who attended alternative schools for delinquent and/or disruptive behavior.

Two largely qualitative studies reveal contradictory findings regarding the impact of alternative placement of student outcomes. Gold and Mann (1984) compared the academic achievement and attitudes of alternative delinquent students with that of traditional school students. The study participants included 60 at-risk students from three secondary alternative schools for delinquent students. The researchers matched the alternative school students with traditional students in the same district according to age, sex, grade point average (GPA), discipline history, self-esteem, and attitude toward school. Data collection occurred over the course of one school year and included 
classroom observations and administration of a pre and posttest for GPA, discipline, selfesteem and attitude toward school.

Results of the pre and post test revealed that the alternative students were significantly less disruptive in school, rated slightly better behaved upon returning to their home school, and were significantly more positive about school than traditional students. With regard to academic achievement however, alternative school students test scores did not improve and were not any better than the traditional school students. This study also revealed that regardless of school type, students who perceived that teachers were considerate of their feelings, needs and abilities reported more confidence in their role as students. The main finding that emerged from classroom observations indicated that alternative school students received more praise and acknowledgement in an alternative school than traditional students received in a regular school.

A qualitative study conducted almost a decade later helps verify the importance of positive teacher relationships to positive student outcomes. Jones (1999) investigated the outcomes of high school students who transitioned from an alternative school back into mainstream schools. A series of eight case studies revealed that successful transitions back into the mainstream school were attributed to the following factors: positive relationships with adults in the schools, parental involvement, encouragement, and positive peer assistance. Conversely, unsuccessful transitions were attributed to lack of advisement initiated by a school counselor, lack of student involvement in school activities, and lack of a formal transition program. Thus, the primary implication that emerged from this study was that successful student transition necessitates the existence of formal transition programs inherent in both the alternative and mainstream schools. 
In contrast to the findings of Gold and Mann (1984) and confirming the finding of Jones (1999) a more intensive qualitative research projects found less positive, more subtle student reactions to their alternative school experience. In a year-long phenomenological study, Sekayi (2001) investigated the perceptions of students attending a "last chance" alternative high school. The participants in the study were at-risk high school students attending a one-year alternative program in a suburban Midwestern city public school district. Although the feeder high school population was 50 percent African American, the majority of the students attending the alternative program were African American and male. Sekayi approached the single site case study using a phenomenological qualitative methodology to aid in gaining a better understanding of student feelings toward the alternative high school structure.

Data collection took the form of formal and informal interviews with administrators, teachers and students, classroom observations and focus groups with students throughout 25 site visits over the span of one academic year. Data were triangulated through the analysis of student records and school documents. The major theme that emerged in this study was student resistance in the form of "intellectual indignation" (p.417) due to the lack of effective communication between teachers and students coupled with student perceptions of the curriculum in the alternative school as "unchallenging, mediocre, and insulting" (p.421).

Though qualitative research is critical in documenting processes as they relate to student outcomes, quantitative research is important to measure significant student outcomes. In a seminal study, Cox, Davidson and Bynum (1995) conducted the first meta-analysis to aid in summarizing research regarding the magnitude (effect size) of at- 
risk /delinquent alternative student outcomes (i.e. academic performance, attitudes toward school, attendance, self-esteem and delinquency). They examined 57 studies (in 27 reports) of alternative schools housed in separate facilities that statistically assessed at least one type of outcome. The majority of these studies were conducted in the late 1970 's and throughout the 1980's. The detailed coding of the studies revealed that alternative schools have a minimal overall effect (indicated by mean effect size) on student performance (.27), attitude toward schools (.38) and self-esteem (34), yet a slightly larger effect on delinquency (.40). Additionally, the meta-analysis revealed that studies using a pre-post research design were more likely to show positive results than studies with comparison designs. The authors suggest that this is due to the lessened rigor and internal validity threats posed by pre-post designs.

In a subsequent study by the first author, Cox (1999) conducted the only study of this topic that used an experimental research design to assess the effectiveness of one alternative school for disruptive/delinquent youths. The sample included $6-8^{\text {th }}$ grade students recommended for placement into an alternative school. The students were randomly assigned into groups consisting of 41 treatment students and 42 control students. Cox used a $2 \times 3$ repeated measures multivariate analysis of variance (MANOVA) design to examine differences in attitude, self esteem, delinquency, grades, and attendance. Independent variables were group $(2=$ control and treatment $)$ and time ( 3 $=$ preprogram, post program and one year post program). Data collection included interviews, self report delinquency and school records. Data analyzed in this study emerged from two sources - interview questionnaire and school records. University graduate students conducted interviews with all of the students in this study (both 
treatment and control). Data collected from official school records included classroom grades, standardized test scores, and school attendance.

The interview format took the form of structured questionnaire interviews. Based on previous similar research, the questionnaire interviews were designed to measure the link between school-related perceptions, self esteem and self reported delinquent behavior (p.328). As is typical for most structured interviews, all items (except the self-report delinquency items) were closed ended. The 61 items on the questionnaire interview sought to measure three constructs. These include (a) attitude toward school, (b) self esteem, and (c) self report delinquency.

The cognitive and attendance measures used in this study emerged from school records. Student's grades in math, English, social studies and science were added and divided by number of courses to determine the grade point average. Standardized test scores (ranging from 400-800) in math and English were collected for each student. School absences consisted on number of actual days absent from school.

The analysis found that there were no statistically significant differences between treatment and control groups for attitude toward school, self-report delinquency or standardized scores. However, a statistically significant effect was found across time for self-esteem. That is, the treatment group scored significantly higher in self-esteem post program while the control group remained the same. However, these differences were not present in the one year follow up.

Analysis of school record data (GPA, test scores, and attendance) yielded interesting findings. The GPA of participation group increased post program but decreased in the one year follow up. The GPA of control students decreased at post 
program but increased at one year follow up. The group $\mathrm{x}$ time interaction revealed that these differences were statistically significant. With respect to attendance, while the control group mean stayed about the same for each time period, the treatment group absences decreased during the program but increased after program participation. So, there was a statistically significant difference in attendance post program, but none after the one year follow up.

The calculation of effect sizes indicate small effect sizes or little magnitude. For all variables except GPA, effect sizes were small (ranging from .008 to .050). However, for GPA, effect size was very large at .171. So in summary, Cox (1999) concluded that while alternative school participants had higher self esteem, better GPA and increased attendance during their time in the program, the effects were not seen one year post program.

As evidenced by this review of research on the outcomes of students placed in alternative schools as a disciplinary measure, findings are inconsistent. The general themes however reveal that any positive outcomes experienced by students appear to be temporary, and that positive outcomes depend heavily on the interpersonal relationships between students and adults within the alternative school. Further, the majority of the studies, aside from the work of Cox, lack methodological rigor and, virtually no study sought to assess the retrospective histories of the students schooling experiences, or the schooling and neighborhood environments that they emerged from as possible predictors of student outcomes, or differential student outcomes according to school level. 


\section{Alternative School Evaluation and Accountability}

Because alternative schools are not subject to the same direct pressures as mainstream schools with respect to accountability, they are less likely to undergo evaluation from at the federal and state level. However, the high stakes accountability environment associated with the Federal No Child Left Behind (NCLB) legislation has let some districts and states to hone in on problematic and low achieving sites. Thus, a few states have reported examining the efficacy and need for accountability of their alternative schools. These states include Kentucky, North Carolina, and Minnesota. These studies/evaluations lend important insight into outcomes of alternative schools.

Kentucky was one of the first states to examine academics in their alternative schools. Thomas (2003) reported that a 2003 evaluation conducted by the state education department documented a large gap between the academic achievement in Kentucky's mainstream schools and alternative schools. Throughout the 176 Kentucky school districts, alternative schools were $30 \%$ lower than mainstream schools. Because this included all alternative schools, the evaluation was unable to determine differences with respect to type of alternative school (e.g., for disruptive student, pregnant students, atrisk/low-achieving students).

In Kentucky, test scores of alternative school students (who have attended at least 100 days within the school year) are reflected back to their home school. During the 2004 school year, the largest Kentucky school district began aggregating test data at the school level for their alternative schools in light of increasing concerns and pressures to make adequate yearly progress (AYP). Schools that don't make AYP are subject to federal sanctions. Consequently, the impetus of this effort was the requests of mainstream 
principals who had several students in alternative schools (personal communication with superintendent of district high schools, January, 2006).

In 1999, North Carolinas State Board of Education adopted a policy requiring alternative schools to participate in their accountability program. The accountability program consisted of achievement standards, testing, professional development, reporting, and reward/sanction system. Results of the 1999-2000 school year suggested that the alternative schools fared better than the mainstream schools (Brewer, Feifs, \& Kaase, 2001). Again, this program evaluation included all alternative schools and did not separate out type of school.

A 2001 project headed by Lange (2003) is attempting to determine the new role of the alternative school settings in the NCLB era. Initial findings indicate that students are being funneled into the schools in part due to testing and performance pressures. Results regarding effectiveness through evaluation have not yet been determined.

Taken together, research on alternative school evaluation appears to indicate contradictory findings regarding alternative school achievement when compared to mainstream schools. Further, no study to date has honed in an aggregated evaluation of alternative schools for disruptive students. This research does however provide some suggestion of "questionable" relationships between alternative schools and mainstream schools within a school system.

\section{Impact of Alternative Schools on the School System}

Two relatively recent studies investigate the impact of alternative schools for disruptive students has on the overall school system. One study examines this from a 
district level and the other from a state level. Both heavily rely on qualitative methodology.

Kershaw and Blank (1993) made a comprehensive effort to aid district administrators by identifying: (a) the intended and unintended outcomes of an alternative school, and (b) the alternative schools' perceived impact within a large Tennessee school system. They conducted a qualitative study comparing student and school staff perceptions in a secondary alternative school with the perceptions of students and school staff in the traditional "base" school where the alternative students returned. Using a descriptive case study methodology, the researchers collected data via semi structured interviews and questionnaires designed to gather information on (a) student progress while attending the alternative schools, (b) assimilation of students back into base schools, and (c) students' academic, behavioral and social progress after return to base schools. Data collected from the three respondent groups (i.e., alternative school students, alternative school faculty and representative base school personnel) were analyzed using inductive methods to allow categories, patterns and relationships to emerge.

Key findings revealed that placement of students in the alternative school varied greatly with respect to offence and severity, however most entered because of truancy and discipline problems including poor attitudes and fighting. The majority of students perceived the class work to be easier than at their base school. School staff/student interpersonal relationships constituted the most positive condition of the alternative school, while strict behavioral expectations and punitive consequences were identified as the least liked aspect of the school by the students. Alternative school faculty and 
students were unified in reporting that traditional schools could better assist this at-risk student population by providing more individual, encouraging and understanding support.

Finally, the authors reported that there was no consistent plan to reintegrate students back into their base school. Of the 41 alternative school students in this study, 26 completed their required "time" in the alternative school and returned to their base school. Of the 26 , only 16 could be found on their base school attendance roles. Of these, nine students were reported as making minimal to significant improvements. The authors suggest that a systemic disconnect and lack of communication between the base school and alternative school was the greatest factor impeding the long-term academic and behavioral improvement of the "disenfranchised" students

In Georgia, the state superintendent conducted a three year study to assess the benefits alternative school programs have on the school system. Schrenko (2000) conducted a highly qualitative longitudinal (three year) evaluation of all the Georgia "Crossroads" Alternative schools ( $\mathrm{n}=132)$ using site visits, interviews, surveys and school records. Approximately $70 \%$ of the schools existed for the purpose of educating students who had been considered too disruptive or dangerous in a mainstream school.

From this large study emerged many interesting findings that both confirm and add to prior research. First, confirming prior research, student achievement was considered minimal, and there was an unintended effect of the concentration of Black male students within the alternative schools. The schools participated in a large network of community collaboratives ( $72 \%$ ), yet there was a concern among the majority of staff that chronically disruptive students were receiving insufficient services to promote successful completion of school. Two additional findings reveal a recidivism rate ranging 
from $22-28 \%$, and staff/administrator concerns that the base schools were using the alternative schools as a "dumping ground."

These two large scale studies illuminate that the relationships between mainstream and alternative schools can be un-conducive to positive student outcomes and may be considered unstructured. In particular, successful transition of students can be challenging as evidenced by recidivism and lack of communication and transition assistance between home and alternative school. A more recent study however, demonstrates that the provision of a holistic support system for youth enrolled in such schools can yield positive outcomes (e.g., successful transition into mainstream school, improved school attendance and grades) while minimizing negative one (e.g., recidivism, juvenile detention).

Weissman et al. (2005) conducted a quasi-experimental study with students who were placed in alternative schools and had difficulty upon their return to the mainstream schools, thus being placed in the alternative school again. The study sought to determine differences in outcomes (post enrollment adjudications and convictions; and pro-social attitudinal and behavioral outcomes) for those who experienced the "treatment" compared with those who did not. The "treatment" was participation a program with several core elements: transitional planning, after school/youth development activities, family support efforts, and opportunities for social bonding with caring adults). The program was voluntary for students who were placed in the alternative school. The treatment sample consisted of $2277^{\text {th }}$ and $8^{\text {th }}$ grade students. By the end of the program $41 \%$ of students successfully completed the program, which was defined as transfer back to mainstream school without reassignment into the alternative school at least 6 months 
post transition. The study also examined outcomes of those who participated but did not complete the program $(n=92)$. The comparison group was made up of $5607^{\text {th }}$ and $8^{\text {th }}$ grade students who did not participate in any aspect of the program. In contrast to the comparison group, students who successfully completed the program demonstrated lower suspension rates, reduced placements in alternative schools, improved attendance, better grades and lower rates of justice involvement. Program participants also demonstrated more positive results in attendance and grades than the comparison group, but in lesser degrees than the successful completers.

\section{Theoretical Framework}

\section{Broader Sociological Frameworks}

Two sociological theories are relevant to school discipline and alternative school research: functionalist and conflict theory. A typical theoretical framework in alternative school research is one of structural functionalism. This theory asserts that all institutions play an important and useful function in society. Accordingly, alternative school placement is regarded as a necessary and useful function within the public school system. While this may be a seemingly appropriate theoretical lens from which to view the role of alternative schools, issues of systemic and institutional inequality are either ignored or viewed as an unfortunate and/or unintended consequence under the dominance of this paradigm.

Conversely, research with an underlying framework of conflict theory emphasizes the role of process and contradictions embedded within institutions. This includes assessment of inequality and domination related to class, race and culture (Ritzer, 2000). Within this framework, the role of multiple systems of oppression that frames the lives of 
people becomes critical. Hill-Collins (1990) maintains that individuals are at a distinct advantage or disadvantage based on differing combinations of race, gender, age and class. This is also called "intersectionality" in recent research on labeling of student behavior (Cassidy \& Jackson, 2005). Because school discipline and alternative school research often points to the overrepresentation of Black male students in all disciplinary practices, understanding the school rules as producing a ranking and sorting system that often leads to internalization of behavior labels is essential (Fergeson, 2000).

Using a systems approach makes it possible to identify interrelationships between elements - otherwise perceived as disconnected fragments (Patton, 1990), and to understand patterns of change (Senge, 1990). Systems theory is rooted in the notion that the whole is greater than the sum of its parts (Tanner \& Fiore, 2004). The school system is interconnected and interdependent. It is an open system with permeable and malleable boundaries that is embedded within a larger system (Lasky, 2003). Using a systems approach to investigate institutional experiences in the K-12 system and links to the juvenile justice system is critical.

The increasing use of exclusionary discipline and alternative school placement reflect policy makers' "constrained worldview" of students who violate school rules (i.e., looking at the individual student as a part unconnected to the system). This worldview mirrors the general orientation of the U.S. criminal justice and legal system wherein individuals are deemed responsible for their behavior and must pay a consequence. Exceptions are made only for special circumstances (e.g., diminished mental capacity). Conversely, an "unconstrained worldview" identifies student misbehavior as a result of social systemic inequities and special circumstances. Because education policy is 
currently tainted with a constrained worldview, exclusion remains the intervention of choice (Morrison et al. 2001).

Many school environments can be viewed as hostile, especially to at-risk students. Examples of hostile school environments include covert processes such as exposure to teacher sarcasm, low expectations, and little additional assistance for those with failing grades (Dupper, 1995). Schools with large concentrations of poverty are often characterized by such elements. Repeated exposure to such contexts during a schooling career can impact student achievement and behaviors. By operating from a systems perspective, this research will help identify factors, including any cumulative disadvantage within the schooling history of students in a system that can lead to the reality, perception and construction of dangerousness.

Most research is grounded in theory, regardless of whether the theory or worldview of the researcher is stated explicitly or not. Within research on school discipline in general and alternative school placement in particular, two theories are generally operating. These include event and process worldviews and broader sociological frameworks.

\section{Two Worldviews: Individual-Event Oriented and Systemic-Process Oriented}

Sagor (1997) explained that since the late 1960's, educators have continued to face an ever-rising number of "disheartened, disaffected and disenfranchised" students. Two possible stances to deal with this reality exist. First, it is possible to view failure to thrive as a disorder residing in the student and to send the defective student away for treatment. This stance often perpetuates the notion that the problem lies within the student and the alternative school curriculum operates out of a deficit model (Cassidy \& 
Jackson, 2005). Second, one can view the failure to thrive as evidence of a systematic problem within the mainstream school setting and attempt to address it systemically. Sagor asserted that most districts choose the first stance.

Based on the work of Morrison et al. (2001) there appears to be two divergent streams of thought on the usefulness of alternative placement as a disciplinary approach. The first is predicated upon the notion of school safety, with an underlying focus on the individual student, his or her violation and the resulting disruption to mainstream students. Through this lens, alternative school placement is viewed as an event.

In contrast, the process oriented worldview is predicated upon the notion of the school as being a potential "dumping ground" (Lange, 2003; Redding \& Shalf 2001).The focus underlying this conceptualization includes attention to the role of the alternative school within the school system including district/school policies and practices facilitating exclusionary placement, the student/school relationship, and system equity concerns. Unlike the individual/event stream of thought, this worldview affords a systemic examination of alternative placement considering institutional policies and climate related to student behavior and typically views alternative placement as a process. Conversely, the individual worldview captures just one event in the process of placement and places the source of deficiency within the individual student. Figure 2 is a conceptual representation of a systemic view of alternative school placement. Unintended consequences are shown. The cyclical nature of the problem is illustrated in Figure 2. 


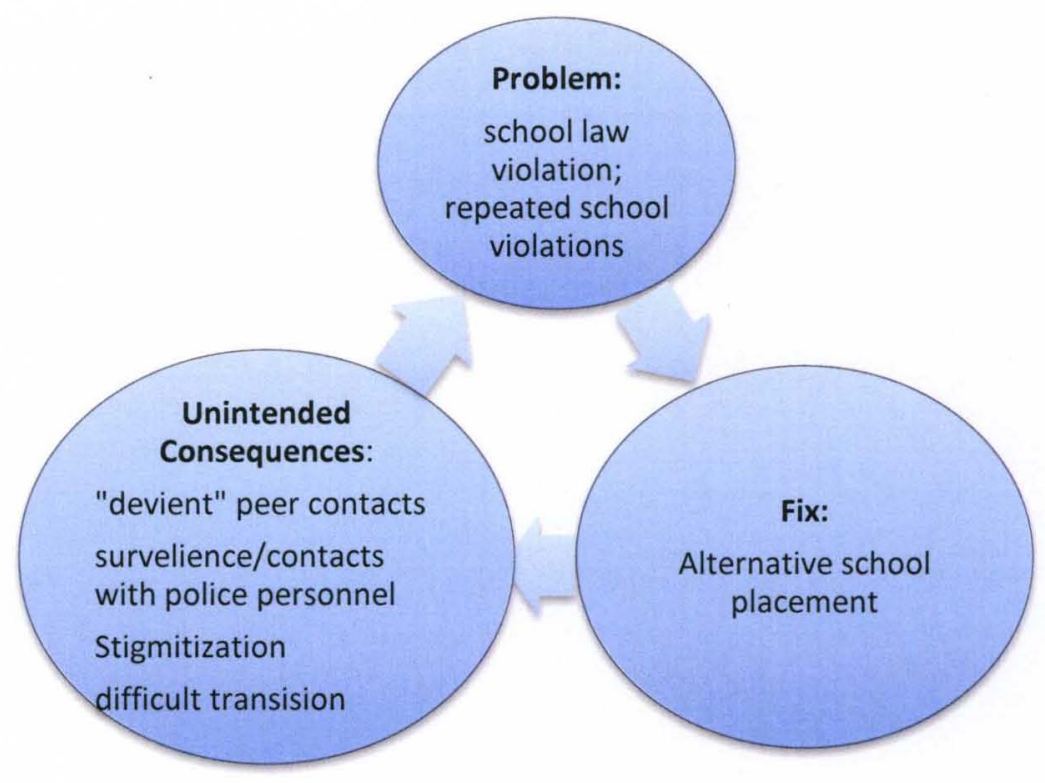

Figure 2. Systemic model of alternative school placement

Consistent with the typical stance taken in the practitioner world, most research on alternative schools for disruptive youth examines alternative school placement as an act and not a process. Because alternative school placement is a function of both a process and an event, future research should consider examination of the combined worldviews to provide a balanced assessment. Understanding what takes place before, during and after alternative school placement would garner a more comprehensive view of the role and function of alternative schools for disruptive students and the pathways that lead into and out of such settings.

\section{The Cumulative Disadvantage Theory}

Cumulative disadvantage theory is rooted in the cumulative advantage theory put forth by Merton (1968). Merton described specifically, how the reward system in scientific careers favors those who have established reputations, and generally, how individuals who start off with more health resources and better educational experiences 
garner beneficial cumulative effects over time. Taking the inverse of this theory, cumulative disadvantage theory emphasizes how early risk factors shape individual trajectories in both the short and long term (Elder, 1995). Evidence supports the effect of cumulative disadvantage on measures of IQ, income and status attainment (Rosenbaum, 1975, 1984). While students inevitably enter into the public schooling system with large variations in the advantages and disadvantages they arrive with, the interactions between home, community, and school through the duration of their schooling experience can pose cascading advantage or disadvantage - with short and long term effects.

\section{School to Prison Pipeline Thesis}

There is ample evidence to support a provisional thesis of an overarching criminalization of school discipline, especially within urban schools. (Hirschfield, 2008). 'Expanded school exclusion is a symbolic form of criminalization, regardless of whether it follows strict guidelines or the subjective whims of authorities. Education agencies increase in the use of exclusionary punishments endorse the prevailing rationale of contemporary criminal justice practice—deterrence and incapacitation' (Garland, 2001).

The prevalent criminalization of school discipline should not be viewed as a singular social project or process. Rather, the present-day, multidimensional punitive realities in our nation's schools are understandable only through tracing their multiple historical and social underpinnings (Garland, 2001). 'The increasingly desolate employment and imprisonment prospects of inner-city youth coupled with school personnel perceptions of these realities are beginning to fit notably in efforts to theorize criminalization in the school context and in strategies to reverse it' (Hirschfield, 2008). 
The punitive nature of the placement into alternative schools for disruptive ASDS coupled with the strong law enforcement presence in them may construct one possible route through the "school-to-prison" pipeline. Viewing these issues within a systemic framework of processes coupled with the notion of cumulative disadvantage provides the broad conceptual framework for this study. Given the research literature and theoretical lens of this study, the conceptual framework of this study is illustrated in Figure 3.

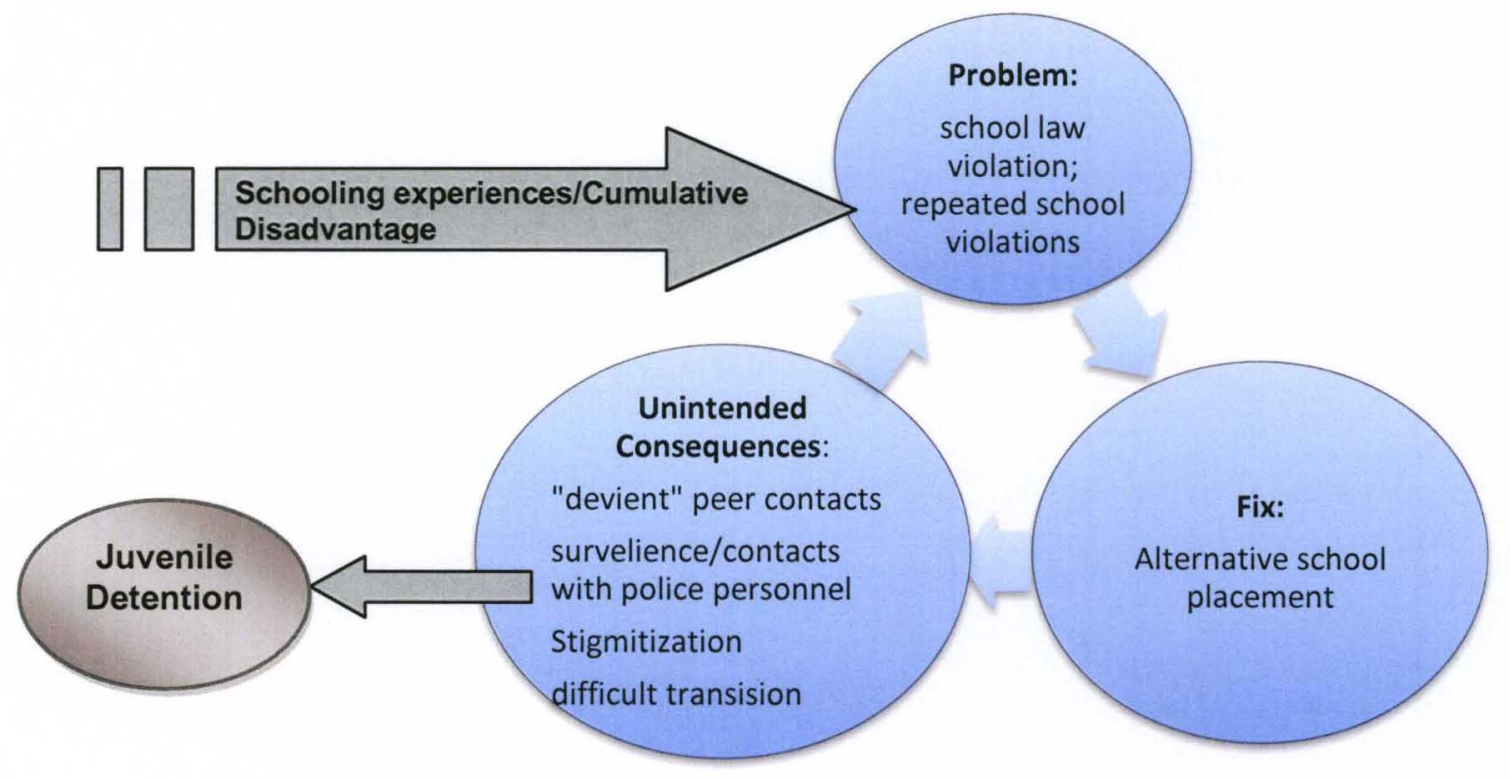

Figure 3. Conceptual Framework of the study

\section{Gaps in Research This Study Will Address}

In light of the recent growth in the placement of disruptive and "dangerous" students in alternative schools coupled with the lack of research regarding effectiveness and student outcomes, there is a pressing need for research on alternative schools for disruptive students. Accordingly, researchers and policy makers in the U.S. and abroad are calling for research and evaluation that will shed light on the quality and effectiveness of these schools (Aaron \& Zwig, 2003; Cassidy \& Jackson, 2005; Cox, 1999; Dunbar, 
2001; Kliner, Porch \& Farris, 2002; Lange and Sleeton, 2002; Settles \& Orwick, 2003).

There is also a need for research examining the relationship between delinquent students and the experiences in schools they have attended (Joseph, 1995).

Previous research has typically focused on student level changes following placement into the alternative school; the impact on the "feeder" schools that had excluded the student(s); and short term (one year) outcomes (self esteem, grades, attitudes and delinquency). Examination of these studies reveals inconsistencies with respect to methodological approaches and results. Furthermore, a void exists on the examination of the disciplinary or academic histories of the students who are placed in the alternative schools for disruptive youth, either from a systematic descriptive standpoint, or for the purpose of investigating predictors of alternative school placement for behavioral matters. Additionally, nearly all of the "school to prison pipeline" research is qualitative or anecdotal and thus there is a great need for empirical research. No previous study investigates alternative school students within a systems framework, examines the longitudinal schooling experiences of these students, identifies both timeconstant and time-varying predictors of alternative school placement, or quantifies subsequent juvenile detention.

There continues to be a void in the literature regarding the schooling experiences and juvenile justice involvement for students placed in alternative schools for behavioral issues. Further, Few studies employ rigorous quantitative methods to examine these issues and no study investigates alternative placement using 10 years/waves of data. Notably, there is a lack of research on elementary level students schooling experiences that may contribute to future placement in alternative schools for behavior issues. Most 
critically, no research examines time-varying predictors of alternative school placement and the proportion of students placed in alternative schools that experience subsequent juvenile detention during their $\mathrm{K}-12$ schooling career.

\section{Statement of the Research Questions}

In light of the many voids revealed by this literature review, the present study attempts to fill some significant shortcomings of the literature regarding alternative schools for disruptive students and the emerging school-to-prison pipeline. In addition to identifying time-varying and time-constant predictors of placement and subsequent juvenile detention, this investigation adds to the theoretical knowledge base of systems thinking in education as it relates to schooling experiences, alternative school placements, and subsequent juvenile detention.

The research questions addressed in this study are:

1. What is the proportion of students who experience a placement in an alternative school event and when are students most likely to experience the placement across a 10 year span (grade 3-12) in a cohort of in 3rd grade students?

2. What are the empirically based time-constant and time-varying predictors of risk associated with an alternative school placement event in a cohort of $3^{\text {rd }}$ grade students across 10 time intervals?

3. Of the students in the $3^{\text {rd }}$ grade cohort who had experienced an alternative placement event, what proportion of students experience subsequent juvenile detention and when are they most likely to experience that event? 


\section{CHAPTER III}

\section{METHOD}

This chapter explicates the methodology employed in the study. Following a summary of the problem and purpose, each component of the methodology is described. These include the research questions, research design and rationale, site of study, population and sample, data collection, variables used in the study, and procedures that were used for data analyses.

\section{Problem and Purpose}

Currently, large gaps exist within the research on various aspects of alternative schools for disruptive students (ASDS), students placed in them, and the "school-toprison pipeline." Most critically, the use of rigorous empirical research is lacking, and particularly there is a void of research that employs a longitudinal view of the problems associated with ASDS, the students and the "school to prison pipeline." Also, most of the studies approach alternative school placement as an event and not as a process that may begin long before placement. The rapid growth in the use of ASDS coupled with the increasing rates of juvenile detention creates an imperative for conducting a rigorous empirical investigation that may shed light such issues, particularly research that provides a longitudinal examination of these issues. The purpose of this study is to help fill several existing gaps through the use of survival analysis, a statistical procedure designed 
to analyze the effects of a set of variables on a future outcome (Tabachnic \& Fidell, 2007).

\section{Research Questions}

The following research questions are addressed in this study:

1. What is the proportion of students who experience placement in a disciplinary alternative school and when are students most likely to experience the placement across a 10 year span (time intervals from grade 3-12) in a cohort of in 3rd grade children?

2. What are the time-constant and time-varying predictors of risk associated with a disciplinary alternative school placement event in a cohort of $3^{\text {rd }}$ grade children across 10 time intervals?

3. Of the students in the $3^{\text {rd }}$ grade cohort who experience a disciplinary alternative placement event, what proportion of students experience subsequent juvenile detention and when are they most likely to experience a subsequent juvenile detention event?

\section{Research Design \& Rationale}

A quantitative longitudinal design was used to answer questions this study addresses. The use of simple regression analyses on longitudinal event data presented two problems. First, simple regression analyses cannot explicate the impact of variables that may change in value over time. Second, there were students in the cohort that did not experience the alternative placement event, thus, there was a question of what to do with these "censored" cases (those that don't experience the event). Survival analysis (also known as event history analysis), is a series of techniques used to model event occurrence 
over time, is used to answer the primary research questions. The main goal of Survival analysis' is to model the underlying distributions of survival/failure times and to assess the dependence of the survival/failure time on other explanatory variables.

Three methodological features of this study constitute $d$ key justifications for the use of survival analysis (Singer \& Willett, 2003). First, there was a target event (placement into an alternative school) with a clear cut transition from one condition-a regular school setting- to another condition -an alternative school setting. Second, there was an initial starting point of $3^{\text {rd }}$ grade when all of the subjects were situated in only one of the possible conditions. No individual in the study would have experienced the target event. Third, in this study, there was a definitive metric for clocking time, annual denoted by school year, in which the event occurrence was documented. In the district database, individual student placements are systematically recorded within and at the end of each school year.

Survival analysis allows one to follow a group of students longitudinally to assess whether, and if so, when they experience some target event and helps to predict the probability of the occurrence of the event (Singer \& Willett, 2003). One important feature of survival analysis is that all data are used to maximize understanding of the issue at hand. That is, data from students who never experience alternative placement are used, thorough the process of censoring, which provide equal amounts of information about non-occurrence as event occurrence. Survival analysis helps describe the proportion of cases experiencing an event at various points in time within a cohort and subsequent regression models within survival analysis can assess the relationship between the time of event and a set of predictors of risk (Tabachnic and Fidel, 2007). The relationship 
between the set of predictors used in this study and the alternative placement event goes beyond simple identification of predictors that remain constant over the time period under study, but also can pinpoint predictors of risk that may be have a greater impact on placement at one grade level than another.

The specific components of survival analysis used in this dissertation include discrete-time methods of the life table and proceeding statistical summaries of the life table - hazard function, survival function, and median lifetime analyses (Singer \& Willett, 2003). Following, a Discrete-time hazard analysis was used to analyze the longitudinal data in this study, by fitting discrete-time hazard models to the data. Further discussion of each technique is presented in the section on analyses.

\section{Site of Study}

The site of this study is a large ethnically diverse urban school district. The

district is the $28^{\text {th }}$ largest school district in the United States and serves approximately 98,000 students. In terms of demographics, $56 \%$ of students are White, $37 \%$ are AfricanAmerican, and 7\% represent other ethnicities. Approximately $60 \%$ of the students receive free or reduced price lunch. The district has a total of 161 schools, 135 mainstream or traditional schools, and 26 alternative schools. The types of alternative schools in the district vary widely in terms of specific school purpose serving various types of student populations such as pregnant and parenting teenage students and students that reside in youth psychiatric units. The four alternative schools for disruptive students (ASDS) in this study specifically serve students who have been deemed too dangerous or disruptive to stay in the regular school setting with the majority having been identified as violating a statute in the student code of conduct. The alternative schools in the district were 
developed as a response to district needs (i.e., implementation a disciplinary action that allows for the removal of students from regular schools while continuing their compulsory education) over a period of approximately 18 years. However, the district experienced an increasing need of placements into the alternative schools designed to educate students who were considered too disruptive or dangerous within mainstream schools following the passage of the Safe and Drug Free Schools and Community Act. The 1994 adoption of this Act resulted in the widespread implementation of zerotolerance policies throughout the district, increasing removal of students deemed dangerous and the consequential use of mandatory placements into alternative schools.

\section{Population and Sample}

Sampling procedures were purposive in light of the study objectives. The sample used in this study consists of an entire cohort of $3^{\text {rd }}$ grade students enrolled in the district during the 1997-1998 school year. The cohort sample size is approximately 7800 students, which exceeds the required sample size for modeling event histories. Because the outcome measure is a discreet event (ASDS placement or not) the rule of 50 applies and works well if the event is relatively rare (VanBelle, 2002) such as in the case of ASDS placement. The entire population of the $3^{\text {rd }}$ grade cohort is used in this study, since survival analysis considers all data within the larger sample regardless if the individuals experience the target event or not.

In order to describe the approximate frequency of occurrences of placement into ASDS, the percentages of students in the entire school population mandated to attend ASDS are presented here. Of the total district student population, approximately between 4-6\% of students are placed in ASDS each year. Of all the students placed in ASDS, 
approximately $15 \%$ are elementary in elementary school, $30 \%$ are in middle school, and $55 \%$ are in high school. Of the total student population served in the alternative schools due to behavioral/disciplinary issues, the majority are African-American and male.

While the entire cohort of $3^{\text {rd }}$ grade students enrolled in the district during the 1997-1998 school year comprised the study sample, the sub sample used to address incidents of juvenile detention (research question 3) was comprised of students in the larger sample that experienced an alternative placement event. Based on the incidences of current student placements in alternative schools described above, it wasvexpected that the sub sample used to address research question 3 would include approximately 410 students. Similar to the rationale above, complete data from the students in this sub sample, regardless if they experience a juvenile detention event, was used to address research question 3.

\section{Data collection \& Procedures}

The data used in this study are considered secondary data in that the data were previously collected for a different purpose. The data used for this study emerged from the district's primary data warehouse demographic, cognitive and non-cognitive measures. The district's research department compiles student and school level data. Student level data were available on all students identified through a unique student identification number.

Once the researchers secured approval of the study from the district research permissions committee and the university institutional review board, the researcher requested the data to be extracted from the district data warehouse with all identifiable data removed (e.g., student names, social security number) from the files. The data file 
was restructured a person-period dataset using a function within SPSS. The personperiod data set, different from the typical person-level format is necessary to model time of event (Singer and Willett, 2003). In a person-period data set, each individual in the cohort contributes multiple rows of data, one per unit of time spent before the occurrence of the event of interest (i.e., alternative placement, juvenile detention). The table below illustrates the person-period data set:

Table 1

Example of a Person-Period Dataset

\begin{tabular}{|c|c|c|c|c|c|}
\hline ID & Grade & $\begin{array}{c}\text { Target Event } \\
\text { (placement) }\end{array}$ & Gender & $\begin{array}{c}\text { Mobility } \\
\text { Rate }\end{array}$ & $\begin{array}{c}\text { Suspension } \\
\text { Incidents }\end{array}$ \\
\hline 3097 & 3 & 0 & 0 & 25.1 & 0 \\
\hline 3097 & 4 & 0 & 0 & 24.3 & 1 \\
\hline 3097 & 5 & 0 & 0 & 29.2 & 2 \\
\hline 3097 & 6 & 0 & 0 & 30.1 & 1 \\
\hline 8423 & 3 & 0 & 1 & 9.8 & 0 \\
\hline 8423 & 4 & 0 & 1 & 11.1 & 0 \\
\hline 8423 & 5 & 0 & 1 & 9.3 & 0 \\
\hline 8423 & 6 & 1 & 1 & 13.1 & 1 \\
\hline
\end{tabular}

In the data set used to investigate alternative school placement, the unit of time was grade (grade level student is enrolled in, noting annual unit of time/school year). Once a student experienced an alternative placement event, they were terminated from the data set - so that each person only experienced the event of placement once. In cases where a student may experience placement in an alternative school multiple times, then their grade of placement was based only on the first occurrence.

The analysis of subsequent juvenile detention only included the subset of cohort students who experienced an alternative placement event and was structured into a 
second data set for analysis. Statistical Package for the Social Sciences (SPSS) version 17 was used to conduct all statistical procedures.

\section{Study Variables}

The dependent outcome variables used in this dissertation included:

Alternative School Placement: This variable is determined through student's record stored in district data base of student entry into one of the ASDS in the study. Only the first occurrence of placement into an ASDS is considered in this study. Alternative school placement is a time-dependent dichotomous variable that records whether in any given period a student did $(=1)$ or did not $(=0)$ experience an alternative school placement in an ASDS at anytime during the school year. In the study site, 4 different disciplinary alternative schools fit the following criteria used in this study: (1) that the student has been determined by school and district administration to be either (a) in violation of the student code of conduct that requires placement or (b) be too disruptive, behaviorally challenged, or dangerous to remain in the regular school setting, and (2) placement is mandatory in order to remain enrolled in a school within the district.

Juvenile Detention: This variable is determined through student's record stored in district data base of enrollment into a youth detention facility that serves students who were adjudicated or are awaiting adjudication. The age range of students served in these facilities ranges from age 11 to 18 . The level of security varies in these facilitates from a seemingly typical school like setting to secure detention similar to a typical jail that houses pre-adjudicated juveniles, perceived as needing the most secure form of detention, prior to their court date. Juvenile Detention is also a time-dependent, dichotomous variable that records whether in any given period after alternative placement, a student 
$\operatorname{did}(=1)$ or did not $(=0)$ experience juvenile detention by the end of the 12 grade. Only a juvenile detention event that occurs after placement into an ASDS is considered in this study.

The predictor variables (covariates) used in the analyses included:

Race: This is a time-constant dichotomous variable where $1=$ Minority and $0=$ White. Minority ethnicities in the district database include African-American, Asian, Hispanic, and other, including multi-racial. While "other" minority ethnicities will be represented by the students in the cohort, $92 \%$ of the Minority students in the $3^{\text {rd }}$ grade Cohort (1997-98) are African-American. Thus, students that would be identified in the "other" category would be too few to consider as a separate category for the purposes of analysis.

Gender: this is a time-constant dichotomous variable where $1=$ Female and $0=$ male.

Free/Reduced Lunch Status: This variable, whether or not the student receives free or reduced lunch, will serve as a proxy for individual student (socio-economic status) SES. The National School Lunch Program is a federally funded program administered by the U.S. Department of Agriculture wherein receipt of free/reduced lunch is based on the income level of the student's parent or guardian. Students qualify for free/reduced lunch if parent's income is between $130 \%$ to $185 \%$ of the federal poverty level. This is a dichotomous variable that is subject to change from year to year, where free/reduced $=1$ and paid lunch $=0$.

Student Mobility: This variable is determined through student's record stored in district data base of the number of times a student is withdrawn from one school and 
enters a new school during the same school year. This variable is subject to change from year to year in that a student's school mobility rate can change from one year to the next for a variety of reasons.

Comprehensive Test of Basic Skills (CTBS) Reading: The CTBS is a standardized, norm referenced achievement test given to all students in grades 3,6 and 9 . This is a continuous time-varying variable that is documented in student's record.

Out of School Suspension: Students can be administered out of school suspension between 1-10 days consecutively, and for a total of any given number throughout the school year. Violation of any pre-determined set of offences written in the student code of conduct can result in suspension. The coding of a violation is ultimately at the discretion of the school administrator. This is a variable identifies the number of out of school suspensions a student receives each school year at the end of each school year, as documented in the students record in the district database. The number of incidences can vary from year to year.

Student Absenteeism: This variable is determined through the student's record that identifies the number of days absent from school. This includes both excused absences and unexcused absences. This is a time-varying variable in that a student's absenteeism rate can fluctuate from year to year.

Special Education/Exceptional Child Education (ECE) Status: Students that have been identified through the processes mandated by the federal Individuals with Disabilities Educational Act (IDEA) are identified to have a particular disability that interferes with the education process. This variable is a dichotomous variable determined through student records of ECE status where $1=$ identified as Behavioral 
Disorder/Emotionally Behavioral disorder, and $0=$ not identified as BD/EBD as one of the non-cognitive covariates; and $1=$ identified as Learning Disabled and $0=$ not identified as Learning Disabled as one of the cognitive covariates. The ECE status of a student can change from year to year as an exit from ECE can occur during the course of their education. An exit code is documented in the student file within the district database.

Retention: Students that are held back to repeat one whole grade is defined as retention in this study. This is determined through the student's record by examining the grade enrolled each school year. If a student is enrolled in grade 3 in 1996-1997 and also in 1997-1998, this student is identified as having been retained in $3^{\text {rd }}$ grade.

\section{Analyses}

Descriptive statistics (frequencies, means, cross-tabs) will be used to present the demographic characteristics of the entire cohort of students at the start of $3^{\text {rd }}$ grade, including gender, ethnicity, age, lunch status, and special education status. Non academic variables (i.e., suspensions, absenteeism, mobility and level of school poverty of attending school) and the available academic variables (i.e., CTBS Math, Reading and Total Battery stanine) will also be presented.

In order to address research question 1 , the number of students who experience an alternative school placement event and when students most likely to experience placement across a 10 year span (time intervals from grade 3-12) in a cohort of schoolaged children in 3rd grade, an essential survival analysis tool, a life table, was employed. The time interval variable is set at grade (grade 3-12), and the status variable, event of interest is placement in alternative school (i.e., ASDS placement $=1$ or not $=0$ ). A table was produced that illustrates the number and proportion of cohort students who 
was produced that illustrates the number and proportion of cohort students who experienced an ASDS placement event and at what point in time (i.e., grade level) the event is experienced. Adjustments are made for censored data for each time interval by illustrating the number of students "exposed to risk" those students who did not experience ASDS placement. Additionally, Descriptive statistics (i.e., frequencies and percentages) were used to identify demographic variables of cohort students who experience the event.

The set of summary statistics, the hazard function and the survivor function were examined. The hazard and survivor functions both address the distribution of ASDS placement times annual by grade. The discrete- time hazard function is used to determine the risk of ASDS placement for each time interval (grade). The discrete-time hazard function provides the conditional probability that individual $i$ will experience the target event in time period $j\left(\mathrm{~T}_{i}=j\right)$ given that s/he didn't experience it in any earlier time $\operatorname{period}\left(\Gamma_{i} \geq j\right)$

$$
h\left(t_{i j}\right)=\operatorname{Pr}\left\{\mathrm{T}_{i}=j \mid \mathrm{T}_{i} \geq j\right\}
$$

The estimated Discrete-time hazard value is a probability statistic that lies between 0 and 1, and can vary widely (Singer \& Willit, 2003). The resulting hazard rate illustrates the percent chance of ASDS placement for those who did not previously experience that event.

This identifies the grade level wherein students are at greatest risk for ASDS placement. Moreover, the estimated hazard probability when plotted on a graph provides a visual display of the change in shape of risk (e.g., does the risk increase, decrease or remain stable across grade levels). 
The survivor function simply provides an additional statistic for each time interval and plotted graph to illustrate the distribution of ASDS placement in different way. The survivor function describes the events of "non placement" across each time interval (grade level) to assess the probability that a randomly selected individual will "survive" (Singer \& Willitt, 2003, p. 334). The survival probability explicates the Probability that individual $i$ will "survive" (i.e., not experience ASDS placement) beyond time period $j$ $\left(\mathrm{T}_{i}>j\right)$

$$
S\left(t_{i j}\right)=\operatorname{Pr}\left\{\mathrm{T}_{i}>j\right\}
$$

Similar to the hazard value, the survival function provides maximum likelihood estimates where the value of the probability statistic that lies between 0 and 1 . It basically provides the cumulative proportion of students surviving at the end of each grade level.

Having illustrated the distribution of ASDS placement over time, a measure of central tendency is called for. Due to the censoring that is an inherent component of survival analysis, the use of means is not appropriate. Thus, Singer and Willitt (2003) suggest the use of a median lifetime function to illustrate the center of the distribution. The median lifetime is the time at which $50 \%$ of the original sample has had an ASDS placement event. This statistic lets us know the median length (grade/year) of ASDS placement. If the estimated median lifetime statistic is below .5 , it will be clear that less than half of the full sample is predicted to experience an ASDS placement event. Based on the frequency of occurrences of ASDS placement described in the site of study section, it is likely that the estimated median lifetime will not reach $50 \%$.

To address research question 2 , the identification of time-constant and varying predictors of risk associated with alternative school placement across each time interval 
(grade), Discrete-Time hazard method was employed. Discrete-time hazard analysis is a technique for statistical modeling to explore if and how the risk of event occurrence is systematically related to predictors (Singer and Willett, 2003). In addition to determining the probability of an event, this method allows for the quantification of the impact of one or many variables upon that probability. As such, employing Discrete-time hazard analysis will allow for the exploration of multiple independent variables (covariates) as predictors of ASDS placement. The power and validity of a survival analysis is related to the number of events rather than the number of participants. Simulation work has suggested that at least 10 events need to be observed for each covariate considered, or the regression coefficients become biased (Peduzzi et al, 1995).Because there are 9 exploratory covariates in the analysis, and an approximation of nearly several hundred events, there will be sufficient power for the Discrete-time hazard analysis.

The values of Discrete-time hazard, as conditional probabilities lie between 0 and 1 which can pose difficulties with interpretations and comparisons. As such, it is recommended that the values are transformed for expression on a different scale - the logit transformations in the forms of odds and log odds where odds = probability/1probability, and the log odds is calculated by taking the natural logarithm of odds. (Singer and Willit, 2003).

Discrete-Time hazard models are semi parametric as the model makes several parametric assumptions because while they do not assume that the effects of the predictor variables are constant over time, the model invokes assumptions about the functional form that links predictors to log hazard (Singer \& Willit, 2003, p.522). The proportional hazards 
model will specify hazard rates as a log-linear function of parameters for the effect of covariates as demonstrated below:

$$
h_{i}(t)=h_{0}(t) \exp \left(\sum_{k=1}^{K} \beta_{k} X_{k k}(t)\right)
$$

where $h_{i}(t)$ is the hazard rate value (alternative placement) for person $i$ at time $t, h_{o}(t)$ is the baseline hazard function that represents the major dimension of time dependence (grade/year), and $X_{i k}(t)$ is the value of the $k^{\text {th }}$ covariate for person $i$ at time $t$. Parameters in Discrete-Time hazard in SPSS are estimated by a form of maximum likelihood, with $h_{o}(t)$ left unspecified but estimated from sample data (Collett, 2003). Statistically significant covariates will be determined according to the alpha level of 0.05 . Results of Discrete-Time hazard modeling are expressed as odds ratio (Exp) that denotes the regression result in terms of $e$ raised to the power of each effect. The interpretation of each parameter $\beta_{k}$ is that $\operatorname{Exp}\left(\beta_{k}\right)$ indicates the hazard ratio, the factor change associated with an increase of one unit in $X_{i k}$, with all other covariates statistically held constant. We can then determine the relative risk of ASDS attributable to each possible variable while fully accounting for other variables included in the model. When using dichotomous predictors, as in regular logistic regression, antilogging a parameter estimate yields the estimated odds-ratio associated with a 1 -unit difference in the predictor. With continuous predictors, antilogging still yields a estimated odds-ratio associated with a 1unit difference in the predictor (Willit \& Singer, 2003). Fitting the Discrete-time hazard models describes the magnitude of the impact race, gender, lunch status, retention, out of school suspension, school mobility, absenteeism, EBD status, and LD status has on the e risk of ASDS placement. 
In order to address research question 3, the proportion of students who had experienced ASDS placement and when are they most likely to experience a subsequent juvenile detention event, descriptive statistics were used with the sample of students who previously experienced the ASDS placement event and a subsequent juvenile detention. The time/duration variable was set at years to determine the number of school years between the first ASDS placement and the juvenile detention event. A table was produced that illustrates the number and proportion of cohort students who experienced a juvenile detention event and the duration of time between ASDS placement and juvenile detention. Additionally, descriptive statistics crosstabs were used to identify demographic variables of cohort students who experience juvenile detention after experiencing ASDS placement. Finally, a logistic regression procedure was conducted to determine the effect of race and gender on juvenile detention after entry into a disciplinary alternative school. Table 2 below illustrates the alignment of the research Questions, Data, Sample, Source, Analysis, and Interpretation of results. 
Table 2

Research Questions, Data, Sample, Source, Analysis, and Interpretation Matrix

\begin{tabular}{|c|c|c|c|}
\hline Research Question & Variables/Sample & Analysis & Interpretation \\
\hline $\begin{array}{l}\text { 1. What is the proportion } \\
\text { of students who } \\
\text { experience a placement in } \\
\text { a disciplinary alternative } \\
\text { school and when are } \\
\text { students most likely to } \\
\text { experience the placement } \\
\text { across a } 10 \text { year span } \\
\text { (time intervals from grade } \\
\text { 3-12) in a cohort of in } 3 \text { rd } \\
\text { grade children }\end{array}$ & $\begin{array}{l}\text { Student placement } \\
\text { event status } \\
\text { variable, ,race, } \\
\text { gender, grade level/ } \\
\text { All } 3^{\text {rd }} \text { grade } \\
\text { students enrolled in } \\
\text { the district during } \\
1997 / 1998 \text { school } \\
\text { year. }\end{array}$ & $\begin{array}{l}\text { Descriptive and } \\
\text { frequency statistics; } \\
\text { Life table analysis } \\
\text { (number of and } \\
\text { proportion of cases } \\
\text { that experienced } \\
\text { event for each time } \\
\text { interval), } \\
\text { corresponding hazard } \\
\text { function, survivor } \\
\text { function, and median } \\
\text { lifetime function. }\end{array}$ & $\begin{array}{l}\text { Estimated } \\
\text { probabilities/risk } \\
\text { statistics of ASDS } \\
\text { placement (hazard), } \\
\text { non-placement } \\
\text { (survival) and } \\
\text { median grade level } \\
\text { of placement } \\
\text { illustrated in life } \\
\text { table and } \\
\text { corresponding } \\
\text { graphs. }\end{array}$ \\
\hline $\begin{array}{l}\text { 2. What are the } \\
\text { empirically based time- } \\
\text { constant and time-varying } \\
\text { predictors of risk } \\
\text { associated with a } \\
\text { disciplinary alternative } \\
\text { school placement event in } \\
\text { a cohort of } 3^{\text {rd }} \text { grade } \\
\text { students across } 10 \text { time } \\
\text { intervals (grade level)? }\end{array}$ & $\begin{array}{l}\text { Race, gender, } \\
\text { free/reduced lunch } \\
\text { status, CTBS total } \\
\text { battery scores, } \\
\text { KCCT reading } \\
\text { level, out of school } \\
\text { suspension, school } \\
\text { mobility, } \\
\text { absenteeism, ECE } \\
\text { status, and poverty } \\
\text { level of attending } \\
\text { school/ All } 3^{\text {rd }} \\
\text { grade students } \\
\text { enrolled in the } \\
\text { district during } \\
\text { 1997/1998 school } \\
\text { year. }\end{array}$ & $\begin{array}{l}\text { Discrete-Time hazard } \\
\text { analyses of the } \\
\text { covariates main } \\
\text { effects and } \\
\text { interaction effects } \\
\text { with time (grade) }\end{array}$ & $\begin{array}{l}\text { Main effects } \\
\text { estimated hazard } \\
\text { ratio values } \\
\text { associated with an } \\
\text { increase of one unit } \\
\text { in each covariate } \\
\text { holding others } \\
\text { constant; estimated } \\
\text { values of } \\
\text { interaction effects } \\
\text { of each covariate } \\
\text { with time, and } \\
\text { corresponding } \\
\text { tables and graphs. }\end{array}$ \\
\hline $\begin{array}{l}\text { 3.Of the students in the } 3^{\text {rd }} \\
\text { grade cohort who had } \\
\text { experienced an alternative } \\
\text { placement event, what } \\
\text { proportion of students } \\
\text { experience subsequent } \\
\text { juvenile detention and } \\
\text { when are they most likely } \\
\text { to experience a subsequent } \\
\text { juvenile detention event? }\end{array}$ & $\begin{array}{l}\text { Student juvenile } \\
\text { detention event } \\
\text { status variable; } \\
\text { duration between } \\
\text { events; race and } \\
\text { gender/ } \\
\text { All students from } \\
\text { the } 3^{\text {rd }} \text { grade cohort } \\
\text { who experienced an } \\
\text { ASDS placement } \\
\text { and subsequent } \\
\text { juvenile detention. }\end{array}$ & $\begin{array}{l}\text { Descriptive and } \\
\text { frequency statistics; } \\
\text { logistic regression }\end{array}$ & $\begin{array}{l}\text { Descriptive tables } \\
\text { and corresponding } \\
\text { graphs; estimates } \\
\text { and odds ratios for } \\
\text { main effects of } \\
\text { predictor variables }\end{array}$ \\
\hline
\end{tabular}




\section{CHAPTER IV}

\section{RESULTS}

The findings that emerged from the data analyses used to answer the research questions are presented in this chapter. The first section of this chapter provides a description of the demographics, non-academic and academic characteristics of the $3^{\text {rd }}$ grade cohort study sample. Following, the results of the first key question regarding the proportion and timing of student placement in a disciplinary alternative school is presented. Within this section, a description of the characteristics of student placed in alternative schools in comparison with the whole cohort by level (elementary, middle, high) is presented as well as an illustration of the number of placements versus the number of unique students placed. Next, results from the discrete-time hazard models that explore the impact of predictor variables on risk of placement are described. Finally, the outcomes of the third research question addressing subsequent juvenile detention are presented. The chapter includes tables and figures illustrating key findings and concludes with a summary of findings.

\section{Description of $3^{\text {rd }}$ grade Cohort Sample}

The original cohort sample included 7793 students. Of this sample, 4 students had already been enrolled in the elementary alternative school by the start of $3^{\text {rd }}$ grade and thus removed from the working file. Additionally, a total of 121 students were excluded 
from sample due to missing data on substantive variables spanning the entire study period. The final study cohort sample was comprised of 7668 students.

\section{Demographics}

The demographic characteristics of the cohort sample in $3^{\text {rd }}$ grade in 1997 are presented in Table 3 . With respect to gender, there is a relatively even distribution as $52 \%$ of the cohort students are male and $48 \%$ are female. Approximately $35 \%$ of the students are African-American, $61 \%$ are White, and 3.5\% represent other ethnicities. When examining the combinations of gender and race, approximately $32 \%$ are White males, 30\% White females, 19\% African American males, and 17\% are AfricanAmerican Females. In terms of providing a proxy for poverty level, 59.6\% received Free or reduced price lunch, and $40.2 \%$ pay for school lunch. With respect to Special Education status, approximately $77 \%$ of students do not receive special education services, $13 \%$ receive special education services for speech, $5 \%$ are considered having a learning disability (LD), and $1.3 \%$ are categorized as having an emotional-behavioral disability (EBD). 
Table 3

Demographic Characteristics of $3^{\text {rd }}$ Grade Cohort 1997-1998 $(\mathrm{N}=7668)$

\begin{tabular}{|c|c|c|}
\hline & $\mathrm{N}$ & $\%$ \\
\hline \multicolumn{3}{|l|}{ Gender } \\
\hline Male & 3996 & 52.1 \\
\hline Female & 3672 & 47.9 \\
\hline \multicolumn{3}{|l|}{ Race } \\
\hline White & 4683 & 61.1 \\
\hline African American & 2715 & 35.4 \\
\hline Other & 120 & 1.5 \\
\hline Hispanic & 76 & 1.0 \\
\hline Asian & 74 & 1.0 \\
\hline \multicolumn{3}{|l|}{ Gender x Race } \\
\hline White Male & 2430 & 31.7 \\
\hline White Female & 2253 & 29.4 \\
\hline African American Male & 1425 & 18.6 \\
\hline African American Female & 1290 & 16.8 \\
\hline Other Male & 60 & 0.8 \\
\hline Other Female & 60 & 0.8 \\
\hline Hispanic Male & 41 & 0.5 \\
\hline Hispanic Female & 35 & 0.5 \\
\hline Asian Male & 40 & 0.5 \\
\hline Asian Female & 34 & 0.4 \\
\hline \multicolumn{3}{|l|}{ Lunch Status } \\
\hline Free/Reduced & 4571 & 59.6 \\
\hline Paid & 3097 & 40.4 \\
\hline \multicolumn{3}{|l|}{ Lunch $x$ Race } \\
\hline Free/Red Minority & 2514 & 32.8 \\
\hline Free/Red White & 2057 & 26.8 \\
\hline Paid Minority & 471 & 6.1 \\
\hline Paid White & 2626 & 34.2 \\
\hline \multicolumn{3}{|l|}{ Special Education Status } \\
\hline Regular Education Student & 5893 & 76.9 \\
\hline Speech/Language & 993 & 12.9 \\
\hline Learning Disability & 373 & 4.9 \\
\hline Mind Mental Disability & 139 & 1.8 \\
\hline \multicolumn{3}{|l|}{ Emotional Behavioral } \\
\hline Disability & 103 & 1.3 \\
\hline Other & 167 & 2.2 \\
\hline
\end{tabular}




\section{Non-Academic Characteristics}

In order to gauge the academic and non-academic status of the students at the start of the study period during the $3^{\text {rd }}$ grade year, descriptive and frequency statistics were used to summarize various academic and non-academic variables. As shown in Table 4, the average mobility was 0.88 moves (i.e., less than 1 move within the school year). A total of $573(7.5 \%)$ students moved at least 1 time within the first school year (19971998). The range for mobility was $0-6$ moves during the school year. In terms of absenteeism, the number of days absent for the cohort during the $3^{\text {rd }}$ grade year was 7.5 days. The range for absenteeism was $0-77$ days absent. The average poverty rate of schools attended by the cohort (i.e., percent of students in the school they attended receiving free/reduced lunch) was $58 \%$. The range of school poverty rate was $13 \%-$ $96 \%$. A total of $129(1.7 \%)$ of the cohort students were given an out of school suspension disciplinary sanction during $3^{\text {rd }}$ grade. The average rate of suspension was 0.21 . The range of days suspended out of school was $0-3$ days.

Table 4

Non-Academic Characteristics of $3^{\text {rd }}$ Grade Cohort 1997-1998 (N=7668)

\begin{tabular}{|c|c|c|c|}
\hline Mean & $S D \quad N$ & & $\%$ \\
\hline & & 573 & $7.5 \%$ \\
\hline 7.56 & 4.79 & 129 & $1.7 \%$ \\
\hline 58.29 & 22.86 & & \\
\hline
\end{tabular}




\section{Academic Characteristics}

For the variable learning disability, $5 \%$ of the entire cohort was diagnosed as having a specific learning disability. With respect to CTBS stanine, the lowest possible is 1 and the highest possible is 9 . Approximately $31 \%$ scored below average, $51 \%$ average, and $18 \%$ above average on the CTBS reading test.

Table 5

Academic Indicators of $3^{\text {rd }}$ Grade Cohort 1997-1998 (N=7668)

\begin{tabular}{lcc}
\hline & $N$ & $\%$ \\
\cline { 2 - 3 } Learning Disability & 373 & $4.9 \%$ \\
CTBS Reading Stanine & & \\
$\quad$ Below Average & 2126 & $30.9 \%$ \\
Average & 3508 & $51.0 \%$ \\
Above Average & 1249 & $18.1 \%$ \\
\hline
\end{tabular}

CTBS reading data for 6883

\section{Research Question 1: Placement in disciplinary alternative school}

The next section in this chapter will address results for research question 1: What is the proportion of students who experience placement in a disciplinary alternative school and when are students most likely to experience the placement across a 10 year span (time intervals from grade 3-12) in a cohort of in 3rd grade children?

\section{Life Table}

Table 6 is the life table that explicates the patterns of censoring and placement for the 7668 students from grade 3 to grade 12. This life table includes the total number of students at risk each year, the total number censored (e.g., students that withdrew from 
district, students previously placed in alternative school), the total number of unique students placed in a disciplinary alternative school, the hazard probabilities (proportion being placed), survivor probabilities (proportion not placed) and cumulative proportion surviving for each time interval (grade).

As demonstrated in the third column of Table 6, of the 7668 students that start in $3^{\text {rd }}$ grade, a total of 4758 students remained in the cohort through grade 12 . This indicates that over the course of ten years, 2,910 students $(37.9 \%)$ were withdrawn due to a variety of factors including transferring into another district out of the county or state, homeschooled, placed in an alternative school, dropped out, and in a few cases were deceased. The number of students censored (withdrawn for reasons other than placement in a disciplinary alternative school) for each time period is shown in the fifth column.

Addressing the primary question of probability of placement, the hazard function, column 6 shows the proportion of unique students placed in a disciplinary alternative school each year. The cumulative proportion of students surviving shown in the last column (i.e., not experiencing the "hazard" of placement) is $91.2 \%$, indicating that $8.8 \%$ of the cohort students experienced the "hazard" of placement in a disciplinary alternative school between $3^{\text {rd }}$ and $12^{\text {th }}$ grade. A total of 544 students experienced placement in a disciplinary alternative school with the lowest number in $3^{\text {rd }}$ grade $(n=2)$ and the highest numbers equally in grades 7 and $8(n=102)$.

A graphic display of the hazard function is shown on Figure 4. The relatively small number of students placed each year creates a small hazard function, or probability of placement each year. Because the hazard function does not go above $2 \%$ in any one grade, the hazard function is shown on a scale from 0 to .02 to clearly illustrate the 
changing pattern of placement between grade 3 to grade12. As illustrated on Figure 4 and explicated in column 6 of Table 6 , the hazard probability of placement begins low during $3^{\text {rd }}$ and $4^{\text {th }}$ grade $(.03 \%$ and $07 \%$ respectively) and while remaining under $1 \%$ until grade 7 , the probability steadily increases each year with the highest risk at grades 7 and $8(1.6 \%$ and $1.7 \%$ respectively $)$. The hazard probability remains fairly steady with a slight dip in grade $9(1.5 \%)$ until a small decline in probability in grades 11 and $12(1 \%$ and $.06 \%$ respectively). Overall, when taking into account the censored students (i.e., withdrawn from the district each year) the total cumulative proportion of students that experienced placement in a disciplinary school is $9 \%$.

Table 6

Life Table of Discrete-time data for the Cohort from 3 rd to $12^{\text {th }}$ Grade (N=7668)

\begin{tabular}{|c|c|c|c|c|c|c|c|}
\hline \multirow[b]{2}{*}{ Year } & \multirow[b]{2}{*}{$\begin{array}{c}\text { Interval } \\
\text { Grade }\end{array}$} & \multicolumn{3}{|c|}{ Number } & \multicolumn{3}{|c|}{ Proportion } \\
\hline & & $\begin{array}{l}n a t \\
\text { Risk }\end{array}$ & $\begin{array}{l}n \text { Placed in } \\
\text { Alt school }\end{array}$ & $\begin{array}{c}n \\
\text { Censored }\end{array}$ & $\begin{array}{c}\text { Hazard } \\
\text { Function }\end{array}$ & $\begin{array}{l}\text { Survivor } \\
\text { Function }\end{array}$ & $\begin{array}{c}\text { Cumulative } \\
\text { Proportion } \\
\text { Surviving }\end{array}$ \\
\hline $1997-98$ & 3 & 7668 & 2 & 345 & 0.0003 & 0.9997 & $0.9997^{\circ}$ \\
\hline $1998-99$ & 4 & 7321 & 5 & 282 & 0.0007 & 0.9993 & 0.9990 \\
\hline 1999-00 & 5 & 7034 & 27 & 351 & 0.0038 & 0.9962 & 0.9952 \\
\hline $2000-01$ & 6 & 6656 & 50 & 222 & 0.0075 & 0.9925 & 0.9877 \\
\hline 2001-02 & 7 & 6384 & 102 & 110 & 0.0160 & 0.9840 & 0.9719 \\
\hline 2002-03 & 8 & 6172 & 102 & 231 & 0.0165 & 0.9835 & 0.9558 \\
\hline 2003-04 & 9 & 5893 & 86 & 145 & 0.0146 & 0.9854 & 0.9419 \\
\hline 2004-05 & 10 & 5662 & 85 & 314 & 0.0150 & 0.9850 & 0.9277 \\
\hline 2005-06 & 11 & 5263 & 55 & 450 & 0.0105 & 0.9895 & 0.9180 \\
\hline 2006-07 & 12 & 4758 & 30 & - & 0.0063 & 0.9937 & 0.9122 \\
\hline
\end{tabular}




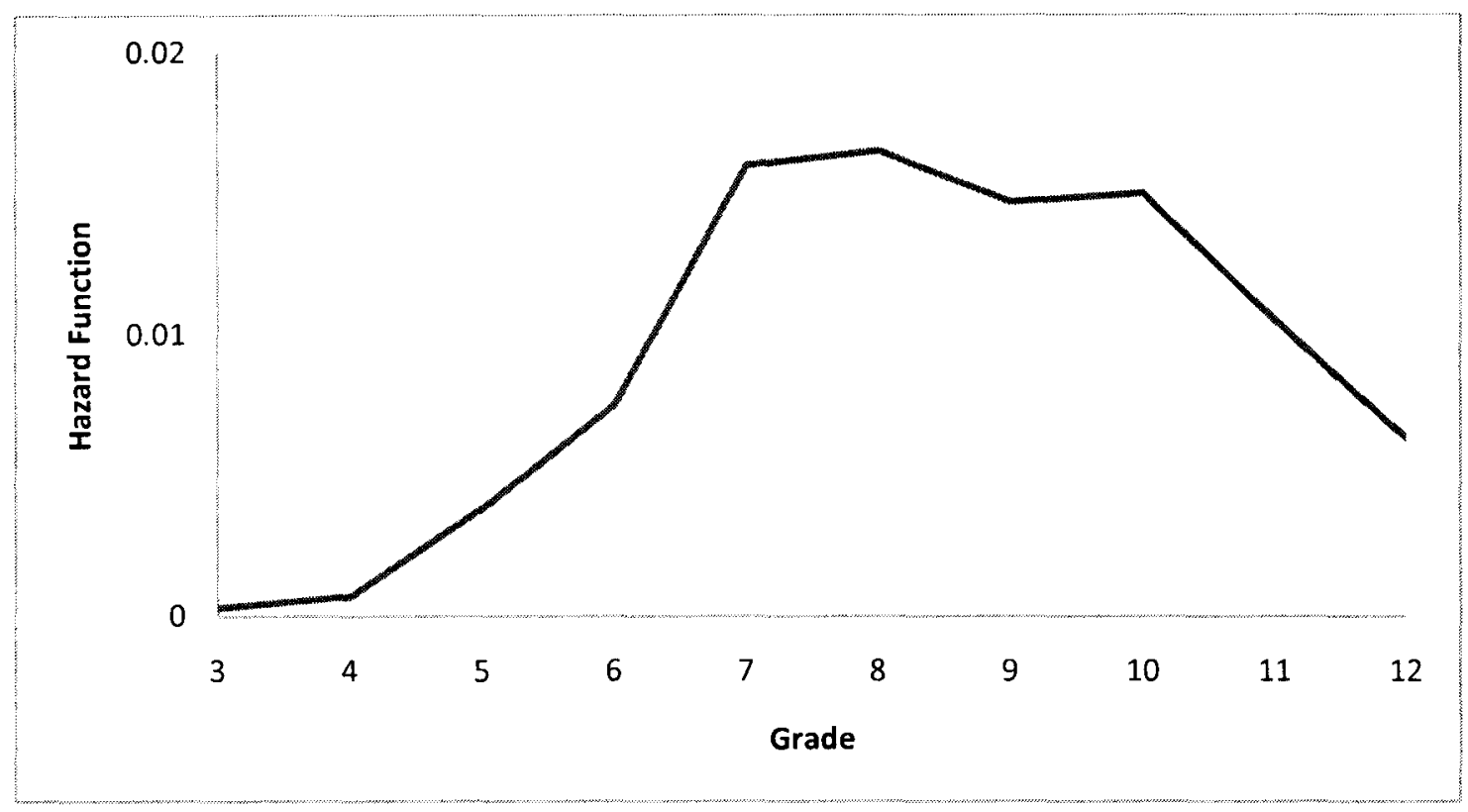

Figure 4: Illustration of hazard function for alternative school placement

Figure 5 is an illustration of the survivor function, or the cumulative proportion of cohort students that do not experience a disciplinary alternative placement event between $3-12^{\text {th }}$ grade. The survivor function provides a context for evaluating the magnitude of hazard, and can be likened to epidemiologists' practice of studying both prevalence and incidence (Singer \& Willett, 2003). Examining the features of the hazard and survivor functions provides information about their interrelationship, so that when looking at Figure 4 and Figure 5 comparatively, it shows that when the hazard is high (grades 7 and 8), the survivor function drops more rapidly, and when the hazard is low (grades 4, 5 and 6) the survivor function drops slowly. 


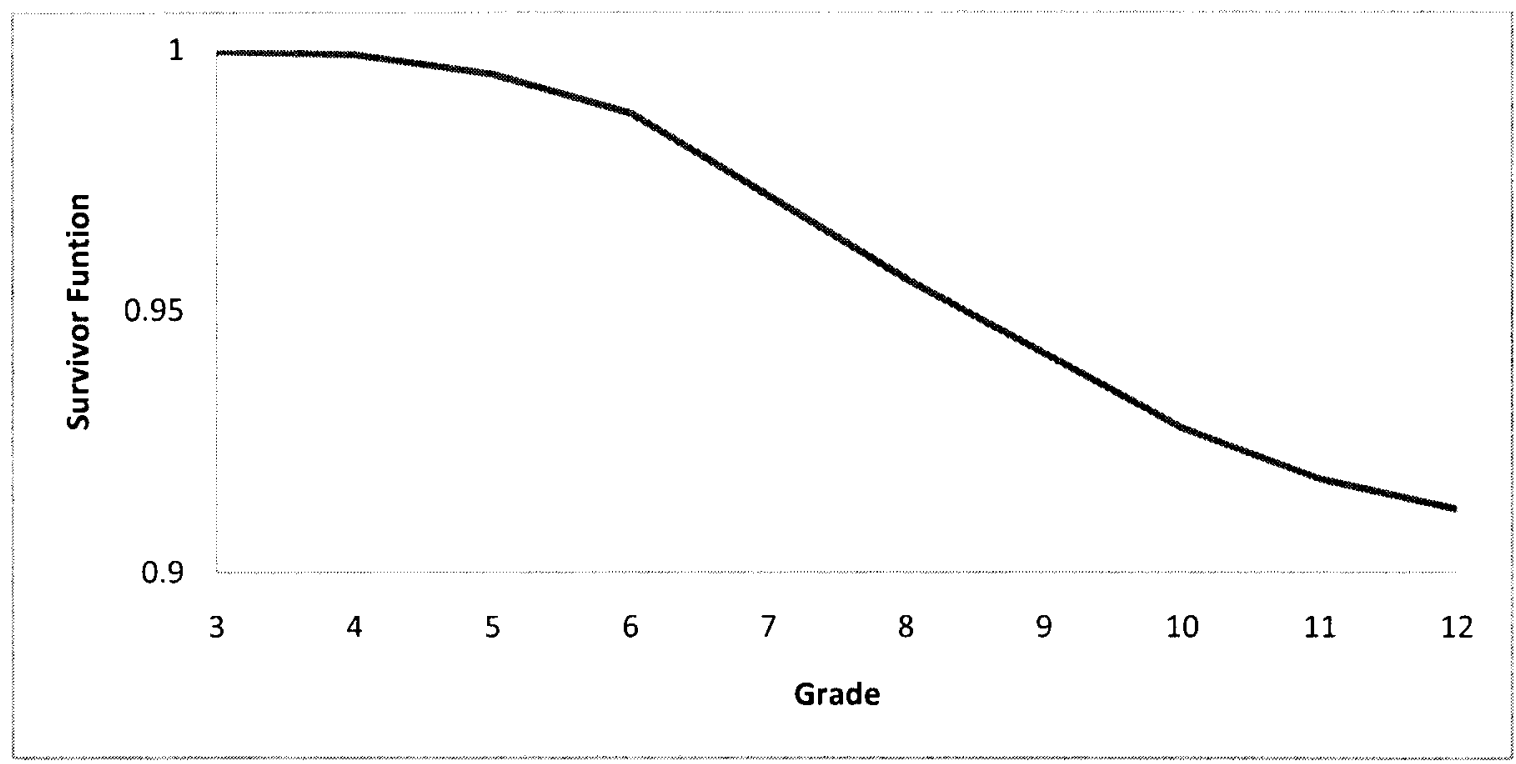

Figure 5. Illustration of the survivor function for placement in alternative school

In studies of less common events, the median lifetime is not calculated for the sample when less than half of the population is not predicted to experience an event (Singer \& Willett, 2003, p 338). As such, because less than half of the cohort experiences a disciplinary alternative school placement event by the last time period in the life table, grade 12 the median lifetime is not presented. Alternatively, in such cases, researchers commonly use five or ten year cumulative survival rates. In the case of alternative school placement, beginning in $3^{\text {rd }}$ grade, the estimated five year survival rate (i.e., not experiencing a disciplinary alternative placement event) is $97 \%$. That is, $97 \%$ of the students who had not experienced a disciplinary alternative placement by $3^{\text {rd }}$ grade will survive for 5 years without experiencing placement in a disciplinary alternative school. 


\section{Descriptive comparison of students placed in alternative schools versus whole cohort sample}

Before presenting the Discrete-time hazard models that assess inferentially the impact of predictor variables on the risk of placement in a disciplinary alternative school, a descriptive comparison is offered. Specifically, this includes descriptive statistics of the students that experienced placement in a disciplinary alternative school in comparison of the whole cohort sample with respect to demographic, non-academic and academic indicators. Several characteristics are presented in for each groups overall that encompass all time periods in Table 7. These include gender, race, gender by race, lunch status and special education status. With respect to gender, of the students placed in alternative schools, $70 \%$ are males while of the total cohort sample population, $52 \%$ are males. In terms of race, the percentages are nearly the exact opposite, confirming the finding of racial disproportionality in the national research literature on this subject. That is, while $35 \%$ of the whole cohort is African-American, $65 \%$ of all the cohort students placed in a disciplinary alternative school were African-American.

When combining race and gender, of the largest racial groups (White and African-American), White females are the smallest group represented in students placed in the disciplinary alternative schools (18\%) while African American males represent the largest group placed in the disciplinary alternative schools (44.5\%). Compared with their representation in the whole cohort (18.6\%) African American males were the most disproportionate group of students placed in alternative schools for disciplinary reasons, again confirming the research literature on this subject. 
The lunch status of students that is used as a proxy for poverty in this study, while remaining stable for the most part, can change from year to year. For the comparison between the cohort and the students placed in alternative schools in Table 7, the percent of students on free/reduced and paid lunch reflects the average over the course of the entire study period. As such the percentages differ slightly from the status of the cohort as they were in $3^{\text {rd }}$ grade shown in Table 3 . The percent of students identified as receiving free/reduced lunch overall is lower which is a trend that is typical not because the actual need is reduced over time, but because students in middle and high schools may not fill out the form to receive free/reduced lunch due to the stigma associated with receiving free/reduced lunch in secondary school. As shown in Table 7, while $52.0 \%$ of the cohort received free/reduced lunch, $79.9 \%$ of students placed in a disciplinary alternative school received free/reduced lunch. When looking at the combination of race and lunch status, minority students that receive free/reduced lunch $(57.5 \%)$ are the most over represented group in disciplinary alternative schools compared with their representation in the cohort $(30.5 \%)$ while White students that can pay for lunch are the most underrepresented in disciplinary alternative schools when compared with their proportion in the cohort ( $10.3 \%$ and $38.1 \%$ respectively).

Similar to the possibility of variation each year for lunch status, a student's special education status also can change over time as students can exit from the special education program. As such the percentages of students receiving special education services in Table 7 reflect the average across the study period. Overall, students identified as having a disability are over represented in the group of students placed in disciplinary alternative schools compared with the whole cohort. Specifically, students identified as 
having a learning disability $(6.6 \%)$, mild mental disability (4.6\%) and emotional behavioral disability (13.6\%) are disproportionately represented when compared to the whole cohort $(5.8 \%, 1.8 \%$ and $1.8 \%$ respectively), with emotional behavioral disability (EBD) status students being the most disproportionately represented in disciplinary alternative schools. 
Table 7.

Demographic Characteristics of Students Placed in Disciplinary Alternative Schools and the Cohort Shown in Percentages

\begin{tabular}{|c|c|c|}
\hline & Alt placed & Cohort \\
\hline \multicolumn{3}{|l|}{ Gender } \\
\hline Male & 70.4 & 52.1 \\
\hline Female & 29.6 & 47.9 \\
\hline \multicolumn{3}{|l|}{ Ethnicity } \\
\hline White & 32.7 & 61.1 \\
\hline African American & 65.3 & 35.4 \\
\hline Other & 1.5 & 1.5 \\
\hline Hispanic & 0.2 & 1.0 \\
\hline Asian & 0.4 & 1.0 \\
\hline \multicolumn{3}{|l|}{ Gender x Ethnicity } \\
\hline White Male & 24.3 & 31.7 \\
\hline White Female & 8.5 & 29.4 \\
\hline African American Male & 44.5 & 18.6 \\
\hline African American Female & 20.8 & 16.8 \\
\hline Other Male & 1.3 & 0.8 \\
\hline Other Female & 0.2 & 0.8 \\
\hline Hispanic Male & 0.2 & 0.5 \\
\hline Hispanic Female & 0.0 & 0.5 \\
\hline Asian Male & 0.2 & 0.5 \\
\hline Asian Female & 0.2 & 0.4 \\
\hline \multicolumn{3}{|l|}{ Lunch Status } \\
\hline Free/Reduced & 79.9 & 52.2 \\
\hline Paid & 20.0 & 47.8 \\
\hline \multicolumn{3}{|l|}{ Lunch $x$ Race } \\
\hline Free/Red Minority & 57.5 & 30.5 \\
\hline Free/Red White & 22.4 & 21.5 \\
\hline Paid Minority & 9.7 & 9.9 \\
\hline Paid White & 10.3 & 38.1 \\
\hline \multicolumn{3}{|l|}{ Special Education Status } \\
\hline Regular Education Student & 62.7 & 75.6 \\
\hline Speech/Language & 9.4 & 12.9 \\
\hline Learning Disability & 6.6 & 5.8 \\
\hline Mind Mental Disability & 4.6 & 1.8 \\
\hline Emotional Behavioral Disability & 13.6 & 1.7 \\
\hline Other & 3.1 & 2.2 \\
\hline
\end{tabular}


In order to assess how characteristics may differ over time for the groups, the characteristics of the students placed in a disciplinary alternative school are compared with the cohort for the elementary grades (i.e., 3, 4, 5), middle grades (i.e., 6, 7, 8) and, high school grades (i.e., 9, 10,11,12). Demographic characteristics are presented in Table 8, non-academic characteristics are presented in Table 9 and academic characteristics are presented in Table 10.

\section{Comparison of Demographics}

At each level (i.e., elementary, middle and high school), African-American males are the most disproportionately represented racial group in the disciplinary alternative schools, with the highest level of overrepresentation at the elementary level. AfricanAmerican females represent the second highest group overrepresented in the alternative school population in elementary, middle and high school. At every level, white females are the most underrepresented group, followed by white males. In terms of students representing other ethnicities, other males are over-represented in the disciplinary alternative school population at the middle grade level.

At each level, students that receive free/reduced lunch are disproportionately represented in disciplinary alternative schools, with the highest level of overrepresentation in elementary. In terms of race and lunch status combinations, minority students that receive free/reduced lunch are disproportionately represented at every grade level, most markedly in elementary. While the in elementary school minority students on free/reduced lunch represent $33.0 \%$ of the cohort population, they represent $76.5 \%$ of students placed in disciplinary alternative schools. 
Table 8

Demographic Characteristics of Students Placed in Disciplinary Alternative Schools and the Cohort by Level Shown in Percentages

\begin{tabular}{|c|c|c|c|c|c|c|}
\hline & \multicolumn{2}{|c|}{ Elem } & \multicolumn{2}{|c|}{ Middle } & \multicolumn{2}{|c|}{ High } \\
\hline & $\begin{array}{c}\text { Alt } \\
(\mathrm{n}=34)\end{array}$ & $\begin{array}{c}\text { Cohort } \\
(\mathrm{n}=7341)\end{array}$ & $\begin{array}{c}\text { Alt } \\
(\mathrm{n}=254)\end{array}$ & $\begin{array}{c}\text { Cohort } \\
(\mathrm{n}=6404)\end{array}$ & $\begin{array}{c}\text { Alt } \\
(n=256)\end{array}$ & $\begin{array}{c}\text { Cohort } \\
(\mathrm{n}=5394)\end{array}$ \\
\hline Race $x$ Gender & & & & & & \\
\hline White Male & 23.5 & 31.4 & 26.8 & 30.0 & 21.9 & 29.1 \\
\hline White Female & 0.0 & 21.9 & 10.2 & 28.9 & 7.8 & 30.1 \\
\hline $\begin{array}{l}\text { African American } \\
\text { Male }\end{array}$ & 55.9 & 18.9 & 39.4 & 19.5 & 48.0 & 18.6 \\
\hline $\begin{array}{l}\text { African American } \\
\text { Female }\end{array}$ & 20.6 & 17.2 & 20.9 & 18.4 & 20.7 & 18.9 \\
\hline Other Male & 0.0 & 1.7 & 2.0 & 1.6 & 1.6 & 1.7 \\
\hline Other Female & 0.0 & 1.5 & 0.8 & 0.7 & 0.0 & 1.5 \\
\hline Lunch Status & & & & & & \\
\hline Free/Reduced & 97.1 & 58.9 & 84.6 & 54.0 & 73.0 & 43.0 \\
\hline Paid & 2.9 & 41.1 & 15.4 & 46.0 & 27.0 & 57.0 \\
\hline $\begin{array}{l}\quad \text { Lunch } \times \text { Race } \\
\text { Free/Red } \\
\text { Minority }\end{array}$ & 76.5 & 33.0 & 56.7 & 32.3 & 55.9 & 26.3 \\
\hline Free/Red White & 20.6 & 25.9 & 28.0 & 21.7 & 17.2 & 16.7 \\
\hline Paid Minority & 0.0 & 6.5 & 6.3 & 8.8 & 14.5 & 14.5 \\
\hline Paid White & 2.9 & 34.6 & 9.1 & 37.2 & 12.5 & 42.6 \\
\hline
\end{tabular}

\section{Comparison of non-academic characteristics}

For the non-academic variables, the continuous variables (i.e., suspension, mobility, absenteeism) are presented in the collapsed categories that are used to graphically display the hazard models in the later part of this results section. As shown in table 9, students identified as having an emotional behavioral disability (EBD) are overrepresented in the disciplinary alternative school population at every level, with the highest over-representation at the elementary level. This is likely due to the fact that the majority of students enrolled in the elementary disciplinary alternative school are identified as EBD students. However, beginning in 1999, some elementary students were 
also being placed in the disciplinary alternative middle school as they expanded to allow students in younger grades to attend. Of all the students placed in elementary $(n=34)$ less than half $(41 \%)$ were placed in the elementary school that serves mostly EBD students while the rest were placed in the middle school with expanded capacity for students in $4^{\text {th }}$ and $5^{\text {th }}$ grade.

In terms of out of school suspension, students with one or more suspensions are over represented in the disciplinary alternative schools at every level. Similarly, students with one or more moves within the school year are over represented in the disciplinary alternative schools at each level. Considering absenteeism, students with medium absenteeism (6-11 days absent) are over represented in the in the disciplinary alternative schools at the elementary level, yet proportional at high school. Students with high absences (12+ days absent) are over represented at every grade level. Students that are absent 6 or more days within a school year are considered truant by the district study site and several forms of intervention can occur (e.g., letters, phone calls, visit) while 12 or more unexcused absences for a student can enact a possible referral to child protective services. 
Table 9.

Non-Academic Characteristics of Alternative Placed Students and the Cohort by Level

\begin{tabular}{|c|c|c|c|c|c|c|}
\hline & \multicolumn{2}{|c|}{ Elem } & \multicolumn{2}{|c|}{ Middle } & \multicolumn{2}{|c|}{ High } \\
\hline & $\begin{array}{c}\text { Alt } \\
(n=34)\end{array}$ & $\begin{array}{c}\text { Cohort } \\
(\mathrm{n}=7341)\end{array}$ & $\begin{array}{c}\text { Alt } \\
(n=254)\end{array}$ & $\begin{array}{c}\text { Cohort } \\
(n=6404)\end{array}$ & $\begin{array}{c}\text { Alt } \\
(n=256)\end{array}$ & $\begin{array}{c}\text { Cohort } \\
(n=5394)\end{array}$ \\
\hline$E B D$ & 52.9 & 1.6 & 11.4 & 2.2 & 10.5 & 1.5 \\
\hline \multicolumn{7}{|c|}{ Suspension } \\
\hline 0 & 26.5 & 98.1 & 12.6 & 85.4 & 29.3 & 88.4 \\
\hline $1-2$ & 47.1 & 1.8 & 36.2 & 12.0 & 50.8 & 10.0 \\
\hline $3+$ & 26.5 & .1 & 51.2 & 2.7 & 19.9 & 1.6 \\
\hline \multicolumn{7}{|l|}{ Mobility } \\
\hline 0 & 76.5 & 95.3 & 77.2 & 96.6 & 68.0 & 98.0 \\
\hline 1 & 14.7 & 4.1 & 14.2 & 3.0 & 25.4 & 1.8 \\
\hline $2+$ & 8.8 & 0.6 & 8.7 & 0.3 & 6.6 & 0.2 \\
\hline \multicolumn{7}{|c|}{ Absenteeism } \\
\hline Low $(0-5)$ & 20.6 & 51.4 & 34.0 & 44.8 & 25.8 & 38.5 \\
\hline Med (6-11) & 38.2 & 26.4 & 26.8 & 25.7 & 23.4 & 23.2 \\
\hline High $(12+)$ & 41.2 & 22.1 & 39.2 & 29.5 & 50.8 & 38.2 \\
\hline
\end{tabular}

\section{Comparison of Academic Characteristics}

As shown on Table 10, students who experience grade retention are

underrepresented in the disciplinary alternative school population in elementary, yet over-represented in middle and high. Students identified as having a learning disability (LD) are underrepresented in the disciplinary alternative school population in elementary, yet over-represented in middle and highly disproportional in high school. In terms of CTBS reading, the categories reflect stanines where below average means their reading stanine score was between 1-3, average between 4-6 and above average between 7-9. The CTBS was only given in grades 3,6 and 9 so the data reflect those particular years and not an average of every grade within each level. Students scoring below average are over 
represented in the disciplinary alternative school population in grades 3,6 and 9. Due to the transient nature of the students placed in disciplinary alternative schools, a large percent of these students did not have a CTBS score. In $3^{\mathrm{h}}$ grade, $29(85 \%)$ had missing scores, in $6^{\text {th }}$ grade $149(41 \%)$ had missing scores, and $160(62 \%)$ had missing scores on CTBS reading in $9^{\text {th }}$ grade. Due to the large amount of missing CTBS data, this variable was removed from the discrete-time hazard analyses.

Table 10.

Academic Characteristics of Alternative Placed Students and the Cohort by Level

\begin{tabular}{lcc|cc|cc}
\hline & \multicolumn{2}{c}{ Elem } & \multicolumn{2}{c}{ Middle } & \multicolumn{2}{c}{ High } \\
& $\begin{array}{c}\text { Alt } \\
(\mathrm{n}=34)\end{array}$ & $\begin{array}{c}\text { Cohort } \\
(\mathrm{n}=7341)\end{array}$ & $\begin{array}{c}\text { Alt } \\
(\mathrm{n}=254)\end{array}$ & $\begin{array}{c}\text { Cohort } \\
(\mathrm{n}=6404)\end{array}$ & \multicolumn{1}{c}{ Alt } & $\begin{array}{c}\text { Cohort } \\
\text { Retained }\end{array}$ \\
\cline { 2 - 7 } & 2.9 & 4.2 & 9.4 & 1.8 & 18.4 & 4.7 \\
$\quad$ LD & 2.9 & 5.8 & 5.9 & 6.5 & 7.8 & 5.2 \\
CTBS Reading* & & & & & & \\
Below Avg & 40.0 & 35.5 & 63.8 & 28.7 & 64.6 & 32.0 \\
Average & 60.0 & 48.5 & 35.2 & 55.0 & 30.2 & 45.4 \\
Above Avg & 0.0 & 16.0 & 1.0 & 16.3 & 5.2 & 22.6 \\
\hline
\end{tabular}

*these represent data from grades 3, 6 and 9 as that is when the students took the CTBS tests. Large amount of missing data for the alternative school students resulted in scores not being used in inferential tests.

\section{Number of Alternative School Entries}

One of the key characteristics of disciplinary alternative schools that is and embedded in the conceptual framework of this study (Figure 2) is the cyclical nature of the placements. The methodology used in this dissertation to examine predictors of 
placement is such that only first placement is considered. As such, in order to provide a sense of the levels of recidivism experienced by the cohort with respect to enrollments into the disciplinary alternative schools, descriptive statistics are used. Table 11 includes the number of entries each year alongside the number of unique students that are represented in the Life Table (Table 6).

The number of entries exceeds the number of unique students because for the purpose of the major analyses in this dissertation, the data set excluded students from the sample immediately after placement. It also excluded any student that was censored for other reasons during each year from every subsequent year. As such, the number of entries includes students experiencing recidivism (i.e., returning to disciplinary alternative schools after entering a "regular" school), as well as entries for students that were censored from the sample. An additional column was added to the table to reflect the cumulative number of students in the cohort placed in disciplinary schools to provide a context in which to view the number of entries. An average for number of entries into the disciplinary alternative schools based on the cumulative number of students placed in the disciplinary alternative schools was not calculated because the number of entries could also have been made up by students withdrawn from the data set for other reasons that then returned (e.g., dropped out, withdrew from district, etc.). As shown in Table 11 and Figure 6, the number of entries climbs steadily from grade 3 to grade 6 with a sharp increase in grade $7(n=266)$. The number of entries remains steady until a slow decline between $11^{\text {th }}$ and $12^{\text {th }}$ grade. 
Table 11.

Number of Unique Students and Number of Alternative School Entries

\begin{tabular}{cccc}
\hline Grade & $\begin{array}{c}\text { Nunique } \\
\text { students }\end{array}$ & $\begin{array}{c}\text { Nof Alt school } \\
\text { Entries }\end{array}$ & $\begin{array}{c}\text { Cumulative } N \\
\text { alt students }\end{array}$ \\
\hline 3 & 2 & 3 & 2 \\
4 & 5 & 8 & 7 \\
5 & 27 & 39 & 34 \\
6 & 50 & 80 & 84 \\
7 & 102 & 266 & 186 \\
8 & 102 & 238 & 288 \\
9 & 86 & 245 & 374 \\
10 & 85 & 272 & 459 \\
11 & 55 & 254 & 514 \\
12 & 30 & 152 & 544 \\
\hline
\end{tabular}

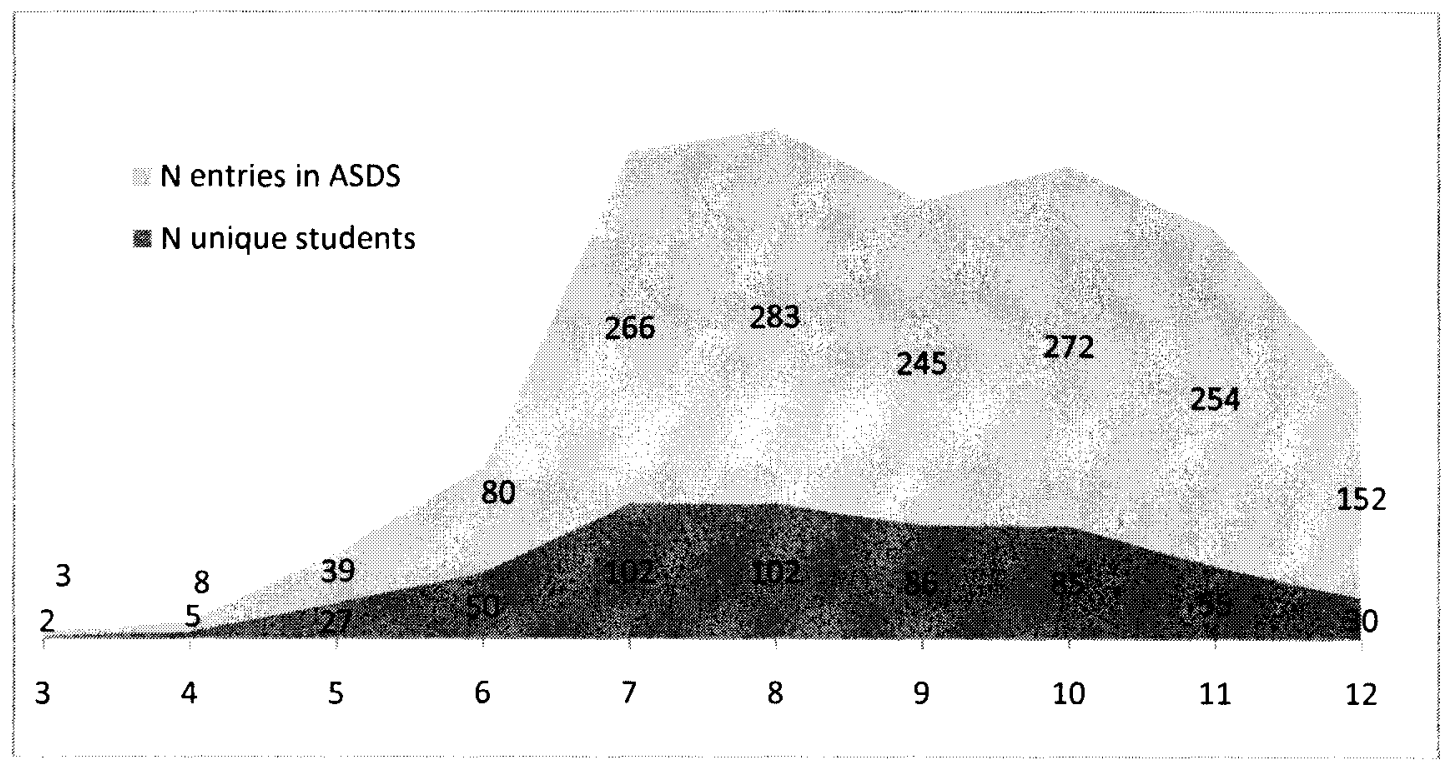

Figure 6. Number of unique students placed and number of entries into disciplinary alternative school 


\section{Research Question 2: Predictors of placement into a disciplinary alternative school}

This section addresses research question 2: What are the time-constant and timevarying predictors of risk associated with an alternative school placement event in a cohort of $3^{\text {rd }}$ grade children across 10 time intervals?

\section{Initial Discrete-time Hazard Model: Main effect of Time}

All Discrete-time survival analyses should begin with an initial model (Singer and Willett, 1993, 2003) for two main reasons (1) to provide a simple model against which to compare more complex models and (2) to provide an interpretation of the $\widehat{\alpha}_{\mathrm{j}}$ 's that give direct information about the shape of the whole-sample hazard function (Singer and Willett, 1993, p 176). This initial model contains no predictors other than the time indicators $\left(D_{3}-D_{12}\right)$ and addresses the question of the risk of placement in a disciplinary alternative school in each time interval. All of the tables depicting the fitted time hazard models in this section will include this initial Model (Model A) as a basis for comparison of the models with other substantive predictors. This initial model gives the estimated value of the logit hazard function for the entire baseline sample.

$$
\text { ModelA: } \quad \operatorname{logith}\left(\mathrm{t}_{\mathrm{j}}\right)=\left[\alpha_{3} D_{3}+\alpha_{8} D_{8}+\ldots+\alpha_{12} D_{12}\right]
$$

Table 12 presents the parameter estimates for the baseline model which includes only the time predictor variables, on both odds and hazard scales. The sample estimates on the hazard scale shown in Table 12 reveal internal consistency as the fitted hazard values are identical to the hazard probabilities in the life table for each time period (Table 6 column 6). As such, the parameter estimates in Table 12 when expressed on the fitted hazard scale are interpreted as the hazard probabilities for risk of placement at each grade explicated in the life table section. For example, showing that among all students in the 
cohort in the $7^{\text {th }}$ grade, the parameter estimate -4.120 when expressed as a hazard probability, it is estimated there is a $1.6 \%$ risk of being placed in a disciplinary alternative school. As shown in Table 12, the steady increase in the estimates over time indicates that in this cohort, the risk of placement in a disciplinary alternative school increases over time, peaking at grade 8 , until grade 9 when it decreases slightly and there is a slow decline in risk between grades 11 and 12. Each time point parameter is significant, which indicates that placement in a disciplinary alternative school is significantly related to time between grades $3^{\text {rd }}$ and $12^{\text {th }}$ grade.

Table 12

Initial Discrete-Time Hazard Model with main effect of TIME Re-expressed Parameter Estimates as Fitted Odds and Fitted Hazard Probabilities

\begin{tabular}{clccc}
\hline Time Period & Predictor & $\begin{array}{c}\text { Parameter } \\
\text { Estimate }\left(\widehat{\alpha}_{\mathrm{j}}\right)\end{array}$ & $\begin{array}{c}\text { Fitted odds } \mathrm{j}^{(} \widehat{\alpha} \\
\frac{1}{1+\mathrm{e}\left(-\widehat{\alpha}^{\mathrm{j}}\right)}\end{array}$ \\
\hline 3 & $\mathrm{D}_{3}$ & $-8.251^{* *}$ & .0003 & .0003 \\
4 & $\mathrm{D}_{4}$ & $-7.288^{* *}$ & .0007 & .0007 \\
5 & $\mathrm{D}_{5}$ & $-5.559^{* *}$ & .0039 & .0038 \\
6 & $\mathrm{D}_{6}$ & $-4.884^{* *}$ & .0076 & .0075 \\
7 & $\mathrm{D}_{7}$ & $-4.120^{* *}$ & .0162 & .0160 \\
8 & $\mathrm{D}_{8}$ & $-4.086^{* *}$ & .0168 & .0165 \\
9 & $\mathrm{D}_{9}$ & $-4.212^{* *}$ & .0148 & .0146 \\
10 & $\mathrm{D}_{10}$ & $-4.184^{* *}$ & .0152 & .0150 \\
11 & $\mathrm{D}_{11}$ & $-4.551^{* *}$ & .0106 & .0104 \\
12 & $\mathrm{D}_{12}$ & $-5.060^{* *}$ & .0063 & .0063 \\
\hline$* \mathrm{p}<.01 * * \mathrm{p}<.001$ & & &
\end{tabular}




\section{Discrete-Time Hazard Models: Effects of Race, Gender and Lunch Status on Risk of Placement}

The next discrete-time hazard models include the demographic characteristics of the cohort to assess the effects of race, gender or lunch status on placement in a disciplinary alternative school. When looking at the models that incorporate substantive predictor variables, it is important to note that fitting these data to Discrete-time hazard models yields two types of parameter estimates: the $\widehat{\alpha}$;s give estimated values of the baseline logit hazard function discussed above, and also as a group are the maximum likelihood estimates of the baseline logit hazard function; and the $\beta$ 's which assess the effects of the predictors (Singer \& Willett, 2003, p. 386-387). The equations for the Models that explore the effect of race, gender, and lunch status (in addition to the baseline Model A) are shown below. The models for each subsequent predictor category (i.e., behavior related, attendance/mobility, academic) follow the same pattern.

$$
\begin{array}{lll}
\text { Model B : } & \operatorname{logit} \mathrm{h}\left(\mathrm{t}_{\mathrm{j}}\right)=\left[\alpha_{3} D_{3}+\alpha_{8} D_{8}+\ldots+\alpha_{12} D_{12}\right]+\beta_{1} M I N \\
\text { Model C : } & \operatorname{logit} \mathrm{h}\left(\mathrm{t}_{\mathrm{j}}\right)=\left[\alpha_{3} D_{3}+\alpha_{8} D_{8}+\ldots+\alpha_{12} D_{12}\right]+\beta_{2} G E N \\
\text { Model D : } & \operatorname{logit} \mathrm{h}\left(\mathrm{t}_{\mathrm{j}}\right)=\left[\alpha_{3} D_{3}+\alpha_{8} D_{8}+\ldots+\alpha_{12} D_{12}\right]+\beta_{3} F R E \\
\text { Model E : } & \operatorname{logit} \mathrm{h}\left(\mathrm{t}_{\mathrm{j}}\right)=\left[\alpha_{3} D_{3}+\alpha_{8} D_{8}+\ldots+\alpha_{12} D_{12}\right]+\beta_{1} M I N+\beta_{2} G E N+\beta_{3} F R E \\
\text { ModelA: } & \operatorname{logith}\left(\mathrm{t}_{\mathrm{j}}\right)=\left[\alpha_{3} D_{3}+\alpha_{8} D_{8}+\ldots+\alpha_{12} D_{12}\right]
\end{array}
$$

It should also be noted that bi-variate correlations at the student level were assessed to screen for the possible effects of multicollinearity prior to examining the discrete-time hazard models with multiple substantive predictors. The highest correlation among variables was between the predictors Race and Lunch Status $(388, \mathrm{p}=.000)$ which indicates that estimates in the models will not be impacted by high levels of correlation between any of the predictor variables. 


\section{Effect of Race on Risk of Placement}

As shown in Table 13, the addition of the dichotomous variable race to the initial model is presented in Model B. By including the time invariant predictor Minority, the goodness of fit statistics shown improvement from the initial model as demonstrated by the increase of the model log-likelihood statistic $(L L)$ from -2952.89 to -2876.75 , indicating that the addition of minority has significantly improved the overall fit of the hazard model (Singer and Willett, 2003). Additionally, the Akaike Information Criterion (AIC) statistic is useful in making comparisons in models with different predictors and takes into account the total sample size and the number of parameters present in the model. The smaller its value is, the better the fit (Singer \& Willett, 2003, p. 402). The AIC value for Model B is 5775 while the AIC value for Model A is 5925.77, providing yet another indicator that the addition of the predictor variable minority significantly improved the model fit.

The estimated coefficient for Minority is $1.088(\mathrm{p}=.000)$. The positive sign indicates that from $3^{\text {rd }}-12^{\text {th }}$, Minority students are at greater risk of placement in a disciplinary alternative school. When antilogging this parameter estimate, it yields an odds ratio $(\exp \beta)$ of 2.96 . The odds ratio reveals that in the estimated odds of placement are 3 times higher for minority students then white students.

As shown in the combined model, Model D, when controlling for gender and lunch status, the estimated coefficient for Minority is .692 ( $p<.001)$. When antilogging this parameter estimate, it yields an odds ratio $(\exp \beta)$ of 1.99. This indicates that when controlling the effects of gender and lunch status, the estimated odds of placement are 2 times higher for minority students then white students. 


\section{Effect of Gender on Risk of Placement}

As shown in Table 13, the addition of the dichotomous variable gender to the initial model is presented in Model C. Several of the goodness of fit statistics indicates that including the time invariant predictor gender did not improve the model fit. The logliklihood statistic $(L L)$ is used as the basis for computing the deviance statistic as noted in the Deviance statistic, which quantifies how much worse the current model is in comparison to the best possible model you could fit. The smaller the Deviance statistic is, the better the fit (Singer and Willett, 2003, p. 398). As can be seen, the Deviance statistic (5816.65) while slightly smaller than the base model, is larger than Model B (5753.50).

Additionally, the AIC value for Model C is 5838.65 while Model B AIC value is 5775.50 indicating again that the inclusion of gender is less powerful a predictor than minority status.

While the estimated coefficient for gender (.850) is statistically significant $(p=.000)$ the addition of gender does not improve the model fit. Taken alone, the positive coefficient indicates that male students are at greater risk of placement in a disciplinary alternative school. Antilogging the parameter estimate $(.850)$ yields an odds ratio $(\exp \beta)$ of 2.34. The odds ratio reveals that in the estimated odds of placement are slightly over 2 times higher for male students then female students. As shown in the combined model, Model D, when controlling for race and lunch status, the estimated coefficient for gender is .824 . When antilogging this parameter estimate, it yields an odds ratio $(\exp \beta)$ of 2.28 . This indicates that when controlling the effects of gender and lunch status, the estimated odds of placement are still slightly 2 times higher for male students then female students. In comparison to minority as a predictor, considering the more improved model fit with 
the addition of the minority predictor variable as well as the descriptive statistics showing greater disporportionality based on race than gender, minority status is a stronger predictor of placement than gender.

\section{Effect of Lunch Status on Risk of Placement}

The addition of the dichotomous variable Lunch status that serves as a proxy for student socio-economic status is shown in Model D on Table 13. By including the time varying predictor Lunch status, the model fit showed improvement from the all previous models (Models A, B and C) as demonstrated by the increase of the model log-likelihood statistic $(L L)$ to -2848.90 , the highest of all the models thus far, and the smallest AIC value yet (5719.8).

The estimated coefficient for Lunch is $1.410(\mathrm{p}=.000)$. The positive sign indicates that from $3^{\text {rd }}-12^{\text {th }}$, students on free/reduced lunch students are at greater risk of placement in a disciplinary alternative school. When antilogging this parameter estimate, it yields an odds ratio $(\exp \beta)$ of 4.10 . The odds ratio reveals that in the estimated odds of placement are 4 times higher for students that receive free/reduced lunch than for students that can pay for lunch. As shown in the combined model, Model D, when controlling for race and gender, the estimated coefficient for Lunch is $.1 .112(\mathrm{p}=000)$. When antilogging this parameter estimate, it yields an odds ratio $(\exp \beta)$ of 3.04 . This indicates that when controlling the effects of race and gender, the estimated odds of placement in a disciplinary alternative school are 3 times higher for students that receive free/reduced lunch than for students that can pay for lunch. 


\section{Full Model of Race, Gender and Lunch Status on Risk of Placement}

Model $\mathrm{E}$ on Table 13 includes the full model that examines the combined impact of race, gender and lunch status on risk of placement. The inclusion of all the demographic predictors provides the best model fit as noted by the smallest Deviance statistic (5562.11) and the AIC statistic (5588.11) and shows lunch status has the largest effect on risk of placement. The size of the Wald chi-square statistic for lunch status of $91.02(p=.000)$ in comparison to the Wald statistic for race $75.76(p=.000)$ and gender of $49.93(\mathrm{p}=.000)$ also lends to the conclusion that lunch status is the strongest demographic predictor of placement in a disciplinary alternative school. 
Table 13.

Results of fitting Discrete-Time Hazard models for Predictor Variables Race, Gender and Lunch Status to the Grade of First Placement in Disciplinary Alternative School

\begin{tabular}{|c|c|c|c|c|c|}
\hline & Model A & Model B & Model C & Model D & Model E \\
\hline \multicolumn{6}{|c|}{ Parameter Estimates and Asymptotic Standard Errors } \\
\hline \multirow[t]{2}{*}{$\mathrm{D}_{3}$} & $-8.251 * *$ & $-8.820^{* *}$ & $-8.781 * *$ & $-9.297 * *$ & $-9.950 * *$ \\
\hline & $(.707)$ & $(.710)$ & $(.710)$ & $(.713)$ & $(.717)$ \\
\hline \multirow[t]{2}{*}{$\mathrm{D}_{4}$} & $-7.288 * *$ & $-7.865 * *$ & $-7.817^{* *}$ & $-8.333 * *$ & $-8.991 * *$ \\
\hline & $(.447)$ & $(.452)$ & $(.452)$ & $(.457)$ & $(.463)$ \\
\hline \multirow[t]{2}{*}{$\mathrm{D}_{5}$} & $-5.559 * *$ & $-6.141 * *$ & $-6.088 * *$ & $-6.582 * *$ & $-7.253 * *$ \\
\hline & $(.193)$ & $(.202)$ & $(.204)$ & $(.214)$ & $(.227)$ \\
\hline \multirow{2}{*}{$\mathrm{D}_{6}$} & $-4.884^{* *}$ & $-5.475 * *$ & $-5.408 * *$ & $-5.885 * *$ & $-6.561 * *$ \\
\hline & $(.142)$ & $(.155)$ & $(.157)$ & $(.169)$ & $(.185)$ \\
\hline \multirow[t]{2}{*}{$\mathrm{D}_{7}$} & $-4.120 * *$ & $-4.715^{* *}$ & $-4.642 * *$ & $-5.103 * *$ & $-5.785 * *$ \\
\hline & $(.100)$ & $(.118)$ & $(.120)$ & $(.135)$ & $(.154)$ \\
\hline \multirow[t]{2}{*}{$\mathrm{D}_{8}$} & $-4.086^{* *}$ & $-4.677 * *$ & $-4.604 * *$ & $-5.051 * *$ & $-5.729 * *$ \\
\hline & $(.100)$ & $(.117)$ & $(.120)$ & $(.134)$ & $(.153)$ \\
\hline \multirow[t]{2}{*}{$\mathrm{D}_{9}$} & $-4.212^{* * *}$ & $-4.804 * *$ & $-4.726 * *$ & $-5.162 * *$ & $-5.839 * *$ \\
\hline & $(.109)$ & $(.125)$ & $(.127)$ & $(.140)$ & $(.158)$ \\
\hline \multirow[t]{2}{*}{$\mathrm{D}_{10}$} & $-4.184 * *$ & $-4.776^{* *}$ & $-4.694 * *$ & $-5.114^{* *}$ & $-5.792 * *$ \\
\hline & $(.109)$ & $(.126)$ & $(.128)$ & $(.140)$ & $(.158)$ \\
\hline \multirow[t]{2}{*}{$D_{11}$} & $-4.551^{* *}$ & $-5.141 * *$ & $-5.057^{* *}$ & $-5.451 * *$ & $-6.127^{* *}$ \\
\hline & $(.136)$ & $(.149)$ & $(.151)$ & $(.161)$ & $(.176)$ \\
\hline \multirow[t]{2}{*}{$\mathrm{D}_{12}$} & $-5.060 * *$ & $-5.643 * *$ & $-5.560 * *$ & $-5.546 * *$ & $-6.284 * *$ \\
\hline & $(.183)$ & $(.193)$ & $(.194)$ & $(.192)$ & $(.207)$ \\
\hline \multirow[t]{3}{*}{ Minority } & & $1.088^{* *}$ & & & $.692 * *$ \\
\hline & & $(.092)$ & & & $(.098)$ \\
\hline & & $\exp \beta 2.96$ & & & $\exp \beta 1.99$ \\
\hline \multirow[t]{3}{*}{ Gender } & & & $.850 * *$ & & $.824 * *$ \\
\hline & & & $(.094)$ & & $(.095)$ \\
\hline & & & $\exp \beta 2.34$ & & $\exp \beta 2.28$ \\
\hline \multirow[t]{3}{*}{ Lunch } & & & & $1.410^{* *}$ & $1.112 * *$ \\
\hline & & & & $(.109)$ & $(.117)$ \\
\hline & & & & $\exp \beta 4.10$ & $\exp \beta 3.04$ \\
\hline \multicolumn{6}{|c|}{ Goodness-of-Fit } \\
\hline$L L$ & -2952.89 & -2876.75 & -2908.33 & -2848.90 & -2781.06 \\
\hline Deviance & 5905.77 & 5753.50 & 5816.65 & 5697.80 & 5562.11 \\
\hline $\mathrm{n}$ parameters & 10 & 11 & 11 & 11 & 13 \\
\hline $\mathrm{AIC}$ & 5925.77 & 5775.5 & 5838.65 & 5719.8 & 5588.11 \\
\hline \multicolumn{6}{|c|}{ Deviance-based Hypothesis Tests } \\
\hline $\mathrm{H}_{0}: \mathrm{B}_{M I N}=0$ & & $152.27^{* *}$ & & & $191.39 * *$ \\
\hline $\mathrm{H}_{0}: \mathrm{B}_{G E N}=0$ & & & $89.12 * *$ & & $254.54 * *$ \\
\hline $\mathrm{H}_{0}: \mathrm{B}_{F R E}=0$ & & & & $207.97 * *$ & $135.69 * *$ \\
\hline \multicolumn{6}{|c|}{ Wald Hypothesis Tests } \\
\hline $\mathrm{H}_{0}: \mathrm{B}_{M I N}=0$ & & $140.105^{* *}$ & & & $75.76^{* *}$ \\
\hline $\mathrm{H}_{0}: \mathrm{B}_{G E N}=0$ & & & $80.932 * *$ & & $49.93^{* *}$ \\
\hline $\mathrm{H}_{0}: \mathrm{B}_{F R E}=0$ & & & & $166.28 * *$ & $91.02 * *$ \\
\hline
\end{tabular}




\section{Graphic displays of fitted hazard function for Race, Gender and Lunch Status}

In order to summarize and illustrate trends over time related to the substantive predictors, graphic displays of the fitted values of hazard are shown for each predictor. This is done by substituting the parameter estimates back into the discrete-time hazard models and obtaining predicted values by outputting parameter estimates for the logistic regression procedure as explicated in Singer and Willett (2003). The syntax used for this procedure was provided by UCLA Academic Technology Services, Statistical Consulting Group (2010). Illustrating the fitted values of hazard is the most effective way to explicitly show how much different the risk of placement is in each grade for students based on their demographic characteristics, and other predictors.

\section{Fitted Hazard Function for Race}

As shown in Figure 7, there is a marked difference in hazard based on race. That is minority students at every grade level from grade 4 through grade 12 are at higher risk of placement in a disciplinary alternative school. The graph corresponds with both the descriptive statistics showing racial disporportionality and Model B in Table 13 . The graphic display in Figure 7 illustrates that the effect of minority status on the hazard of placement increases over time, peaking between grades 7 through grade 10 . 


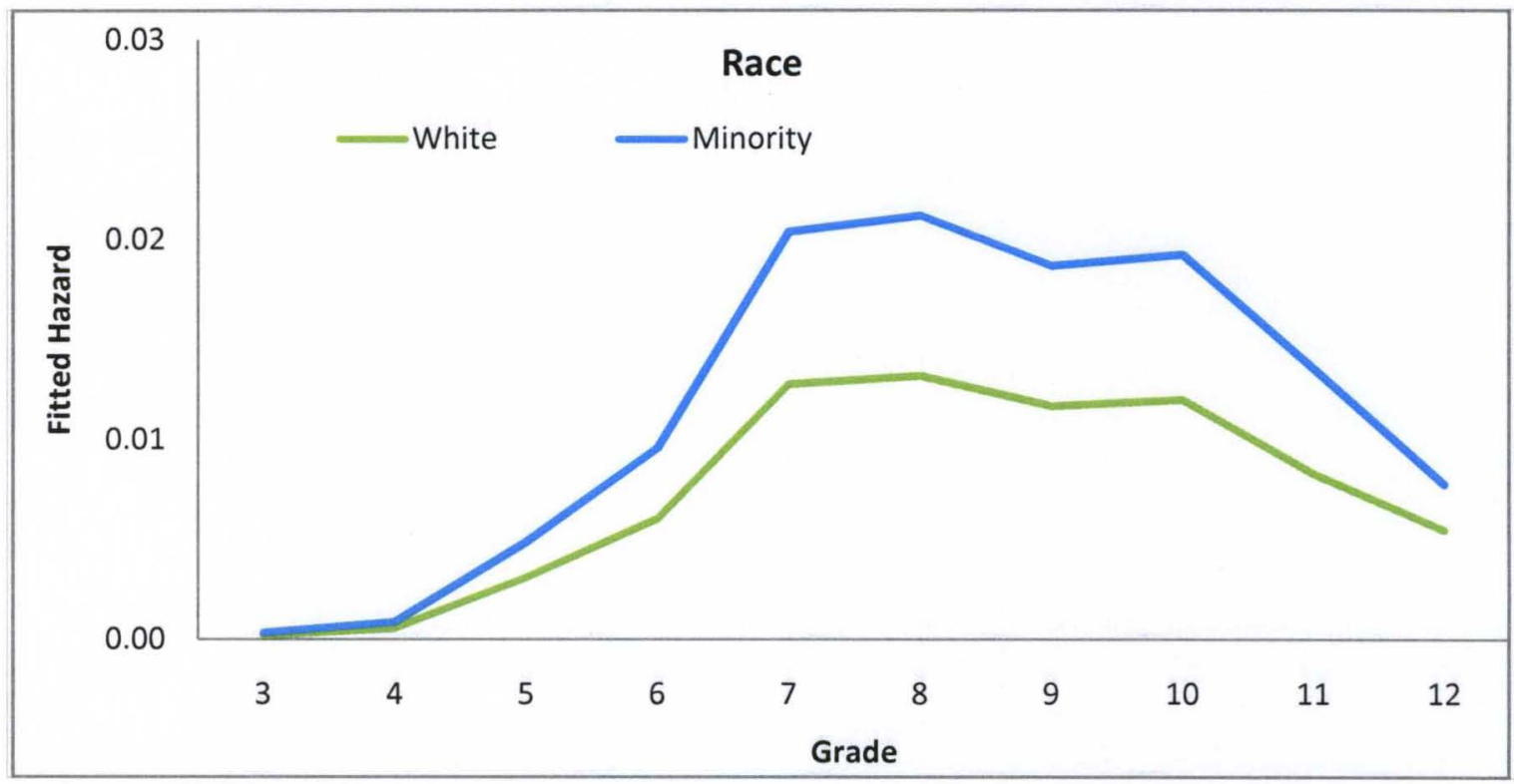

Figure 7. Illustration of fitted hazard function for the grade of placement with main effects of Time and Race.

Fitted Hazard Function for Gender

As shown in Figure 8, there is a difference in hazard based on gender. Male students are at higher risk. Recalling the lack of improved fit that adding gender to the model in Table 13, as well as the proportional overrepresentation of male students in the overall population of the cohort (52\%) and students placed (70\%), the graphic display of the fitted hazard for gender clearly illustrates an observable difference. 


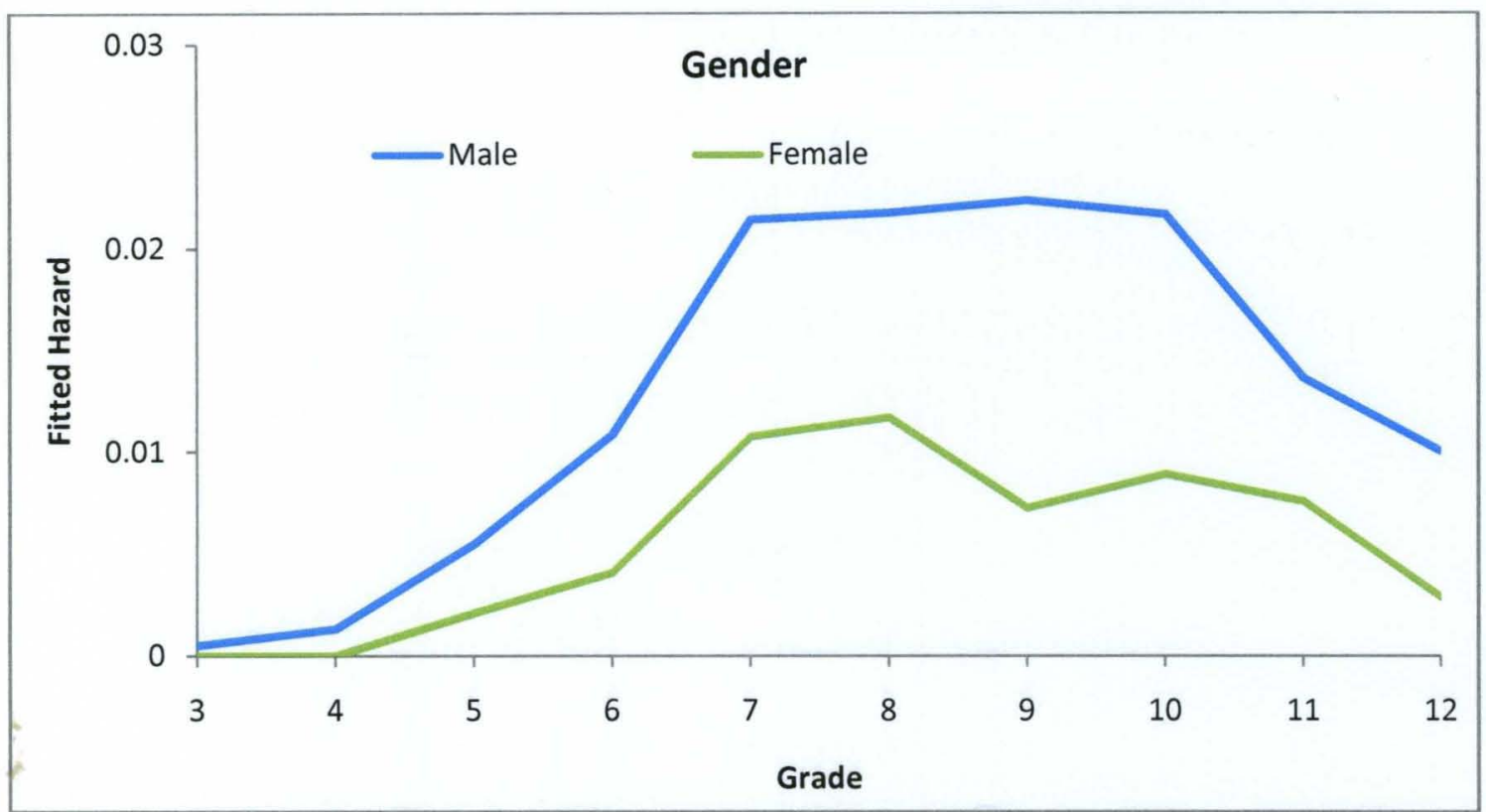

Figure 8. Illustration of fitted hazard function for the grade of placement from with main effects of Time and Gender

\section{Fitted Hazard Function for Lunch Status}

As shown in Figure 9, there is a definitive difference in hazard based on lunch status. Students receiving free/reduced price lunch at every grade are at higher risk of placement into a disciplinary alternative school. Similar to race, the difference in risk is evident throughout, but is most apparent between grades 7-10. The illustration in Figure 9 corresponds with both the descriptive statistics showing disproportionality based on lunch status at every level and in the fit statistics and odds ratio shown in Model D in Table 13. The graphic display demonstrates that the effect of socioeconomic status on the hazard of placement increases over time, peaking in $8^{\text {th }}$ grade. While the impact shifts very slightly throughout the years, the impact of receiving free/reduced lunch maintains a strong effect on placement over time. 


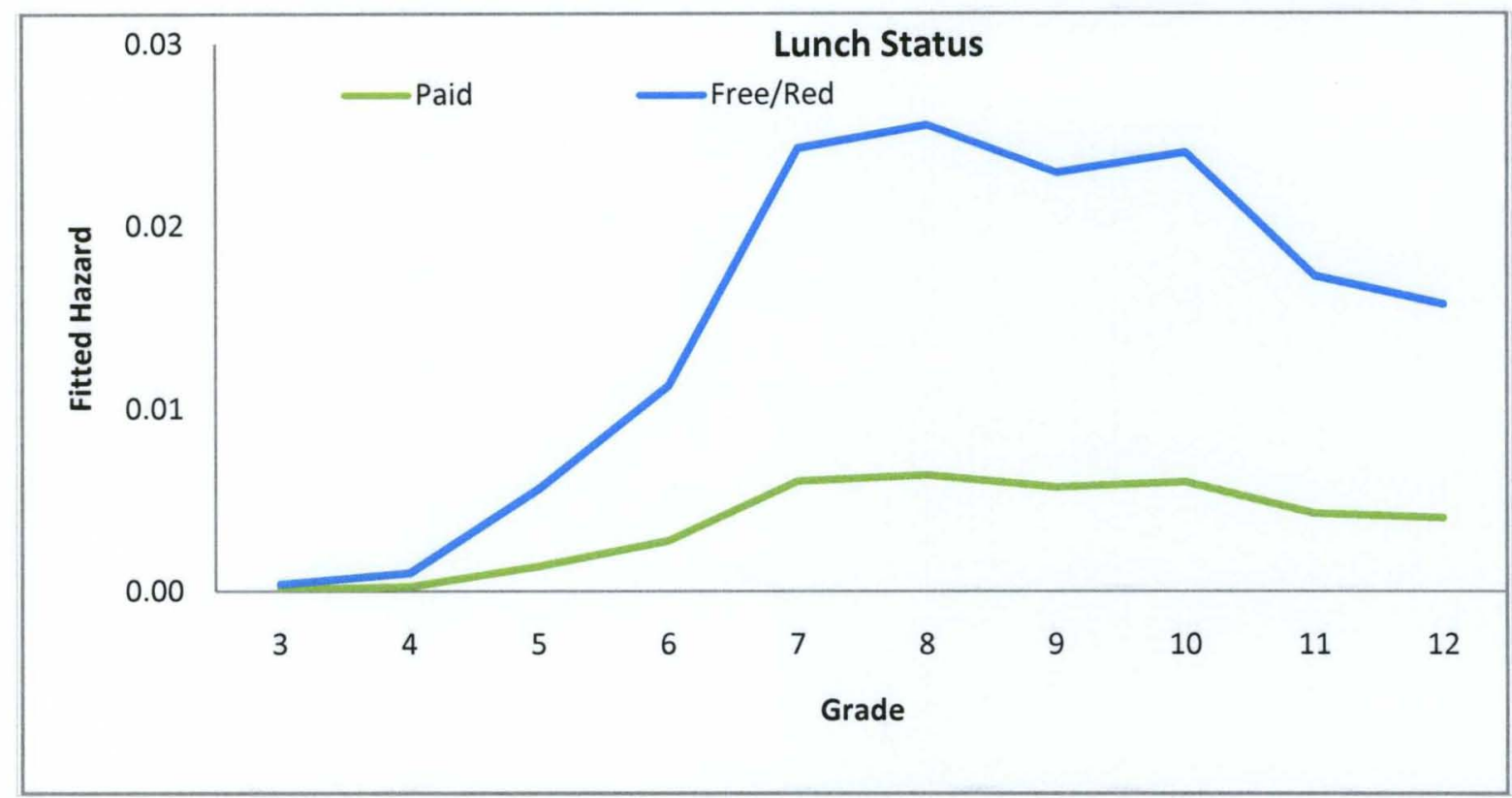

Figure 9. Illustration of fitted hazard function for the grade of placement from with main effects of time and lunch status

\section{Discrete-Time Hazard Models: Effects of Suspension and EBD status on Risk of Placement}

The next discrete-time hazard models include the non-academic characteristics related to behavior and discipline. These models are designed to assess the effects of out of school suspension and identification as having an Emotional-Behavioral disorder (EBD) on placement in a disciplinary alternative school. The previous models included only dichotomous predictor variables. In this section, a continuous variable, out of school suspension is explored. Just as with dichotomous predictors, antilogging estimates from continuous predictors still yields a estimated odds-ratio that can be used as a metric of effect size, associated with a 1-unit difference in the predictor (Singer \& Willett, 2003).

\section{Effect of Emotional Behavioral Disorder (EBD) status on Risk of Placement}

As shown on Table 14, the addition of the dichotomous variable Emotional Behavioral Disorder (EBD) identification status to the initial model is presented in Model 
F. By including EBD as a predictor, the goodness of fit statistics showed improvement from the initial model as demonstrated by the increase of the model log-likelihood statistic $(L L)$ from -2952.89 to -2866.89 indicating that the addition of EBD has significantly improved the overall fit of the hazard model. The decreased deviance statistic (5733.78) and decreased AIC value (5755.78) lends to the conclusion that the addition of the predictor variable EBD has a significant effect on risk of placement.

The estimated coefficient for EBD is $2.135(\mathrm{p}=.000)$. The positive sign indicates that from $3^{\text {rd }}-12^{\text {th }}$, EBD students are at greater risk of placement in a disciplinary alternative school. When antilogging this parameter estimate, it yields an odds ratio $(\exp \beta)$ of 8.46 . The odds ratio reveals that in the estimated odds of placement are over 8 times higher for EBD students then non-EBD students. As shown in the combined model, Model $\mathrm{H}$, when controlling for suspension, the estimated coefficient for EBD is .977 $(\mathrm{p}=.000)$. When antilogging this parameter estimate, it yields an odds ratio $(\exp \beta)$ of 2.65. This indicates that when controlling the effects of gender and lunch status, the estimated odds of placement are 2.6 times higher for EBD students then non EBD students.

\section{Effect of Out of School Suspension on Risk of Placement}

The effect of the continuous variable suspension is shown on Model $\mathrm{G}$ in Table 14. By including the predictor suspension, the model fit showed improvement from the previous model $\mathrm{F}$ as demonstrated by the increase of the model log-likelihood statistic $(L L)$ to -2280.44 , the highest of all the models, and the smallest AIC value yet (4582.88). The decreased deviance statistic (4560.88) also lends to the conclusion that the addition of the predictor variable suspension has a large, significant effect on risk of placement. 
The estimated coefficient for Suspension is $2.176(p=.000)$. The positive sign indicates that from $3^{\text {rd }}-12^{\text {th }}$, out of school suspension is a strong predictor of risk of placement. That is, students who are suspended are more likely to be placed in a disciplinary alternative school. Antilogging the parameter estimate (2.176) yields an odds ratio $(\exp \beta)$ of 8.81 . This indicates that in the estimated odds of placement are almost 9 times for greater for students that are have a one unit higher in suspension.

Because the interpretation of odds ratios with continuous variables can be less intuitive than with dichotomous, transforming them into relative risk ratios make them more understandable (Bollmer, $\mathrm{J}$ et al, 2007; Osborn, 2006). The risk ratios are used with collapsed categories graphically displayed in Figure 11 where suspension is categorized into 0 suspensions, 1-2 suspensions, and 3 or more suspensions. By dividing the probability for students in alternative schools compared with the cohort in the category 12 suspensions (.438 and .077 respectively) and $3+$ suspensions (.349 and .014 respectively) the results show that students who are suspended 1-2 times are 5.7 times more likely to be placed in alternative schools, and students that are suspended 3 or more times are 25.6 times more likely to be placed in a disciplinary alternative school.

\section{Full Model of EBD and suspension on Risk of Placement}

As shown in the combined model, Model $\mathrm{H}$, when controlling for EBD status, the estimated coefficient for Suspension is $.2 .114(\mathrm{p}=000)$. When antilogging this parameter estimate, it yields an odds ratio $(\exp \beta)$ of 8.28. This indicates that when controlling the effects EBD, the estimated odds of placement in a disciplinary alternative school are still over 8 times higher for students that have a one unit higher in suspension. The risk ratio and strength of the effect size for suspension indicate it is the most powerful predictor of 
placement in any of the behavior and demographic models. Additionally, the size of the Wald chi-square statistic for suspension of $1300.20(p=.000)$ in comparison to the Wald statistic for EBD $43.87(\mathrm{p}=.000)$ also lends to the conclusion that suspension is the strongest behavior related non-academic predictor of placement in a disciplinary alternative school. 
Table 14

Results of fitting Discrete-Time Hazard models for Predictor Variables EBD and Suspension to the Grade of First Placement in Disciplinary Alternative School

\begin{tabular}{|c|c|c|c|c|}
\hline & Model A & Model F & Model G & Model H \\
\hline \multicolumn{5}{|c|}{ Parameter Estimates and Asymptotic Standard Errors } \\
\hline \multirow[t]{2}{*}{$\mathrm{D}_{3}$} & $-8.251 * *$ & $-8.347 * *$ & $-8.428 * *$ & $-8.484 * *$ \\
\hline & $(.707)$ & $(.707)$ & $(.708)$ & $(.708)$ \\
\hline \multirow[t]{2}{*}{$\mathrm{D}_{4}$} & $-7.288^{* *}$ & $-7.413 * *$ & $-7.468 * *$ & $-7.548 * *$ \\
\hline & $(.447)$ & $(.448)$ & $(.448)$ & $(.449)$ \\
\hline \multirow[t]{2}{*}{$\mathrm{D}_{5}$} & $-5.559 * *$ & $-5.698 * *$ & $-5.845^{* *}$ & $-5.923 * *$ \\
\hline & $(.193)$ & $(.194)$ & $(.196)$ & $(.199)$ \\
\hline \multirow[t]{2}{*}{$\mathrm{D}_{6}$} & $-4.884 * *$ & $-5.034 * *$ & $-6.121 * *$ & $-6.152 * *$ \\
\hline & $(.142)$ & $(.144)$ & $(.162)$ & $(163)$ \\
\hline \multirow[t]{2}{*}{$\mathrm{D}_{7}$} & $-4.120 * *$ & $-4.272 * *$ & $5.508 * *$ & $-5.541 * *$ \\
\hline & $(.100)$ & $(.102)$ & $(.127)$ & $(.127)$ \\
\hline \multirow[t]{2}{*}{$\mathrm{D}_{8}$} & $-4.086^{* *}$ & $-4.228 * *$ & $-5.590^{* * *}$ & $-5.599 * *$ \\
\hline & $(.100)$ & $(.110)$ & $(.129)$ & $(.129)$ \\
\hline \multirow[t]{2}{*}{$\mathrm{D}_{9}$} & $-4.212^{* *}$ & $-4.341 * *$ & $-5.508 * *$ & $-5.519 * *$ \\
\hline & $(.109)$ & $(.110)$ & $(.133)$ & $(.133)$ \\
\hline \multirow[t]{2}{*}{$\mathrm{D}_{10}$} & $-4.184 * *$ & $-4.295 * *$ & $-5.252 * *$ & $5.260^{* *}$ \\
\hline & $(.109)$ & $(.111)$ & $(.127)$ & $(.127)$ \\
\hline \multirow{2}{*}{$D_{11}$} & $-4.551 * *$ & $-4.642 * *$ & $-5.517 * *$ & $-5.534 * *$ \\
\hline & $(.136)$ & $(.136)$ & $(.151)$ & $(.151)$ \\
\hline \multirow[t]{2}{*}{$\mathrm{D}_{12}$} & $-5.060 * *$ & $-5.131 * *$ & $-5.739 * *$ & $-5.745^{* *}$ \\
\hline & $(.183)$ & $(.184)$ & $(.192)$ & $(.192)$ \\
\hline \multirow[t]{3}{*}{ EBD } & & $2.135 * *$ & & $.977 * *$ \\
\hline & & $(.131)$ & & $(.148)$ \\
\hline & & $\exp \beta 8.46$ & & $\exp \beta 2.65$ \\
\hline \multirow[t]{3}{*}{ Suspension } & & & $2.176^{* *}$ & $2.114 * *$ \\
\hline & & & $(.058)$ & $(.059)$ \\
\hline & & & $\exp \beta 8.81$ & $\exp \beta 8.28$ \\
\hline \multicolumn{5}{|c|}{ Goodness-of-Fit } \\
\hline LL & -2952.89 & -2866.89 & -2280.44 & -2261.37 \\
\hline Deviance & 5905.77 & 5733.78 & 4560.88 & 4522.75 \\
\hline $\mathrm{n}$ parameters & 10 & 11 & 11 & 12 \\
\hline $\mathrm{AIC}$ & 5925.77 & 5755.78 & 4582.88 & 4546.75 \\
\hline \multicolumn{5}{|c|}{ Deviance-based Hypothesis Tests } \\
\hline $\mathrm{H}_{0}: \mathrm{B}_{E B D}=0$ & & $171.99 * *$ & & $38.13 * *$ \\
\hline $\mathrm{H}_{0}: \mathrm{B}_{\text {SUSP }}=0$ & & & $1344.89 * *$ & $1211.03 * *$ \\
\hline \multicolumn{5}{|c|}{ Wald Hypothesis Tests } \\
\hline $\mathrm{H}_{0}: \mathrm{B}_{E B D}=0$ & & $266.94 * *$ & & $43.87 * *$ \\
\hline $\mathrm{H}_{0}: \mathrm{B}_{S U S P}=0$ & & & $1431.28 * *$ & $1300.20 * *$ \\
\hline
\end{tabular}




\section{Fitted Hazard Function for Emotional-Behavioral Disorder (EBD)}

As shown in Figure 10, there is a marked difference in hazard based on EBD status. Students who are identified as EBD in grades 5-12 are at higher risk of placement into a disciplinary alternative school. The difference in risk is most apparent between grades 7-10. The illustration in Figure 10 corresponds with both the descriptive statistics showing disproportionality based on EBD status at every level and in the fit statistics and odds ratio shown in Model $\mathrm{F}$ in Table 14. The graphic display demonstrates that the effect of EBD status on the hazard of placement increases over time, peaking in $7^{\text {th }}$ grade. While the impact shifts very slightly during the middle and high school years, the impact of EBD status maintains a strong effect on placement over time.

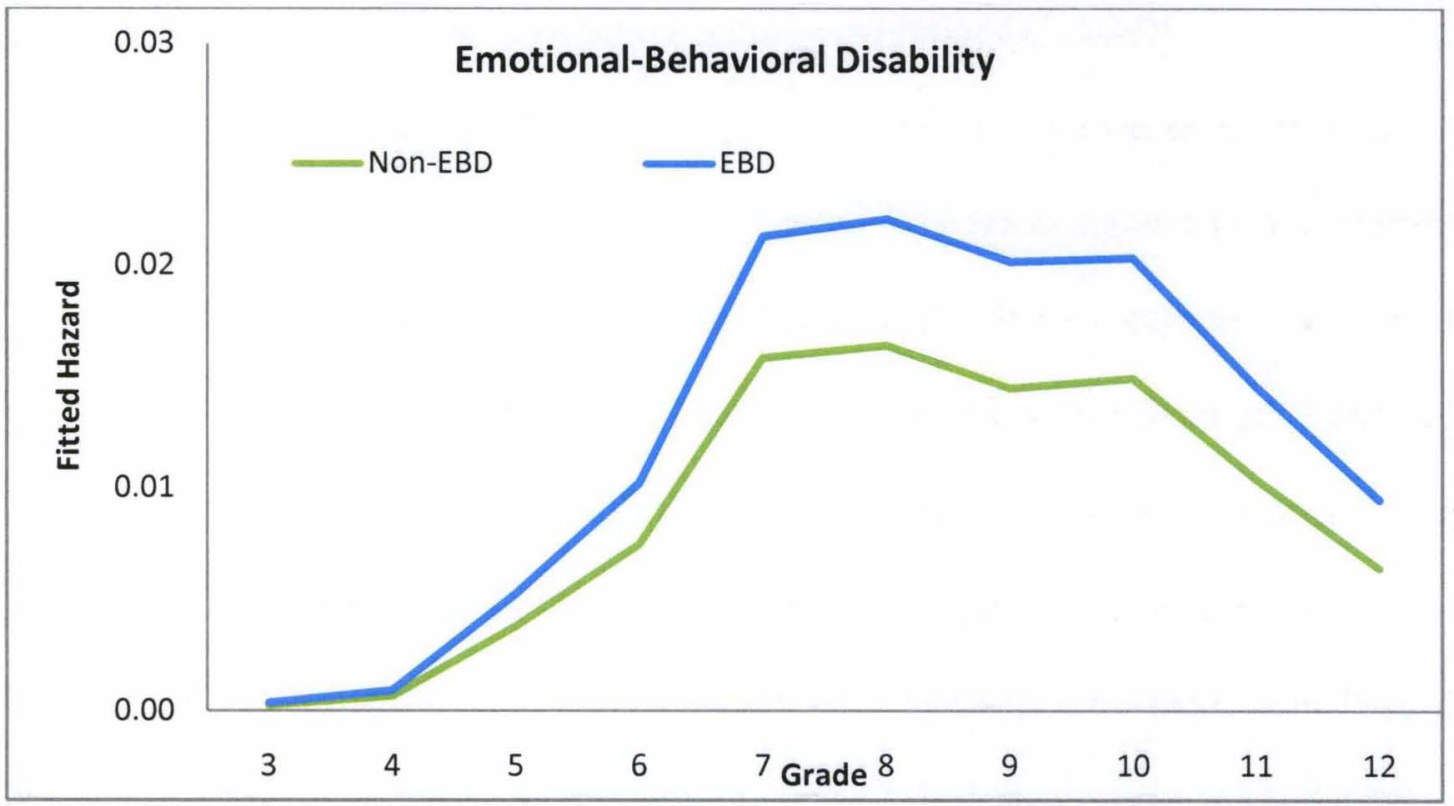

Figure 10. Illustration of fitted hazard function for the grade of placement from with main effects of time and Emotional-Behavioral Disorder 


\section{Fitted Hazard Function for Out of School Suspension}

As illustrated in Figure 11, there is a clear difference in hazard based on suspension. Students who are suspended, particularly within grades 5-12 are at higher risk of placement into a disciplinary alternative school. The illustration in Figure 11 corresponds with both the descriptive statistics showing disproportionality based on suspensions at every level and in the fit statistics and odds ratio shown in Model G in Table 14. The graphic display demonstrates that the effect of suspension on the hazard of placement increases over time, peaking in $8^{\text {th }}$ grade. As can be seen, the graph demonstrates no distinction between students suspended 1-2 times and 3 or more times in elementary. However, beginning in $7^{\text {th }}$ grade the pattern indicates that the higher the number of suspensions the greater the risk. This pattern remains through high school but the degree of separation between students with 1-2 and 3+ is not as large as it is in middle school.

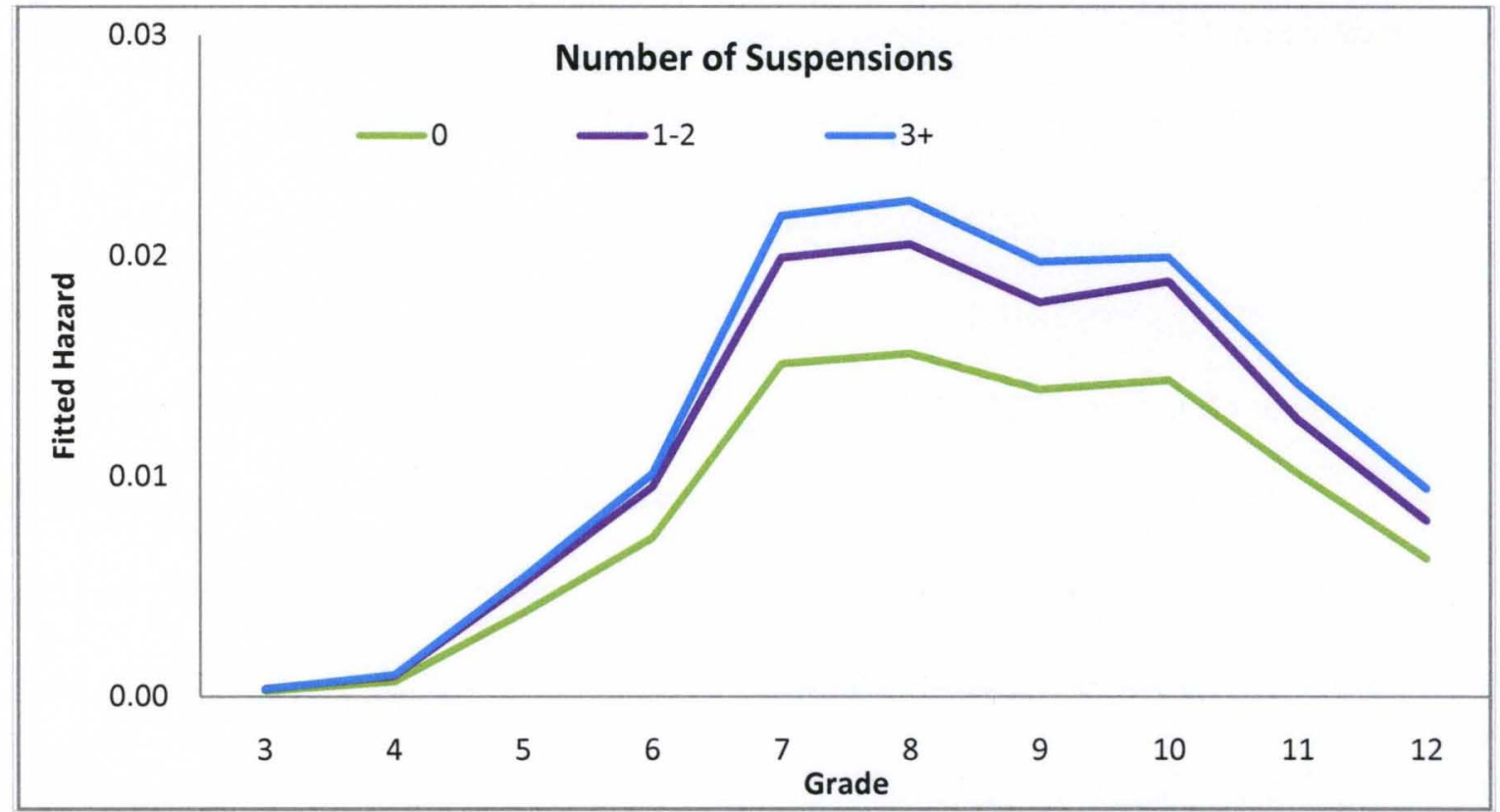

Figure 11. Illustration of fitted hazard function for the grade of placement from with main effects of time and suspension 
Discrete-Time Hazard Models: Effects of Mobility and Attendance on Risk of
Placement

The next discrete-time hazard models include the non-academic characteristics related to school mobility and attendance, two factors that students have little control over particularly in elementary and middle school. Both mobility and attendance are continuous variables in the model, whose estimated odds-ratio is still associated with a 1unit difference in the predictor as in the case of dichotomous variables (Singer \& Willett, 2003).

\section{Effect of School Mobility on Risk of Placement}

As shown in Model I on Table 15, the addition of the school mobility to the initial model greatly improved the goodness of fit statistics as demonstrated by the increase of the model log-likelihood statistic $(L L)$ from -2952.89 to -2724.74 indicating that the addition of mobility has significantly improved the overall fit of the hazard model. The decreased deviance statistic (5449.48) and decreased AIC value (5471.48) when compared to the initial model (Model A) also indicates that including mobility as a predictor significantly improved the model fit.

The estimated coefficient for mobility is $2.081(\mathrm{p}=.000)$. The positive sign indicates that from $3^{\text {rd }}-12^{\text {th }}$, students that experience school mobility within a school year are at greater risk of placement in a disciplinary alternative school. The antilog of this parameter estimate yields an odds ratio $(\exp \beta)$ of 7.52

This indicates that in the estimated odds of placement are almost 7.5 times greater for students that have a one unit higher in mobility. Just as with the continuous variable suspension, the interpretation of odds ratios is transformed into relative risk 
ratios to make them more intuitive. The risk ratios are used with collapsed categories graphically displayed in Figure 12 where mobility is categorized into 0 moves, 1 move, and 2 or more school moves within the school year. By dividing the probability for students in alternative schools compared with the cohort for 1 move (.195 and .030 respectively) and $2+$ moves $(.077$ and .004$)$ respectively) the results show that students who move schools 1 time within the school year are 6.5 times more likely to be placed in alternative schools than students that do not move, and students that move more than once are 19.3 times more likely to be placed in a disciplinary alternative school than students that don't move. As shown in the combined model, Model H, when controlling for absenteeism, the estimated coefficient for moblity is.2010 $(\mathrm{p}=000)$. When antilogging this parameter estimate, it yields an odds ratio $(\exp \beta)$ of 7.46 . This indicates that when controlling the effects absenteeism, the estimated odds of placement in a disciplinary alternative school are still over 7 times higher for students that have a one unit higher in mobility.

\section{Effect of School Absenteeism on Risk of Placement}

As shown in Model $\mathrm{J}$ on Table 15, the addition of the school absenteeism to the initial model improved the goodness of fit statistics as demonstrated by the increase of the model log-likelihood statistic $(L L)$ from -2952.89 to -2796.72 indicating that the addition of attendance has improved the overall fit of the hazard model. The decrease in the deviance statistic (5593.44) and AIC (5615.44) from the initial model also indicates that including absenteeism as a predictor improved the model fit. However, these fit statistics when compared to those from Model I reveal that absenteeism is not as strong of a predictor of placement as mobility. 
The estimated coefficient for absenteeism is $.278(\mathrm{p}=.000)$. While much smaller than the coefficient for mobility, the positive sign indicates that from $3^{\text {rd }}-12^{\text {th }}$, students that experience higher absenteeism within a school year are at greater risk of placement in a disciplinary alternative school. The antilog of this parameter estimate yields an odds ratio $(\exp \beta)$ of 1.32 , indicating that in the estimated odds of placement are almost 1.3 times greater for students that have a one unit higher in absenteeism.

Just as with the continuous variables suspension and mobility, the interpretation of odds ratios is transformed into relative risk ratios to make them more intuitive. The risk ratios are used with collapsed categories graphically displayed in Figure 13 where absenteeism is categorized into 0-5 days absent, 6-11 days, and 21 or more days absent within the school year. By dividing the probability for students in alternative schools compared with the cohort for 6-11 days absent (.256 and .242 respectively) and $12+$ days absent (.441 and .287) respectively) the results show that students who are absent between 6-11 days within the school year are 1.1 times more likely to be placed in alternative schools than students who are absent between 0-5 days. Students that are absent more than 12 days are 1.4 times more likely to be placed in a disciplinary alternative school than students who are absent less than 12 days.

\section{Full Model of Mobility and Absenteeism on Risk of Placement}

As shown in the combined model, Model $\mathrm{H}$, when controlling for mobility, the estimated coefficient for absenteeism $.284(p=000)$. As such, the odds ratio does not change as it remains $(\exp \beta)$ of 1.32 . This indicates that when controlling the effects mobility, absenteeism is still not a significant predictor of placement, particularly in comparison to race, lunch status, EBD, suspension and mobility. Conversely, the risk 
ratio and strength of the effect size for mobility indicate it is a powerful predictor of placement. Additionally, the size of the Wald chi-square statistic for mobility of 661.85 $(\mathrm{p}=.000)$ in comparison to the Wald statistic for absenteeism $51.27(\mathrm{p}=.000)$ also lends to the conclusion that mobility is a much stronger predictor of placement in a disciplinary alternative school than absenteeism. 
Table 15

Results of fitting Discrete-Time Hazard models for Predictor Variables Mobility and Absenteeism to the Grade of First Placement in Disciplinary Alternative School

\begin{tabular}{|c|c|c|c|c|}
\hline & Model A & Model I & Model J & Model K \\
\hline \multicolumn{5}{|c|}{ Parameter Estimates and Asymptotic Standard Errors } \\
\hline $\mathrm{D}_{3}$ & $\begin{array}{c}-8.251 * * \\
(.707)\end{array}$ & $\begin{array}{c}-8.944^{* *} \\
(.711)\end{array}$ & $\begin{array}{c}-8.569^{* *} \\
(.710)\end{array}$ & $\begin{array}{c}-9.264^{* *} \\
(.714)\end{array}$ \\
\hline $\mathrm{D}_{4}$ & $\begin{array}{c}-7.288^{* *} \\
(.447)\end{array}$ & $\begin{array}{c}-7.652^{* *} \\
(.450)\end{array}$ & $\begin{array}{c}-7.620^{* *} \\
(.451)\end{array}$ & $\begin{array}{c}-7.969^{* *} \\
(.454)\end{array}$ \\
\hline $\mathrm{D}_{5}$ & $\begin{array}{c}-5.559^{* *} \\
(.193)\end{array}$ & $\begin{array}{c}-5.843^{* *} \\
(.197)\end{array}$ & $\begin{array}{c}-5915^{* * *} \\
(.205)\end{array}$ & $\begin{array}{c}-6.214^{* *} \\
(.210)\end{array}$ \\
\hline$D_{6}$ & $\begin{array}{c}-4.884^{* *} \\
(.142)\end{array}$ & $\begin{array}{c}-5.220^{* *} \\
(.148)\end{array}$ & $\begin{array}{c}-5.342^{* *} \\
(.162)\end{array}$ & $\begin{array}{c}-5.668^{* *} \\
(.168)\end{array}$ \\
\hline $\mathrm{D}_{7}$ & $\begin{array}{c}-4.120^{* *} \\
(.100)\end{array}$ & $\begin{array}{c}-4.423^{* *} \\
(.105)\end{array}$ & $\begin{array}{c}-4.533^{* *} \\
(.122)\end{array}$ & $\begin{array}{c}-4.841^{* *} \\
(.127)\end{array}$ \\
\hline$D_{8}$ & $\begin{array}{c}-4.086^{* *} \\
(.100)\end{array}$ & $\begin{array}{c}-4.359^{* *} \\
(.104)\end{array}$ & $\begin{array}{c}-4.533^{* *} \\
(.124)\end{array}$ & $\begin{array}{c}-4.820^{* *} \\
(.129)\end{array}$ \\
\hline $\mathrm{D}_{9}$ & $\begin{array}{c}-4.212 * * \\
(.109)\end{array}$ & $\begin{array}{c}-4.428^{* *} \\
(.112)\end{array}$ & $\begin{array}{c}-4.635^{* *} \\
(.131)\end{array}$ & $\begin{array}{c}-4.871^{* *} \\
(.136)\end{array}$ \\
\hline$D_{10}$ & $\begin{array}{c}-4.184^{* *} \\
(.109)\end{array}$ & $\begin{array}{c}-4.428^{* *} \\
(.114)\end{array}$ & $\begin{array}{c}-4.651^{* *} \\
(.134)\end{array}$ & $\begin{array}{c}-4.906^{* *} \\
(.139)\end{array}$ \\
\hline$D_{11}$ & $\begin{array}{c}-4.551^{* *} \\
(.136)\end{array}$ & $\begin{array}{c}-4.773^{* *} \\
(.139)\end{array}$ & $\begin{array}{c}-4.990^{* *} \\
(.155)\end{array}$ & $\begin{array}{c}-5.229^{* *} \\
(.161)\end{array}$ \\
\hline$D_{12}$ & $\begin{array}{c}-5.060^{* *} \\
(.183)\end{array}$ & $\begin{array}{c}-5.166^{* *} \\
(.184)\end{array}$ & $\begin{array}{c}-5.631^{* *} \\
(.211)\end{array}$ & $\begin{array}{c}-5.754^{* *} \\
(.213)\end{array}$ \\
\hline Mobility & & $\begin{array}{c}2.018^{* *} \\
(.076) \\
\exp \beta 7.52\end{array}$ & & $\begin{array}{c}2.010^{* *} \\
(0.78) \\
\exp \beta 7.46\end{array}$ \\
\hline Absenteeism & & & $\begin{array}{r}.278^{* *} \\
(.039) \\
\exp \beta 1.32\end{array}$ & $\begin{array}{c}.284^{* *} \\
(.040) \\
\exp \beta 1.32\end{array}$ \\
\hline \multicolumn{5}{|c|}{ Goodness-of-Fit } \\
\hline LL & -2952.89 & -2724.74 & -2796.72 & -2581.21 \\
\hline Deviance & 5905.77 & 5449.48 & 5593.44 & 5162.42 \\
\hline n parameters & 10 & 11 & 11 & 12 \\
\hline AIC & 5925.77 & 5471.48 & 5615.44 & 5186.42 \\
\hline \multicolumn{5}{|c|}{ Deviance-based Hypothesis Tests } \\
\hline $\mathrm{H}_{0}: \mathrm{B}_{M O B}=0$ & & $456.29 * *$ & & $431.02 * *$ \\
\hline \multicolumn{4}{|c|}{$\begin{array}{l}\text { Ho. }{ }_{A B S}-0 \\
\text { Wald Hypothesis Tests }\end{array}$} & $287.06^{* *}$ \\
\hline $\mathrm{H}_{0}: \mathrm{B}_{M O B}=0$ & & $788.19 * *$ & & $661.85 * *$ \\
\hline $\mathrm{H}_{0}: \mathrm{B}_{A B S}=0$ & & & $52.07 * *$ & $51.27 * *$ \\
\hline
\end{tabular}




\section{Fitted Hazard Function for Mobility}

As illustrated in Figure 12, there is a clear difference in hazard based on mobility. Students who move between schools within a school year, particularly in middle school are at higher risk of placement into a disciplinary alternative school than students that do not experience mobility. The illustration in Figure 12 corresponds with both the descriptive statistics showing disproportionality based on mobility at every level and in the fit statistics and odds ratio shown in Model I in Table 15. The graphic display demonstrates that the effect of mobility on the hazard of placement increases over time through middle school and then decreases slightly in high school. As can be seen, the graph demonstrates a clear distinction between students who move 1 time and students that move 2 or more times in $8^{\text {th }}$ and $12^{\text {th }}$ grade. Otherwise the pattern of risk looks similar regardless of the number of moves within the school year. 


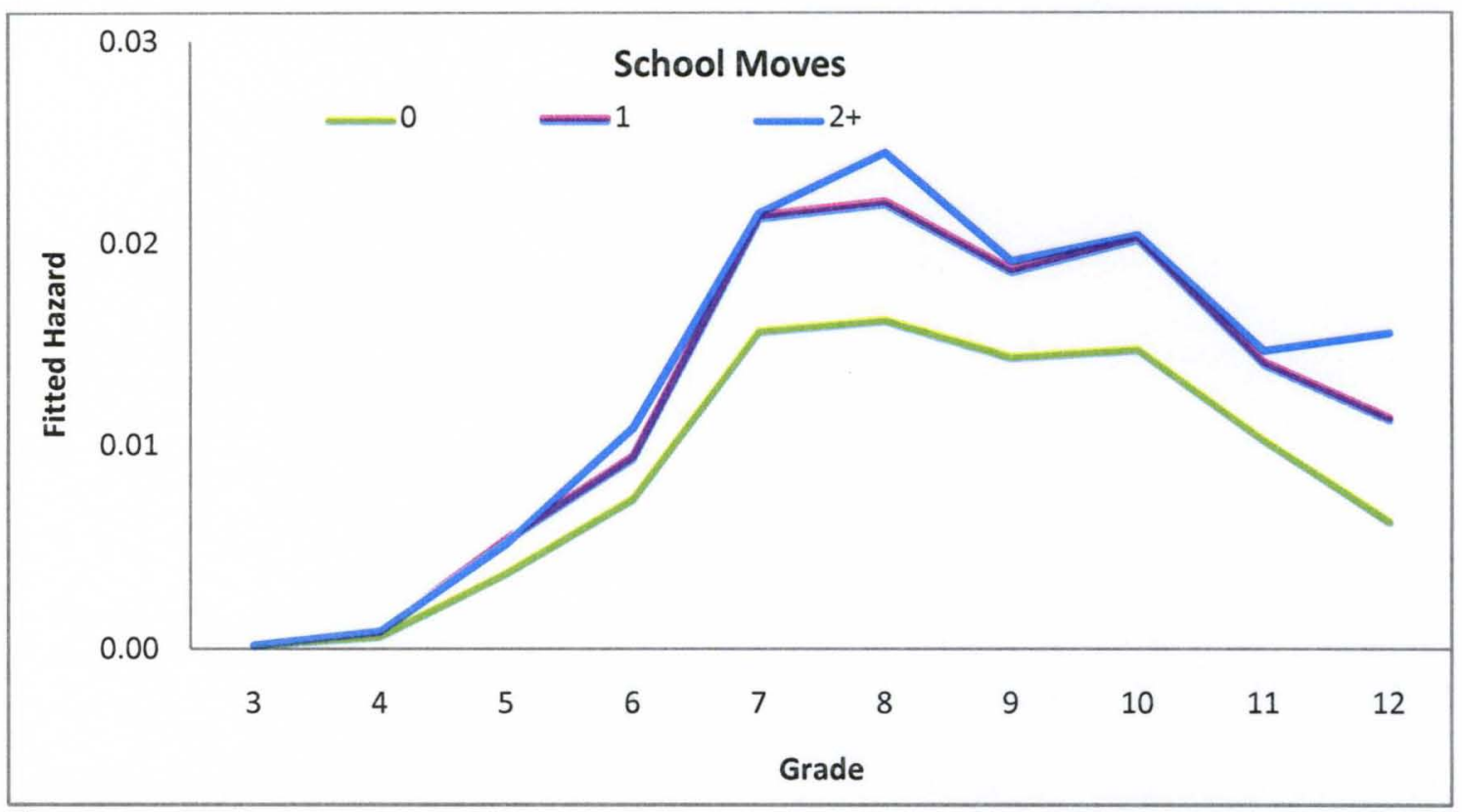

Figure 12 . Illustration of fitted hazard function for the grade of placement from with main effects of time and mobility

\section{Fitted Hazard Function for absenteeism}

As illustrated in Figure 13, there is a difference in hazard based on absenteeism; however the difference is slight for students who are absent between 0-5 times and between 6-11 times. Students who are absent more than 12 times within a school year between grades 7-10 are at higher risk of placement into a disciplinary alternative school. The illustration in Figure 13 corresponds with both the descriptive statistics for absenteeism and in the fit statistics and odds ratio shown in Model $\mathrm{J}$ in Table 15. The graphic display demonstrates that the effect of absenteeism on the hazard of placement increases between $6^{\text {th }}$ and $7^{\text {th }}$ grade, but that overall, the hazard of placement is more pronounced for students with 12 or more absences within a school year. 


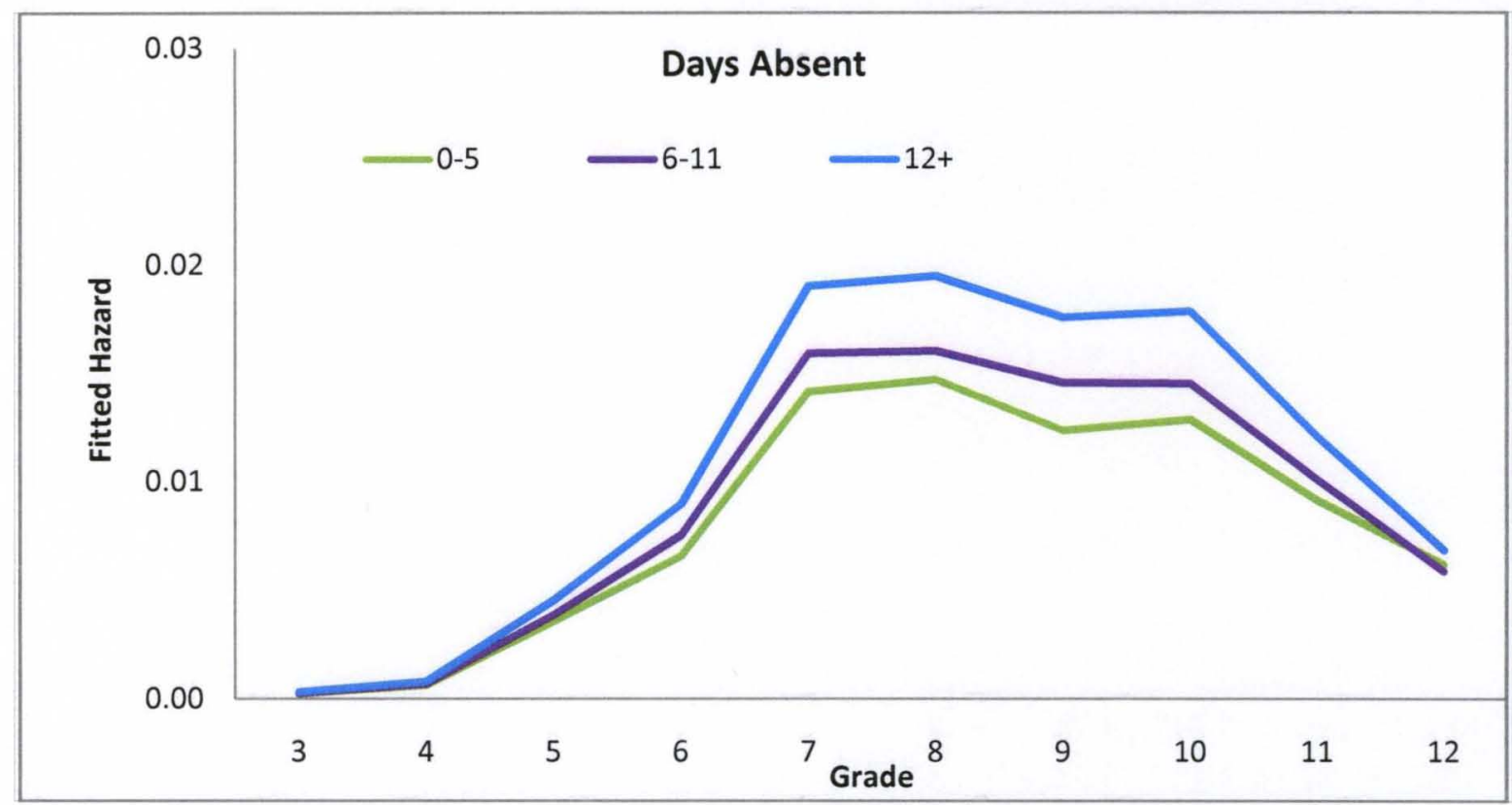

Figure 13. Illustration of fitted hazard function for the grade of placement from with main effects of time and absenteeism

\section{Discrete-Time Hazard Models: Effects of Retention and Learning Disability status on Risk of Placement}

The next discrete-time hazard models include the academic characteristics to assess the effects of grade retention and identification as having a learning disability (LD) on placement in a disciplinary alternative school.

\section{Effect of Retention on Risk of Placement}

As shown on Table 16, the addition of the dichotomous variable retention to the initial model is presented in Model L. By including retention as a predictor, the goodness of fit statistics showed improvement from the initial model as demonstrated by the increase of the model log-likelihood statistic $(L L)$ from -2952.89 to -2905.59 . The decreased value of the Deviance statistic (5904.64) and AIC value (5833.18) also signifies that the addition of retention has improved the overall fit of the hazard model. 
The estimated coefficient for retention is $1.511(\mathrm{p}=.000)$. The positive sign indicates that from $3^{\text {rd }}-12^{\text {th }}$, retained students are at greater risk of placement in a disciplinary alternative school. When antilogging this parameter estimate, it yields an odds ratio $(\exp \beta)$ of 4.53 . The odds ratio reveals that in the estimated odds of placement are over 4.5 times higher for retained students then promoted students. As shown in the combined model, Model N, when controlling for suspension, the estimated coefficient for retention is $.1 .510(\mathrm{p}=.000)$ and $\exp \beta=4.53$, which indicates that the addition of Learning Disability status did not change the effect size of retention on placement.

\section{Effect of Learning Disability status on Risk of Placement}

As shown on Table 16, the addition of the dichotomous variable LD to the initial model is presented in Model M. By including LD as a predictor, the goodness of fit statistics showed no improvement from the initial model as demonstrated by the stable log-likelihood statistic ( $L L)$ ( -2952.32), and increased AIC value (5926.64). The estimated coefficient for LD is .116. Though there is a positive coefficient, the lack of statistical significant, especially with such a large sample size, reveals no need for interpretation of the impact of LD on placement in disciplinary alternative school. Finally, the insignificant Wald chi-square statistic $.447(\mathrm{p}=.504)$ demonstrates no relationship between the risk of placement and LD in this study. 
Table 16

Results of fitting Discrete-Time Hazard models for Predictor Variables Retention and LD to the Grade of First Placement in Disciplinary Alternative School

\begin{tabular}{|c|c|c|c|c|}
\hline & Model A & Model L & Model M & Model N \\
\hline \multicolumn{5}{|c|}{ Parameter Estimates and Asymptotic Standard Errors } \\
\hline$D_{3}$ & $\begin{array}{c}-8.251^{* *} \\
(.707)\end{array}$ & $\begin{array}{c}-8.251^{* *} \\
(.707)\end{array}$ & $\begin{array}{c}-8.257 * * \\
(.707)\end{array}$ & $\begin{array}{c}-8.255^{* *} \\
(.707)\end{array}$ \\
\hline $\mathrm{D}_{4}$ & $\begin{array}{c}-7.288^{* *} \\
(.447)\end{array}$ & $\begin{array}{c}-7.590^{* *} \\
(.450)\end{array}$ & $\begin{array}{c}-7.296^{* *} \\
(.448)\end{array}$ & $\begin{array}{c}-7.595^{* *} \\
(.450)\end{array}$ \\
\hline$D_{5}$ & $\begin{array}{c}-5.559^{* *} \\
(.193)\end{array}$ & $\begin{array}{c}-5.650^{* *} \\
(.193)\end{array}$ & $\begin{array}{c}-5.567 * * \\
(.193)\end{array}$ & $\begin{array}{c}-5.654^{* *} \\
(.194)\end{array}$ \\
\hline $\mathrm{D}_{6}$ & $\begin{array}{c}-4.884^{* *} \\
(.142)\end{array}$ & $\begin{array}{c}-4.902 * * \\
(.142)\end{array}$ & $\begin{array}{c}-4.892^{* *} \\
(.143)\end{array}$ & $\begin{array}{c}-4.097^{* *} \\
(.143)\end{array}$ \\
\hline $\mathrm{D}_{7}$ & $\begin{array}{c}-4.120^{* *} \\
(.100)\end{array}$ & $\begin{array}{c}-4.194^{* *} \\
(.101)\end{array}$ & $\begin{array}{c}-4.128^{* *} \\
(.101)\end{array}$ & $\begin{array}{c}-4.198^{* *} \\
(.101)\end{array}$ \\
\hline $\mathrm{D}_{8}$ & $\begin{array}{c}-4.086^{* *} \\
(.100)\end{array}$ & $\begin{array}{c}-4.178^{* *} \\
(.101)\end{array}$ & $\begin{array}{c}-4.094^{* *} \\
(.101)\end{array}$ & $\begin{array}{c}-4.182^{* *} \\
(.102)\end{array}$ \\
\hline $\mathrm{D}_{9}$ & $\begin{array}{c}-4.212^{* *} \\
(.109)\end{array}$ & $\begin{array}{c}-4.255^{* *} \\
(.109)\end{array}$ & $\begin{array}{c}-4.220^{* *} \\
(.109)\end{array}$ & $\begin{array}{c}-4.259^{* *} \\
(.110)\end{array}$ \\
\hline $\mathrm{D}_{10}$ & $\begin{array}{c}-4.184 * * \\
(.109)\end{array}$ & $\begin{array}{c}-4.426^{* *} \\
(.115)\end{array}$ & $\begin{array}{c}-4.190^{* *} \\
(.110)\end{array}$ & $\begin{array}{c}-4.430^{* *} \\
(.116)\end{array}$ \\
\hline$D_{11}$ & $\begin{array}{c}-4.551^{* *} \\
(.136)\end{array}$ & $\begin{array}{c}-4.765^{* *} \\
(.140)\end{array}$ & $\begin{array}{c}-4.557^{* *} \\
(.136)\end{array}$ & $\begin{array}{c}-4.768^{* *} \\
(.140)\end{array}$ \\
\hline$D_{12}$ & $\begin{array}{c}-5.060^{* *} \\
(.183)\end{array}$ & $\begin{array}{c}-5.164^{* *} \\
(.184)\end{array}$ & $\begin{array}{c}-5.065^{* *} \\
(.183)\end{array}$ & $\begin{array}{c}-5.168^{* *} \\
(.184)\end{array}$ \\
\hline Retention & & $\begin{array}{c}1.511 * * \\
(.134) \\
\exp { }^{4.53}\end{array}$ & & $\begin{array}{c}1.510^{* *} \\
(.134) \\
\exp \beta 4.53\end{array}$ \\
\hline LD & & & $\begin{array}{c}.116 \\
(.174) \\
\exp \beta 1.12\end{array}$ & $\begin{array}{c}0.70 \\
(.174) \\
\exp \beta 1.07\end{array}$ \\
\hline \multicolumn{5}{|c|}{ Goodness-of-Fit } \\
\hline $\mathrm{LL}$ & -2952.89 & -2905.59 & -2952.32 & -2905.15 \\
\hline Deviance & 5905.77 & 5811.18 & 5904.64 & 5811.03 \\
\hline $\mathrm{n}$ parameters & 10 & 11 & 11 & 12 \\
\hline AIC & 5925.77 & 5833.18 & 5926.64 & 5835.03 \\
\hline \multicolumn{5}{|c|}{ Deviance-based Hypothesis Tests } \\
\hline $\mathrm{H}_{0}: \mathrm{B}_{R E T}=0$ & & $94.59 * *$ & & $93.61^{* *}$ \\
\hline \multicolumn{5}{|c|}{ Wald Hypothesis Tests } \\
\hline $\mathrm{H}_{0}: \mathrm{B}_{L D}=0$ & & & .447 & .159 \\
\hline
\end{tabular}




\section{Illustration of fitted hazard function for the grade of placement from with main effects of time and retention}

As illustrated in Figure 14, there is a clear difference in hazard based on retention between $3^{\text {rd }}$ and $9^{\text {th }}$ grade. Students who are retained anytime between $3^{\text {rd }}$ and $9^{\text {th }}$ grade have a higher risk of placement into a disciplinary alternative school than students that are not retained. The illustration in Figure 14 corresponds with both the descriptive statistics showing disproportionality based on retention in middle and high school and in the fit statistics and odds ratio shown in Model L in Table 16. The graphic display demonstrates that the effect of retention on the hazard of placement increases greatly between $6^{\text {th }}$ and $7^{\text {th }}$ grade peaking at $8^{\text {th }}$ grade, and maintaining and impact through high school with a slight decrease in $11^{\text {th }}$ grade.

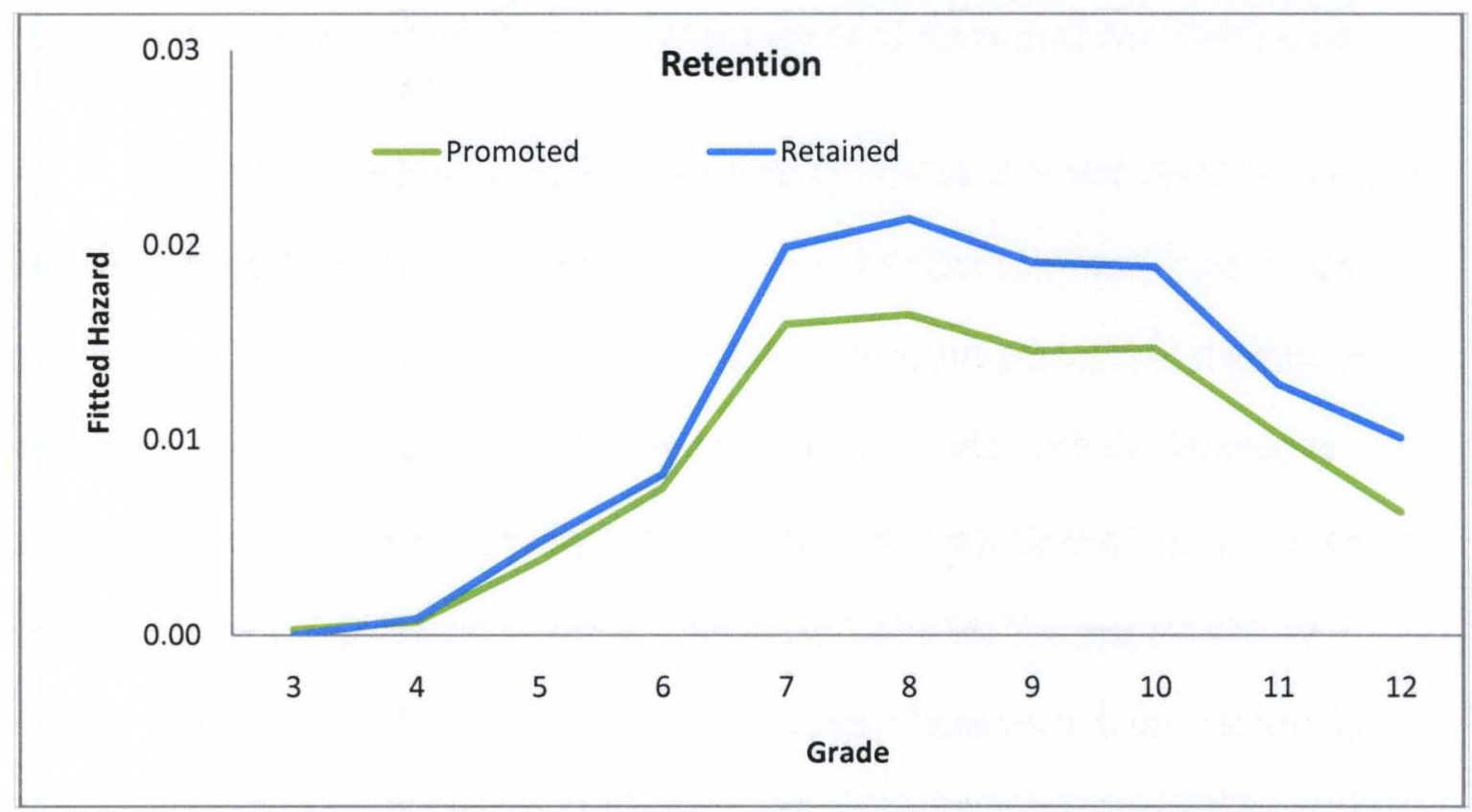

Figure 14. Illustration of fitted hazard function for the grade of placement from with main effects of time and retention 
Final Hazard Model with substantive significant predictors: lunch, suspension, mobility and retention to the grade of first placement in a disciplinary alternative school

In order to assess the impact of the most significant predictors of placement from the previous models within each category (i.e., demographic, non-academic and academic) a final model was constructed that includes lunch, suspension, mobility and retention. As shown in Table 17, the inclusion of these variables produced the best model fit of all previous models, with the largest $L L$ likelihood statistic (-2129.47) and smallest Deviance statistic (4258.94) and AIC value (4286.94). As shown in Model O, the impact of lunch status, when controlling for the effects of suspension, mobility and retention, while still statistically significant, is reduced as demonstrated by coefficient size (.585) and odds ratio of 1.79 . The Wald chi-square statistic is statistically significant 24.39 $(p=.000)$ signifying that lunch status is significantly associated with risk of placement in alternative schools. After controlling for many key non academic and academic factors, students receiving free/reduced lunch are still almost 1.8 times more likely to be placed in a disciplinary alternative school than students that can pay for lunch.

The predictor variable suspension among all others maintained its large effect size on the risk of placement. That is, when controlling for lunch, mobility and retention, the coefficient (1.996) and odds ratio for suspension $(\exp B 7.36)$ remained large in comparison to the other substantive predictors and has the greatest association with the hazard of placement as indicated by the Wald chi-square statistic $1024.38(\mathrm{p}=.000)$.

The effect of the predictor variable mobility, when controlling for the effects of lunch status, suspension and retention also remained strong as evidenced by the coefficient (1.577) and odds ratio (expB 4.84). While this effect size was reduced from 
the previous model from $\operatorname{expB} 7.46$, it still indicates that the higher the student mobility, the greater the risk of placement. In fact the Wald chi square statistic $302.91(p=.000)$ signifies that after suspension, mobility is the second strongest predictor associated with the hazard of placement in a disciplinary alternative school.

While still significant at the $\mathrm{p}<.01$ level, when controlling for the effects of lunch status, suspension and mobility, the effect of the predictor variable retention was reduced from an odds ratio of $\operatorname{expB} 4.53$ to $\operatorname{expB} 1.49$. Of all the substantive predictors in the model, retention had the smallest effect size and Wald chi square statistic $6.844(p=.000)$ yet it still indicates that there is a significant relationship between retention and placement. When controlling for lunch status, suspension and school mobility, students that are retained are one and a half times more likely to be placed in a disciplinary alternative school than students that are promoted. 
Table 17

Results of fitting Discrete-Time Hazard models for Predictor Variables Lunch, Suspension, Mobility and Retention to the Grade of First Placement in Disciplinary Alternative School

\begin{tabular}{|c|c|c|c|c|c|c|}
\hline & Model A & Model D & Model G & Model I & Model L & Model O \\
\hline \multicolumn{7}{|c|}{ Parameter Estimates and Asymptotic Standard Errors } \\
\hline \multirow[t]{2}{*}{$\mathrm{D}_{3}$} & $-8.251 * *$ & $-9.297 * *$ & $-8.428 * *$ & $-8.944 * *$ & $-8.251 * *$ & $-9.262 * *$ \\
\hline & $(.707)$ & $(.713)$ & $(.708)$ & $(.711)$ & $(.707)$ & $(.716)$ \\
\hline \multirow[t]{2}{*}{$\mathrm{D}_{4}$} & $-7.288 * *$ & $-8.333 * *$ & $-7.468 * *$ & $-7.652 * *$ & $-7.590 * *$ & $-8.203 * *$ \\
\hline & $(.447)$ & $(.457)$ & $(.448)$ & $(.450)$ & $(.450)$ & $(.460)$ \\
\hline \multirow[t]{2}{*}{$\mathrm{D}_{5}$} & $-5.559 * *$ & $-6.582 * *$ & $-5.845^{* *}$ & $-5.843 * *$ & $-5.650 * *$ & $-6.457 * *$ \\
\hline & $(.193)$ & $(.214)$ & $(.196)$ & $(.197)$ & $(.193)$ & $(.220)$ \\
\hline \multirow[t]{2}{*}{$\mathrm{D}_{6}$} & $-4.884 * *$ & $-5.885^{* *}$ & $-6.121 * *$ & $-5.220 * *$ & $-4.902 * *$ & $-6.759 * *$ \\
\hline & $(.142)$ & $(.169)$ & $(.162)$ & $(.148)$ & $(.142)$ & $(.193)$ \\
\hline \multirow[t]{2}{*}{$\mathrm{D}_{7}$} & $-4.120 * *$ & $-5.103 * *$ & $5.508 * *$ & $-4.423 * *$ & $-4.194 * *$ & $-6.071 * *$ \\
\hline & $(.100)$ & $(.135)$ & $(.127)$ & $(.105)$ & $(.101)$ & $(.155)$ \\
\hline \multirow[t]{2}{*}{$\mathrm{D}_{8}$} & $-4.086 * *$ & $-5.051 * *$ & $-5.590 * *$ & $-4.359 * *$ & $-4.178 * *$ & $-6.102 * *$ \\
\hline & $(.100)$ & $(.134)$ & $(.129)$ & $(.104)$ & $(.101)$ & $(.156)$ \\
\hline \multirow{2}{*}{$\mathrm{D}_{9}$} & $-4.212 * *$ & $-5.162 * *$ & $-5.508 * *$ & $-4.428 * *$ & $-4.255^{* *}$ & $-5.933 * *$ \\
\hline & $(.109)$ & $(.140)$ & $(.133)$ & $(.112)$ & $(.109)$ & $(.157)$ \\
\hline \multirow[t]{2}{*}{$\mathrm{D}_{10}$} & $-4.184 * *$ & $-5.114 * *$ & $-5.252 * *$ & $-4.428^{* *}$ & $-4.426^{* *}$ & $-5.819^{* *}$ \\
\hline & $(.109)$ & $(.140)$ & $(.127)$ & $(.114)$ & $(.115)$ & $(.156)$ \\
\hline \multirow[t]{2}{*}{$\mathrm{D}_{11}$} & $-4.551 * *$ & $-5.451 * *$ & $-5.517 * *$ & $-4.773 * *$ & $-4.765^{* *}$ & $-6.033^{* *}$ \\
\hline & $(.136)$ & $(.161)$ & $(.151)$ & $(.139)$ & $(.140)$ & $(.174)$ \\
\hline \multirow[t]{2}{*}{$\mathrm{D}_{12}$} & $-5.060 * *$ & $-5.546^{* *}$ & $-5.739 * *$ & $-5.166^{* *}$ & $-5.164 * *$ & $-5.944 * *$ \\
\hline & $(.183)$ & (.192) & $(.192)$ & $(.184)$ & $(.184)$ & $(.198)$ \\
\hline \multirow[t]{3}{*}{ Lunch } & & $1.410 * *$ & & & & $.585^{* *}$ \\
\hline & & $(.109)$ & & & & $(.118)$ \\
\hline & & $\exp \beta 4.10$ & & & & $\exp \beta 1.79$ \\
\hline \multirow[t]{3}{*}{ Suspension } & & & $2.176^{* *}$ & & & $1.996^{* *}$ \\
\hline & & & $(.058)$ & & & $(.062)$ \\
\hline & & & $\exp \beta 8.81$ & & & $\exp \beta 7.36$ \\
\hline \multirow[t]{3}{*}{ Mobility } & & & & $2.018 * *$ & & $1.577 * *$ \\
\hline & & & & $(.076)$ & & $(.091)$ \\
\hline & & & & $\exp \beta 7.52$ & & $\exp \beta 4.84$ \\
\hline \multirow[t]{3}{*}{ Retention } & & & & & $1.511 * *$ & $.402 *$ \\
\hline & & & & & $(.134)$ & $(.153)$ \\
\hline & & & & & $\exp \beta 4.53$ & $\exp \beta 1.49$ \\
\hline \multicolumn{7}{|c|}{ Goodness-of-Fit } \\
\hline $\mathrm{LL}$ & -2952.89 & -2848.90 & -2280.44 & -2724.74 & -2905.59 & -2129.47 \\
\hline Deviance & 5905.77 & 5697.80 & 4560.88 & 5449.48 & 5811.18 & 4258.94 \\
\hline $\begin{array}{l}\mathrm{n} \\
\text { parameters }\end{array}$ & 10 & 11 & 11 & 11 & 11 & 14 \\
\hline $\mathrm{AIC}$ & 5925.77 & 5719.80 & 4582.88 & 5471.48 & 5833.18 & 4286.94 \\
\hline
\end{tabular}




\begin{tabular}{|c|c|c|c|c|c|}
\hline \multicolumn{6}{|c|}{ Deviance-based Hypothesis Tests } \\
\hline $\mathrm{H}_{0}: \mathrm{B}_{F R E}=0$ & $207.97 * *$ & \multirow{4}{*}{$1344.89^{* *}$} & \multirow{4}{*}{$456.29 * *$} & & $1438.86^{* *}$ \\
\hline $\mathrm{H}_{0}: \mathrm{B}_{S U S P}=0$ & & & & & $301.94 * *$ \\
\hline $\mathrm{H}_{0}: \mathrm{B}_{M O B}=0$ & & & & & $1190.54 * *$ \\
\hline $\mathrm{H}_{0}: \mathrm{B}_{R E T}=0$ & & & & $94.59 * *$ & $1552.24 *$ \\
\hline \multicolumn{6}{|c|}{ Wald Hypothesis Tests } \\
\hline $\mathrm{H}_{0}: \mathrm{B}_{F R E}=0$ & $166.28^{* *}$ & & & & $24.39^{* *}$ \\
\hline $\mathrm{H}_{0}: \mathrm{B}_{S U S P}=0$ & & $1431.28^{* *}$ & & & $1024.38 * *$ \\
\hline $\mathrm{H}_{0}: \mathrm{B}_{M O B}=0$ & & & $788.19 * *$ & & $302.91 * *$ \\
\hline $\mathrm{H}_{0}: \mathrm{B}_{R E T}=0$ & & & & $127.63 * *$ & $6.844 *$ \\
\hline
\end{tabular}

\section{Research Question 3: Subsequent Juvenile Detention}

The final section of the results chapter addresses research question 3: Of the students in the $3^{\text {rd }}$ grade cohort who experience an alternative placement event, what proportion of students experience subsequent juvenile detention and when are they most likely to experience a subsequent juvenile detention event? The exploration of subsequent juvenile detention is used primary through descriptive statistics, and includes disaggregation of the data by race and gender.

\section{Proportion of students that experienced subsequent juvenile detention}

As shown on Table 18, Of the 544 students in the cohort that experienced a disciplinary alternative placement, a total of 215 (39.5\%) experienced juvenile detention at some point between their time of placement and $12^{\text {th }}$ grade. 
Table 18.

Number of Students Placed in Alternative School and Number and Percent of Students Subsequently Detained $(n=544)$

\begin{tabular}{|c|c|c|c|}
\hline $\begin{array}{c}\text { Grade Placed in } \\
\text { Alternative School }\end{array}$ & $\begin{array}{c}\text { N Placed in } \\
\text { Alternative } \\
\text { School }\end{array}$ & $\begin{array}{c}N \\
\text { Eventually } \\
\text { Detained }\end{array}$ & $\begin{array}{c}\% \text { Eventually } \\
\text { Detained }\end{array}$ \\
\hline 3 & 2 & 1 & 50.0 \\
\hline 4 & 5 & 2 & 40.0 \\
\hline 5 & 27 & 15 & 55.6 \\
\hline Elementary Total & 34 & 18 & 52.9 \\
\hline 6 & 50 & 27 & 54.0 \\
\hline 7 & 102 & 46 & 45.1 \\
\hline 8 & 102 & 37 & 36.3 \\
\hline Middle Total & 254 & 110 & 43.3 \\
\hline 9 & 86 & 28 & 32.6 \\
\hline 10 & 85 & 25 & 29.4 \\
\hline 11 & 55 & 9 & 16.4 \\
\hline 12 & 30 & 1 & 3.3 \\
\hline High Total & 256 & 63 & 24.6 \\
\hline Total & 544 & 191 & 35.1 \\
\hline
\end{tabular}




\section{Time between placement and detention}

In order to assess the time between alternative school placement and juvenile detention for those students that experience a juvenile detention event, the time between placement and detention was explored using the same interval as in prior analyses, years. As shown in Table 19, approximately half (53\%) of students experienced a juvenile detention event either within the same year they were placed in alternative school or one year later (24\% and 29\%, respectively). Approximately $35 \%$ experienced a juvenile detention event between $2-3$ years after being placed in a disciplinary alternative school. Almost 10\% experience juvenile detention between 4-5 years after placement in a disciplinary alternative school, and $2.6 \%$ between $6-8$ years after placement.

Table 19

Number of Years Between Placement in a Disciplinary Alternative School and Juvenile Detention Between $3^{\text {rd }}-12^{\text {th }}$ Grade $(\mathrm{n}=191)$

\begin{tabular}{ccc}
\hline $\begin{array}{c}\text { Number of years from Alt } \\
\text { placement to Juvenile } \\
\text { Detention }\end{array}$ & $N$ & $\%$ \\
\hline 0 (within same year) & 45 & 23.6 \\
1 & 56 & 29.3 \\
2 & 39 & 20.4 \\
3 & 28 & 14.7 \\
4 & 13 & 6.8 \\
5 & 5 & 2.6 \\
6 & 3 & 1.6 \\
7 & 0 & 0.0 \\
8 & 2 & 1.0 \\
\hline
\end{tabular}




\section{Grade of Placement and Time to Subsequent Juvenile Detention}

Students between the ages of 11 to 18 are received by the juvenile detention facilities in this study, which includes students in elementary, middle and high school students. Descriptive statistics were used to describe the relationship between the first grade of alternative school placement and the length of time to subsequent juvenile detention. Shown in Table 20, of the students placed in alternative school during elementary that were subsequently detained, they had an average of almost 4 years between placement and detention. For middle school students, the average time between placement and detention was almost 2 years. Students placed in high schools on average were detained within the same year they were placed in alternative school. A statistically significant negative correlation between grade of first alternative school placement and the length of time between placement and juvenile detention $\mathrm{r}=-.632, \mathrm{n}=191, \mathrm{p}=$ 0.000 . simply confirms that the higher the grade of placement, the less time there is before a juvenile detention event.

Table 20.

Average Number of Years Between Grade Level of Placement and Subsequent Juvenile Detention

\begin{tabular}{lccc}
\hline Level & $\mathrm{n}$ & Mean & $\mathrm{SD}$ \\
\hline Elementary & 18 & 3.83 & 2.31 \\
Middle & 110 & 1.95 & 1.29 \\
High & 63 & .73 & .87 \\
Total & 191 & 1.72 & 1.56 \\
\hline
\end{tabular}


In order to determine the specific grade of subsequent juvenile detention based on the grade of first placement in a disciplinary alternative school, the number and percent of students in each grade are presented in Table 21. As shown, the students who were placed in a disciplinary alternative school in $3^{\text {rd }}$ or $4^{\text {th }}$ grade were eventually placed in juvenile detention in $10^{\text {th }}, 11^{\text {th }}$, or $12^{\text {th }}$ grade. Students placed in alternative school in $5^{\text {th }}$ and $6^{\text {th }}$ grade were eventually detained between $6^{\text {th }}$ through $11^{\text {th }}$ grade a relatively evenly distribution. Of the student placed in alternative school in $7^{\text {th }}$ grade, $63 \%$ were detained 1-2 years later in $8^{\text {th }}$ or $9^{\text {th }}$ grade. Of the student placed in alternative school in $8^{\text {th }}$ grade, $24 \%$ were detained that same year, and $54 \%$ were detained in $9^{\text {th }}$ and $10^{\text {th }}$ grade.

For students that had their first disciplinary alternative school placement in high school, of the student placed in alternative school in $9^{\text {th }}$ grade, $25 \%$ were detained that same year, $43 \%$ were detained the following year $\left(10^{\text {th }}\right.$ grade), and $32 \%$ were detained in $11^{\text {th }}$ or $12^{\text {th }}$ grade. For students placed in alternative school in $10^{\text {th }}$ grade, $60 \%$ were detained that same year and the rest were detained the following year $\left(11^{\text {th }}\right.$ grade). Of the students placed in alternative school in $11^{\text {th }}$ grade, the majority $(78 \%)$ were detained that same year. The one student that was placed in a disciplinary alternative school in $12^{\text {th }}$ grade that was eventually detained was detained that same year. However it is important to keep in mind that since the study only follows the students through $12^{\text {th }}$ grade, data on subsequent detention past $12^{\text {th }}$ grade is not known. The patterns in Table 20 seems to show that for middle and high school students placed in disciplinary alternative schools, those that are subsequently detained, are detained within the same year or between 1-2 years after placement. 


\section{Table 21}

Grade of First Alternative School Placement and Subsequent Grade of Juvenile Detention $(\mathrm{n}=191)$

\begin{tabular}{|c|c|c|c|c|c|c|c|c|}
\hline \multirow{2}{*}{$\begin{array}{c}\text { Grade lst } \\
\text { alt school } \\
\text { entry }\end{array}$} & \multicolumn{8}{|c|}{ Grade of first juvenile detention } \\
\hline & 6 & 7 & 8 & 9 & 10 & 11 & 12 & Total \\
\hline \multirow[t]{2}{*}{3} & & & & & & 1 & & 1 \\
\hline & & & & & & $100.00 \%$ & & $100.00 \%$ \\
\hline \multirow[t]{2}{*}{4} & & & & & 1 & & 1 & 2 \\
\hline & & & & & $50.00 \%$ & & $50.00 \%$ & $100.00 \%$ \\
\hline \multirow[t]{2}{*}{5} & 3 & 4 & 2 & 2 & 2 & 2 & & 15 \\
\hline & $20.00 \%$ & $26.67 \%$ & $13.33 \%$ & $13.33 \%$ & $13.33 \%$ & $13.33 \%$ & & $100.00 \%$ \\
\hline \multirow[t]{2}{*}{6} & 1 & 6 & 4 & 7 & 7 & 2 & & 27 \\
\hline & $3.70 \%$ & $22.22 \%$ & $14.81 \%$ & $25.93 \%$ & $25.93 \%$ & $7.41 \%$ & & $100.00 \%$ \\
\hline \multirow[t]{2}{*}{7} & & 5 & 15 & 14 & 8 & 3 & 1 & 46 \\
\hline & & $10.87 \%$ & $32.61 \%$ & $30.43 \%$ & $17.39 \%$ & $6.52 \%$ & $2.17 \%$ & $100.00 \%$ \\
\hline \multirow[t]{2}{*}{8} & & & 9 & 8 & 12 & 7 & 1 & 37 \\
\hline & & & $24.32 \%$ & $21.62 \%$ & $32.43 \%$ & $18.92 \%$ & $2.70 \%$ & $100.00 \%$ \\
\hline \multirow[t]{2}{*}{9} & & & & 7 & 12 & 5 & 4 & 28 \\
\hline & & & & $25.00 \%$ & $42.86 \%$ & $17.86 \%$ & $14.29 \%$ & $100.00 \%$ \\
\hline \multirow[t]{2}{*}{10} & & & & & 15 & 10 & & 25 \\
\hline & & & & & $60.00 \%$ & $40.00 \%$ & & $100.00 \%$ \\
\hline \multirow[t]{2}{*}{11} & & & & & & 7 & 2 & 9 \\
\hline & & & & & & $77.78 \%$ & $22.22 \%$ & $100.00 \%$ \\
\hline \multirow[t]{2}{*}{12} & & & & & & & 1 & 1 \\
\hline & & & & & & & $100.00 \%$ & $100.00 \%$ \\
\hline \multirow[t]{2}{*}{ Total } & 4 & 15 & 30 & 38 & 57 & 37 & 10 & 191 \\
\hline & $2.09 \%$ & $7.85 \%$ & $15.71 \%$ & $19.90 \%$ & $29.84 \%$ & $19.37 \%$ & $5.24 \%$ & $100.00 \%$ \\
\hline
\end{tabular}




\section{Subsequent Juvenile Detention and Student Race and Gender}

The proportion of students that experienced each event (i.e., alternative school placement and juvenile detention) against their proportion in the cohort based on race and gender, percentages of students based on race by gender can be seen in Tables $22-24$. These percentages were disaggregated based on the level (i.e., elementary, middle, high) of when they were placed in a disciplinary alternative school. In order to illustrate the patterns that emerged, stacked bar charts that represent the data are shown in Figures 1517 each placed directly below the respective table.

Shown in Table 22 and illustrated in Figure 15, African American males are disproportionately represented in the population of students placed in alternative school in elementary and markedly over represented in the population of students that were subsequently detained as juveniles. Of all the female groups, only African-American females were represented in the population of students placed in alternative schools in elementary (21\%) and those eventually detained after placement (11\%). 
Table 22

Percent of Students by Race and Gender in Cohort, Alternative Schools and Detained for Students Placed in Alternative School in Elementary School

\begin{tabular}{lccc}
\hline & $\begin{array}{c}\text { Cohort } \\
(\mathrm{n}=7341)\end{array}$ & $\begin{array}{c}\text { Alt Placed } \\
(\mathrm{n}=34)\end{array}$ & $\begin{array}{c}\text { Detained } \\
(\mathrm{n}=18)\end{array}$ \\
\cline { 2 - 4 } Elementary & & & \\
African American Male & 18.9 & 55.9 & 61.1 \\
African American Female & 18.9 & 20.6 & 11.1 \\
White Male & 31.4 & 23.5 & 27.7 \\
White Female & 21.9 & 0.0 & 0.0 \\
Other Male & 1.7 & 0.0 & 0.0 \\
Other Female & 1.5 & 0.0 & 0.0 \\
Total & 100.0 & 100.0 & 100.0 \\
\hline
\end{tabular}

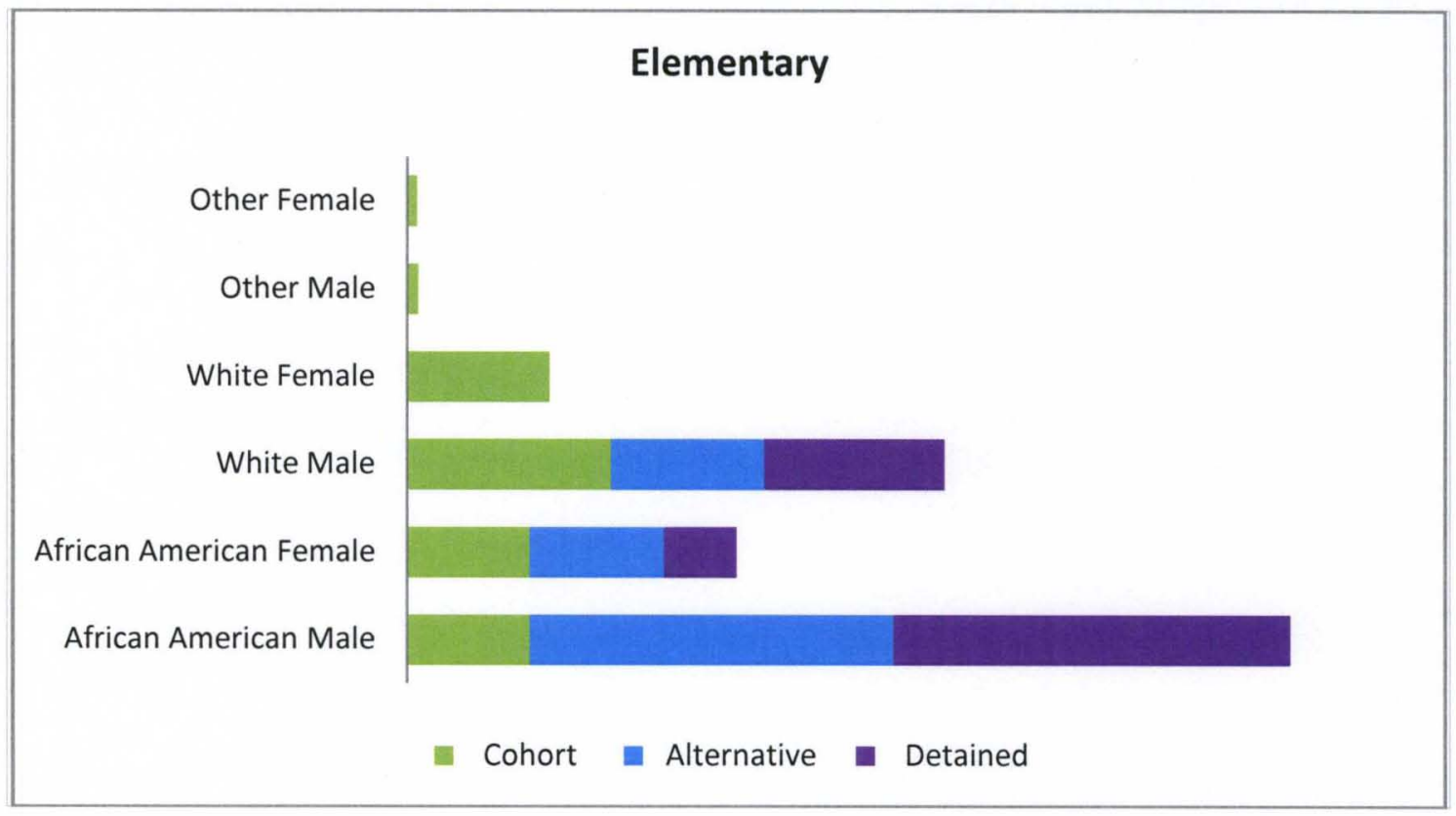

Figure 15. Illustration of Table 21. 
Shown in Table 23 and illustrated in Figure 16, African American males are disproportionately represented in the population of students placed in alternative middle school and clearly over represented in the population of students that were subsequently detained as juveniles, while white males were underrepresented. Of the female groups, the proportion of African-American females represented in the population of students placed in alternative schools in middle were double that of white females and of those eventually detained after placement the African-American female rate was more than triple that of white females.

Table 23

Percent of Students by Race and Gender in Cohort, Alternative Schools and Detained for Students Placed in Alternative School in Middle School

\begin{tabular}{lccc}
\hline & $\begin{array}{c}\text { Cohort } \\
(\mathrm{n}=6404)\end{array}$ & $\begin{array}{c}\text { ASDS Placed } \\
(\mathrm{n}=254)\end{array}$ & $\begin{array}{c}\text { Detained } \\
(\mathrm{n}=110)\end{array}$ \\
\cline { 2 - 4 } Middle & & & \\
African American Male & 19.5 & 39.4 & 50.9 \\
African American Female & 18.4 & 20.9 & 17.3 \\
White Male & 30.0 & 26.8 & 22.7 \\
White Female & 28.9 & 10.2 & 4.5 \\
Other Male & 1.6 & 2.0 & 2.7 \\
Other Female & 0.7 & 0.4 & 5.4 \\
Total & 100.0 & 100.0 & 100.0 \\
\hline
\end{tabular}




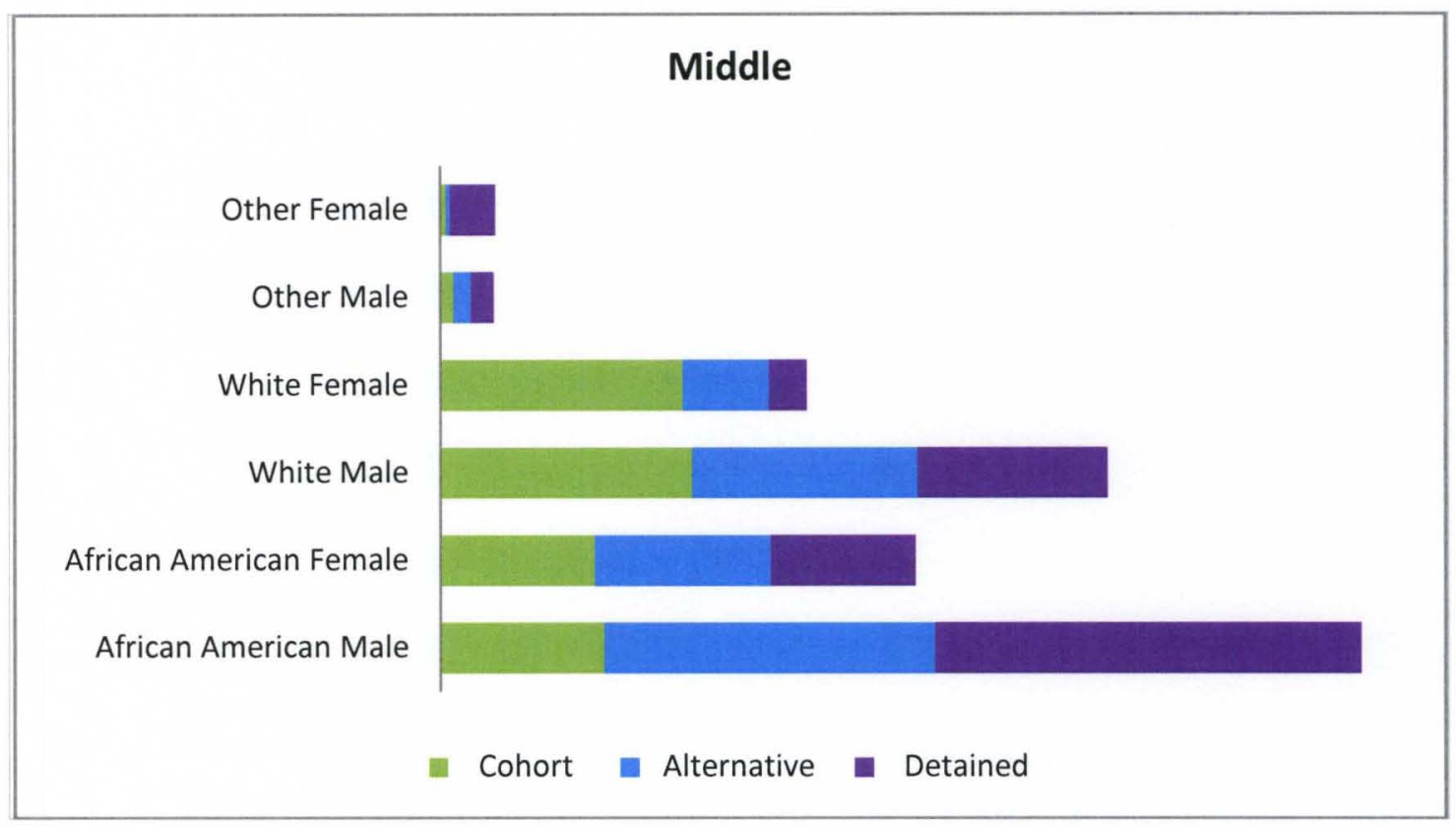

Figure 16. Illustration of Table 22

Shown in Table 24 and illustrated in Figure 17, the same patterns emerge as those for students placed in elementary and middle. African American males are disproportionately represented in the population of students placed in alternative school those that were subsequently detained as juveniles. Of the female groups, the proportion of African-American females represented in the population of students placed in alternative high schools were more than double that of white females and quadrupled for those eventually detained after placement. 
Table 24

Percent of Students by Race and Gender in Cohort, Alternative Schools and Detained for Students Placed in Alternative School in High School

\begin{tabular}{lccc}
\hline High & $\begin{array}{c}\text { Cohort } \\
(\mathrm{n}=5394)\end{array}$ & $\begin{array}{c}\text { ASDS Placed } \\
(\mathrm{n}=256)\end{array}$ & $\begin{array}{c}\text { Detained } \\
(\mathrm{n}=63)\end{array}$ \\
\cline { 2 - 4 } African American Male & 18.6 & 48.0 & 58.7 \\
African American Female & 18.9 & 20.7 & 14.3 \\
White Male & 29.1 & 21.9 & 23.8 \\
White Female & 30.1 & 7.8 & 3.2 \\
Other Male & 1.7 & 1.6 & 0.0 \\
Other Female & 1.5 & 0.0 & 0.0 \\
Total & 100.0 & 100.0 & 100.0 \\
\hline
\end{tabular}

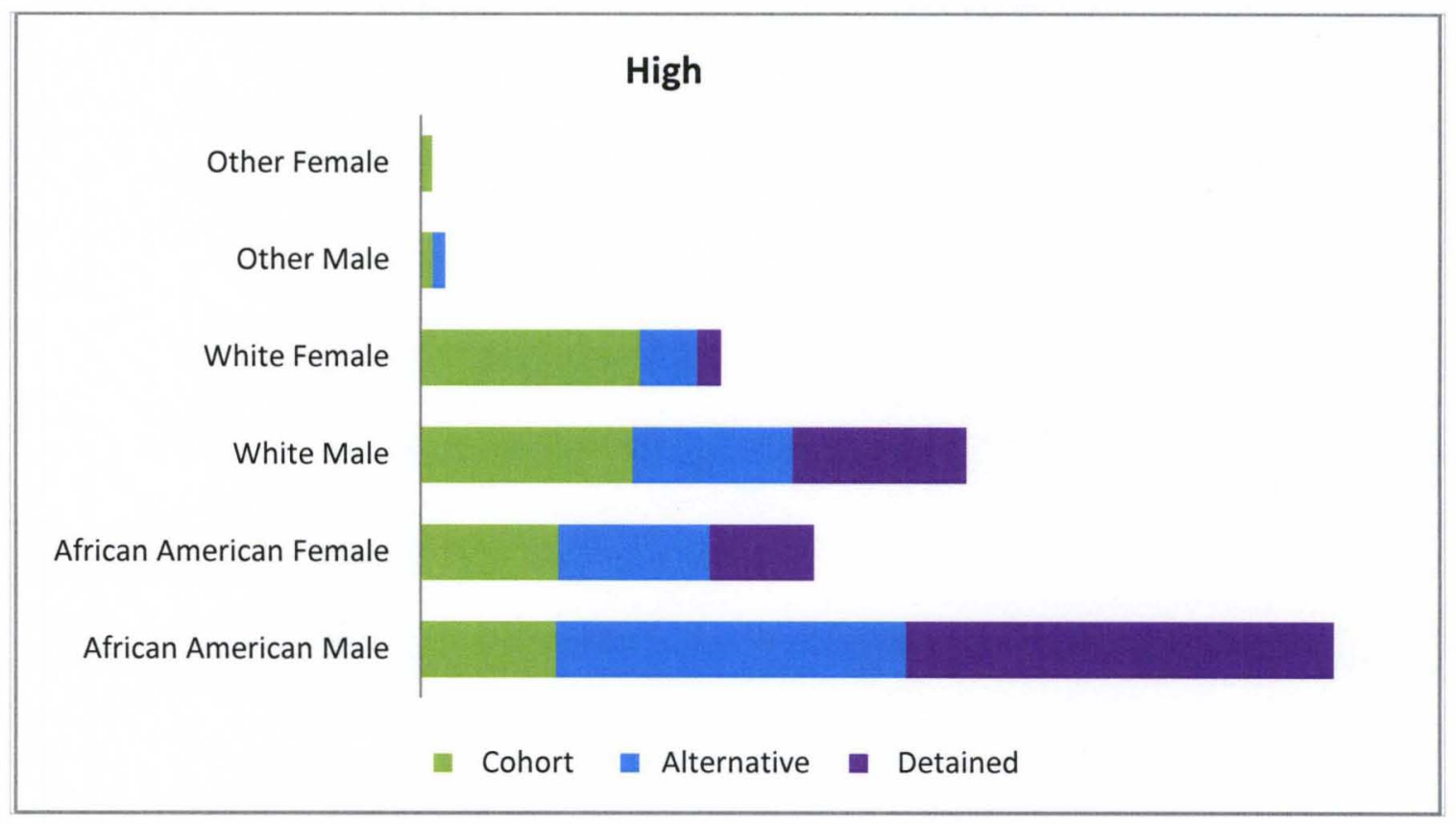

Figure 17. Illustration of Table 23 
Due to the descriptive findings of racial disparities in subsequent juvenile detention even with the already overrepresentation of minorities in alternative schools, a logistic regression analysis was conducted using a separate data file with only the students who were placed in the alternative schools $(n=544)$. The results revealed that when controlling for gender, the odds of subsequent detention were 1.5 times for minority students than white students. The level of significance and odds ratio for males is even higher indicating that regardless of race, the odds of subsequent detention are almost 2 times higher for males.

Table 25

Logistic Regression Predicting Juvenile Detention with Race and Gender ( $N=544)$

\begin{tabular}{lccc}
\hline Predictor & $\beta$ & SE & Odds ratio \\
\hline Minority & $0.37^{*}$ & 0.19 & 1.45 \\
Male & $0.66^{* *}$ & 0.20 & 1.94 \\
\hline
\end{tabular}

${ }^{*} \mathrm{p}<.05 . \quad{ }^{* *} \mathrm{p}<.01$

In an effort to summarize the major answers to the research questions posed in this dissertation, Table 26 provides a brief description of key findings for each question. 
Table 26

Summary of Results

\begin{tabular}{|c|c|c|}
\hline $\begin{array}{l}\text { Primary research question } \\
\text { focus }\end{array}$ & Analysis & Results \\
\hline $\begin{array}{l}\text { Proportion and description of } \\
\text { students placed in alternative } \\
\text { school between } 3^{\text {rd }}-12^{\text {th }} \\
\text { grade }\end{array}$ & $\begin{array}{l}\text { Life Table analysis } \\
\text { and descriptive } \\
\text { statistics }\end{array}$ & $\begin{array}{l}\text { Cumulative proportion of cohort } \\
\text { placed }=8.8 \% \text {; Greatest hazard } \\
\text { of placement was in } 7^{\text {th }} \text { grade. }\end{array}$ \\
\hline Predictors of Placement & $\begin{array}{l}\text { Discrete-time hazard } \\
\text { analyses }\end{array}$ & $\begin{array}{l}\text { Minority, male and free/reduced } \\
\text { lunch were significant predictors } \\
\text { across time, lunch status had } \\
\text { largest effect size; EBD status, } \\
\text { mobility, retention, and } \\
\text { attendance were significant } \\
\text { predictors; when controlling for } \\
\text { the predictors with the largest } \\
\text { effect sizes, out of school } \\
\text { suspension remained the strongest } \\
\text { non-demographic predictor of } \\
\text { placement over time. }\end{array}$ \\
\hline $\begin{array}{l}\text { Risk of subsequent juvenile } \\
\text { detention }\end{array}$ & $\begin{array}{l}\text { Descriptive statistics } \\
\text { and logistic } \\
\text { regression }\end{array}$ & $\begin{array}{l}53 \% \text { of students placed in } \\
\text { elementary, } 43 \% \text { of middle and } \\
25 \% \text { of students placed in high } \\
\text { school experienced a subsequent } \\
\text { juvenile detention. The average } \\
\text { time between placement and } \\
\text { detention was approximately } 3 \\
\text { years for elementary, } 2 \text { for middle } \\
\text { and within the same year for } \\
\text { students placed in high school. } \\
\text { Race and gender were significant } \\
\text { predictors of subsequent juvenile } \\
\text { detention. African-American } \\
\text { males were heavily over- } \\
\text { represented in alternative } \\
\text { placement and subsequent } \\
\text { juvenile detention at every grade } \\
\text { level. }\end{array}$ \\
\hline
\end{tabular}




\section{CHAPTER V}

\section{DISCUSSION}

This chapter includes an overview of the purpose and significance of the study, summary and interpretation of the main findings, including key implications; limitations of the study, directions for future research, and concluding recommendations for policy and practice.

\section{Purpose and Significance of the Study}

Alternative school settings for students who are identified as "disruptive or dangerous" are playing an increasingly prominent role in the world of public education, yet many gaps in the research literature are abound. This dissertation study is an effort to contribute to an understanding of the schooling histories of students enrolled in these schools, identify longitudinal predictors of placement, and assess the risk of subsequent involvement of the juvenile justice system.

The purpose of this exploratory study was three fold. The first was to describe the proportion of students that were placed in disciplinary alternative schools and when their first placement occurred. The second purpose was to determine the time-constant and time-varying predictors of alternative school placement. Third, this study sought to explore whether, and if so when, students who experienced an alternative placement

event subsequently experienced a juvenile detention before $12^{\text {th }}$ grade, and if grade level 
of placement impacted the risk of juvenile detention. Based on descriptive results, an analysis of race and gender as predictors of subsequent detention was also explored.

Since the initial review of the research literature took place for this dissertation, there has been mounting attention mostly in the forms of anecdotal reports and editorials on the topics of exclusionary school discipline and the "school to prison pipeline" thereby signifying increased unease of the trends by the educational community and the community at large. The timely nature of this dissertation will add to the growing knowledge base on these issues.

The significance of this study is characterized by the nature of the issues of school exclusion and juvenile detention themselves and the void in the research literature the study helps to address. The rigorous methodology used to investigate these issues also adds to the significance of the study. By addressing the three primary purposes explicated above using longitudinal data, this study's significance lies in its aim to contribute to an understanding of the predictors of placement to promote considerations of policies and practices that can prevent placements in these schools. Additionally, by exploring subsequent juvenile detention this study provides a contribution to the growing literature on the "school to prison pipeline" by quantifying the risk of subsequent juvenile detention. Finally, by applying the techniques of Discrete-time hazard analysis using ten years of longitudinal data, the study yielded results with more precision than would have been produced through the use of a more typical quantitative methodology with a crosssectional design. 


\section{Key Findings and Implications}

\section{Percent and grade of placement}

Following a cohort of $76683^{\text {rd }}$ grade students, the life table results show that the cumulative proportion that were placed in a disciplinary alternative school between $3^{\text {rd }}$ and $12^{\text {th }}$ grade was $8.8 \%$. The proportion of students placed at each grade level varied from a low of $.03 \%$ in $3^{\text {rd }}$ grade to a high of $1.7 \%$ in $8^{\text {th }}$ grade. Comparing these percentages to national data can prove difficult due to the lack of data on enrollment in this particular type of alterative school, and because this is a longitudinal study of one cohort, not a study of the entire student population over 10 years. The closest comparative figure emerges from a recent study (Chiang \& Gill, 2010) of alternative schools in an urban school district of Philadelphia. Though the district is larger and has a higher poverty rate and minority student enrollment than the district in this study, results are in a similar range because one in ten students was enrolled in an alternative school for at risk students at some point by 2003-2004.

The life table results show that starting in $3^{\text {rd }}$ grade, the risk of placement increases each year peaking at grades 7 and 8 and remaining fairly steady until a slight decline in $11^{\text {th }}$ and $12^{\text {th }}$ grade. Clearly the risk of placement in middle school points to a need to study the dynamics of middle school placement. Importantly, 34 elementary children in this one cohort were placed during elementary school years. The instances of the elementary placements in this study occurred ten years ago, and even then, some the middle alternative schools were expanded to serve elementary grade students. Evidence continues to emerge that disciplinary alternative schools are increasingly serving younger students (NCES, 2010; Orefield, Loosen, Wald \& Swanson, 2004). The decisions and 
ramifications of placement of even younger children should also be kept at the forefront of district and national policy discussions.

\section{Recidivism}

While not a key research focus of the study, evidence of recidivism was examined descriptively. Conforming prior research (Chiang \& Gill, 2010; Schrenko, 2000) the number of entries into the alternative schools for the cohort students indicates there may be a cyclical nature to the problem as illustrated in the conceptual framework. For example, in $7^{\text {th }}$ grade, while there were only 102 unique students placed, there were 266 entries into the alternative schools signifying repeat placements within the same year. These repeat entrances raise one fundamental question: is placement in alternative school as a disciplinary measure deterring future unwanted actions or behaviors that led to alternative school placement in the first place? In addition to considering what strategies, supports and practices are implemented within the alternative school to address the root cause of the placement, ensuring systemic support for students as they return to the regular school is critical. Jones (1999) found that successful student transition back to the regular school environment necessitates the existence of formal transition programs inherent in both the alternative and mainstream schools.

\section{Predictors of Placement}

For the three demographic characteristics that are beyond the control of the child, their gender, race and poverty status, the findings in this study confirm previous research showing that males, minority students and poor students are most likely to be placed in disciplinary alternative schools. The Discrete-time hazard models indicate that the strongest demographic predictor was lunch status. In elementary $97 \%$ of those placed 
were on free/reduced lunch compared with $59 \%$ of the cohort. When controlling for race and gender, across time the odds of placement for students on free/reduced lunch were three times higher than for students that can pay for lunch. Just as with poverty, the salience of race is undisputable. African-American males were the most over-represented among the students placed, confirming all other research showing exclusionary discipline being disproportionately applied to Black male students (Arnove \& Strout, 1980; Cox, Davidson \& Bynum, 1995; Noguera, 2008 ; Verdugo \& Glenn; Wald \& Losen, 2003, 2006). The Discrete-time hazard model showed that even when controlling for gender and lunch status, the odds of placement for minority students are two times higher than for white students. Prior research documenting the increased disproportionality caused by the implementation of zero tolerance policies; it would be wise for districts to examine such policies and the processes by which they exacerbate racial disparities in school exclusion and adopt alternative solutions. Related, the process of engaging in the difficult conversations around issues of race and culture are beginning to be embraced by school districts that have committed to addressing head on the longstanding issue of cultural competence and institutional racism.

Analysis of variables used in the study that point to students academic standing, yielded interesting results. Contrary to prior research conducted by Lehr, Soon Tan \& Ysseldyke (2009) students identified as having a Learning Disability (LD) were not found to have a considerable presence among the students placed. However, the descriptive statistics of the CTBS reading scores for those with available data indicated that the majority of students placed in alternative school during middle and high school scored below average on a nationally standardized test of reading. Not all students who 
would qualify for services due to a learning disability are diagnosed. In fact, students with undiagnosed learning problems may exhibit misbehavior in the form of defiance as a reaction to situations in which they have difficulty coping and as a means of protecting themselves from feelings of incompetence, loss of autonomy, and negative relationships (Adleman \& Taylor, 1990).

Grade retention was found to be a significant predictor of placement in alternative school. Of the students placed in middle school, $9 \%$ had been retained and in high school $18 \%$ of students placed were retained. Standing alone, the odds of placement were over 4.5 times higher for retained students than promoted students. When controlling for poverty, mobility, and suspension, the odds, still significant, were reduced to being 1.5 times higher for retained students. These results are not surprising given that retention has been found to be predictive of emotional distress, low self-esteem, poor peer relations, alcohol and drug abuse and violent behaviors (Jimerson, Anderson, \& Whipple, 2002).

Student mobility was the second strongest time-varying predictor in the study. Even when controlling for lunch status, retention, and suspension, the effect size of mobility remained significantly large (exp $\beta 4.84)$. The finding of school mobility as a significant predictor at every grade level lends evidence to the overwhelmingly unstable nature of the students' experience both within the school system and without. The majority of school mobility is due to residential mobility, and while it can also indicate a higher degree of poverty, it is also an indicator of family structure. Families without both biological parents have higher incidence of residential moves and higher rates of school 
moves, and taken together have been found to be important markers of increased risk for adjustment problems (Adam \& Chase-Lansdal, 2002).

Confirming other research (Lehr \& Lange, 2003), students diagnosed with Emotional Behavioral Disorder (EBD) had a sizeable presence in the population of students placed. Students identified as EBD are over-represented in the disciplinary alternative school population at every level, with the highest over-representation at the elementary level. Concerns have been expressed that the increasing trend is indicative a wider pervasive problem of segregation based on disability in the educational system (Blanchett, Mumford \& Beachum, 2005) and that there may be a lack of services provided to EBD students in alternative settings (Lehr \& Lange, 2003b). The stigma already experienced by students labeled as EBD coupled with the poor outcomes even without alternative school placement such as low school completion rates and involvement with the criminal justice system makes this group of students particularly critical when making placement decisions. Assuming the identification of a student as Behaviorally Disordered is valid in the first place, should students be further excluded from mainstream educational environments and punished for behavior or actions that may be a manifestation of an identified disability? Ensuring high quality services and supports to EBD students prior to, during, and after placement is an ethical imperative.

Of all the predictors both time-constant and time-varying, out of school suspension was the strongest predictor of placement into a disciplinary alternative school. Students that were suspended 3 or more times were 25.6 times more likely to be placed in a disciplinary alternative school. The large effect size $(\exp \beta=8.81)$ was minimally lessened $(\exp \beta=7.36)$ even when controlling for the effects of lunch status, mobility and 
retention. This may be the most important finding in this study because it reveals that among the set of variables including those beyond the control of the district (i.e., lunch status, race, gender, mobility, attendance), the strongest predictor is one that is in essence within the realm of district control. Several decades of research confirm that suspension is an ineffective form of punishment (Skiba, Peterson \& Williams, 1997; 1999). Since the fitted hazard graph illustrated little difference between 1-2 suspensions and 3 or more on the risk of placement, similar to the question posed above: What is it about the practice of suspension that would lend to its utility in preventing subsequent violations?

Since suspension significantly supersedes alternative school placement, the impact and effectiveness of this initial act of exclusionary discipline should be carefully considered, as should alternatives to reliance on this practice. While initially more timeconsuming, restorative justice practices and programs are proving to be promising alternatives that helps students learn to solve problems on their own, respond to conflict nonviolently while contributing to students' social and emotional development and keeping them in school, and simultaneously improving school culture (Graves \& Mirsky, 2007). Additionally, Positive Behavior Intervention Support (PBS) programs have demonstrated effectiveness in positively impacting the learning environment of schools in order to support students and improve behavior systematically.

\section{Subsequent Juvenile Detention}

Kentucky is the second highest in the nation for incarcerating juveniles for nonviolent offences (Kids Count Data Book, 2008). Coupled with the void in research on the incidence of subsequent detention for students placed in alternative schools, the third aim of this study was to describe the proportion of students who experienced a subsequent 
juvenile detention and when the subsequent detention took place. Based on results, additional analyses were conducted to determine if the grade of placement impacted the length of time between placement and detention, and if race and gender impacted the likelihood of subsequent detention after alternative school placement.

Just over half (53\%) of the students placed in elementary school were subsequently detained as juveniles before the end of $12^{\text {th }}$ grade. Approximately $43 \%$ of students placed during the middle school years were eventually detained before the end of $12^{\text {th }}$ grade and almost quarter $(25 \%)$ were detained before the end of $12^{\text {th }}$ grade. This indicates a high likelihood of subsequent juvenile detention for those students placed in alternative disciplinary schools, particularly for students placed in elementary school.

There was a smaller percentage subsequently detained in high school could be due to the smaller period of time in this study available for subsequent detention compared with students placed in earlier grades. If the study time was extended to post high school the percent of subsequent detention or interaction with the criminal justice system may be similar to those placed in elementary or middle school.

Further examination of the data comparing the race and gender of students who experienced juvenile detention with the proportion of those placed in alternative schools and the cohort at large reveal a strikingly clear and statistically significant pattern. Among all of the groups, African American males are disproportionately represented in both those placed and those subsequently detained. While this is the case regardless of the grade level, most notably, the data show that $61 \%$ of African American males placed in disciplinary alternative schools in elementary experienced subsequent juvenile detention before $12^{\text {th }}$ grade. Though the data cannot speak to the reason for placement or 
detention, regardless of cause, the glaring racial disparities in the patterns of placement should be closely examined, discussed, and addressed. There is evidence that 32 of 44 states have shown differences in juvenile justice decision-making that was unaccounted for by differential criminal activity and in Kentucky, African-American youth and other youth of color are overrepresented at some of the key decision-making points within Kentucky's juvenile justice system (Grieshop-Goodwin, Swann, \& Colwell, 2009).

Because the data in this study reveal that there is a greater length of time between elementary alternative school placement and detention (3.8 years), there is more time and thus evens more opportunity for effective intervention to prevent subsequent detention. The finding that the earlier the grade of alternative placement the longer time it took for subsequent juvenile detention, and vice versa suggests for students placed in the earlier grades there is more than ample time to provide effective interventions to reduce the likelihood of juvenile detention. In light of these findings, policies and practices within the alternative schools that may help prevent or promote contacts with the criminal justice system should be considered. Verdugo \& Glenn, 2006) stated that disciplinary alternative schools appear to emphasize collaborating with protective agencies such as juvenile justice and police more than collaborating with community organizations, job placement centers, and family services, careful assessment of the types of partnerships used and emphasized and the corresponding worldviews they promote is key to tackling the "school-to-prison" pipeline. 


\section{Additional Recommendations for Policy and Practice}

Though some specific implications for school practice and district policy were presented with each key finding in the section above, the following are additional recommendations for policy and practice.

The results in this study point to several key student characteristics that significantly increase the hazard of placement in a disciplinary alternative school through elementary, middle and high school. The district in the study has the unique capacity and strong management of a large data system that collect daily individual student data. As

such, the implementation of an early warning student identification program would allow for the systematic intervention for students early and could prevent placement in disciplinary alternative schools. The strength of suspension as a predictor denotes that particular attention to repeat exclusionary sanctions be strongly encouraged. Though an early warning system can aid in early prevention efforts, careful consideration of the benefits, ramifications, and efficacy of current disciplinary practices and policies is an important and necessary precondition for districts that aim to systematically ensure the implementation of best-practices in the area of school discipline.

The graphic illustration of the race and gender of students in the cohort, placed in alternative school and subsequently detained reinforced the presence of a "school to prison pipeline" for African-American male students and most disturbingly in elementary. This reality reflects nothing less than a state of crisis. In fact the Council of Great City Schools (2010) recently recommended convening a conference at the White House to develop a call to action and strategic directions for improvement. This pipeline problem can be seen as nothing other than a systemic one, which requires and equally 
systemic response. The combined efforts of other key community institutions will remain critical keys to addressing and mediating the impact of concentrated poverty, broken family institutions, poor mental health and social supports, and other neighborhood effects that have demonstrated powerful influences on schooling outcomes (Bryk et al, 2010). Building a network of support through creating, nurturing and continually improving the effectiveness of partnerships with community institutions are critical to fortifying the potential of children that is all too often wasted, and as such will remain a grave necessity.

\section{Limitations of the Study}

Limitations are inherent in all research studies. As such, this study has multiple limitations that should be noted. First, though the longitudinal nature of the study is a strength, the primary limitation is the study sample consisted of one cohort of $3^{\text {rd }}$ grade students within one large urban school district. This will have implications for generalizing the findings. Second, due to missing data, direct measures of student academic performance (i.e., standardized test scores) were not examined. Third, the variables used in this study were also limited in that they did not include psycho-social and home or other direct environmental measures. Factors that research has documented definitively help shape the levels of risk for poor student experiences and outcomes related to schooling. Fourth, the specific impetus for the alternative placement decision and subsequent juvenile detention was not examined in this study. Understanding the reasons behind placement and detention at the various grade levels is a key element to understanding policies and practices that can assist with reducing or preventing the possible unnecessary placement and detention of children and youth. Finally, this study 
did not include data on students in kindergarten through $2^{\text {nd }}$ grade. Due to the increasing use of exclusion and calls for disciplinary alternative schools for the youngest of our public school students, this is an area in great need of investigation.

\section{Directions for Future Research}

The increased use of alternative schools for students deemed dangerous or disruptive coupled with the large gaps in research require substantial growth in empirical research. There are a multitude of facets that need further exploration that should be accompanied with a sense of urgency. These include the qualitative investigation of students' experiences before, during and after placement; examination of multiple student short term and long term outcomes; and the dynamics of placement decisions themselves. Due to consistent findings of repeat entrances into disciplinary alternative schools exploration of the contributing factors to recidivism can help identify policies and factors in these schools and at the regular schools they return to that may facilitate recidivism. Methodologically, conducting a multilevel Discrete-time hazard analysis that examines the possible nested impact of student and school characteristics would lend evidence to environmental school factors that increase the hazard of placement. Importantly, using a mixed methodology would offer the most ideal approach for future studies on disciplinary alternative schools.

Though not presented in this dissertation, during the analysis of student data, the incidences of placement for students in alternative schools and residential enrollments in foster care facilities and some subsequent placements into psychiatric hospital care was noticed. Other researchers have indicated a cyclical relationship between different 
institutions that serve particularly vulnerable at -risk youth and this line of investigation should continue particularly as it relates to disciplinary alternative schools.

While research studies that diagnose the problem are an important first step toward identification of solutions, much research is needed to delineate best practices within disciplinary alternative schools to implement as well as to minimize those found to be detrimental. While a fair amount is known about risk factors and characteristics of students likely to be placed, far less is known about protective factors of children that act as a mediator of the known individual and environmental risk factors. Research in this area would also aid in efforts to strengthen such protective factors in students. Importantly, it would also promote and facilitate discussions that highlight resilient characteristics of children and youth as opposed to the dominate conversations that are steeped in a deficit view of children placed at risk.

\section{Concluding Thoughts}

There are varied lenses through which the use of disciplinary alternative schools is viewed. For some, these schools are highly valued for providing students that would otherwise be expelled an alternative setting allowing them to continue their schooling. For others, they are places where students most in need of support are tracked, and stigmatized leading to further marginalization. And for some, these schools play a simultaneously beneficial and harmful role within the public school system. The findings of this study suggest a need for districts to ensure clarity of purpose on the role of these schools and the students that are filling them. Revisiting and carefully considering the benefits, ramifications, and efficacy of current disciplinary policy around disciplinary alternative schools in particular and exclusionary discipline in general are an important 
and necessary precondition for districts that aim to systematically ensure the success of their most vulnerable students. 


\section{REFERENCES}

Adam, E., \& Chase-Lansdale (2002) Home Sweet Home(s): Parental Separations, Residential Moves, and Adjustment Problems in Low-Income Adolescent Girls. Developmental Psychology 38 (5), 792-805.

Adelman, H.S., \& Taylor, L. (1990). Intrinsic motivation and school misbehavior: Some intervention implications. Journal of Learning Disabilities. 23, 541-550.

Arnove, R. F., \& Strout, T. (1980). Alternative schools for disruptive youth. Educational Forum, 44, 453-471.

Aron, L. Y., \& Zweig, J. M. (2003). Educational alternatives for vulnerable youth. Washington, D.C.: The Urban Institute.

Banicky, L. A. (2000). Alternative schools: Education policy brief(Policy Brief No. 6). University of Deleware, College of Human Resources, Education and Public Policy.

Barber, R. (1980, Spring). Alternative education to address student behavior concerns. Frankfort, KY: Kentucky State Department of Education.

Blanchett, W., Mumford, V., \& Beachum, F. (2005, March/April). Urban school failure and disproportionality in the post-brown era: Benign neglect of the constitutional rights of students of color. Remedial and Special Education, 26(2), 70-81. 
Brewer, D., Feifs, H., \& Kaase, K. (2001, April). Accountability policy for North Carolina's alternative schools: One year results. North Carolina: North Carolina Public Schools Accountability Division. (ERIC Document Reproduction Service No. 453271)

Bollmer, J, Bethel, J., Garrison-Mogren, R, and Brauen, M. (2007).Using the Risk Ratio to Assess Racial/Ethnic Disproportionality in Special Education at the SchoolDistrict Level. Journal of Special Education, 41(3),186-198.

Bush, G. (n.d.). No Child Left Behind (Archived Information ed.) [Brochure].

Byrk, A., Bender-Sebring, P., Allensworth, E, Luppescu, S., and Easton, J. (2010). Organizing Schools for Improvement: Lessons from Chicago. University of Chicago Press: Chicago.

Cassidy, W., \& Jackson, M. (2005, Winter). The need for equity in education: An intersectionality examination of labeling and zero tolerance practices. McGill Journal of Education, 40(3), 445-465.

Chiang, H., \& Gill, B. (2010). Student Characteristics and Outcomes in Alternative and Neighborhood High Schools in Philadelphia. Mathmatica Policy Research report \# 06716.

Collett, D. (2003). Modeling survival analysis in medical research. Chapman and Hall

Collins, P. H. (1990). Black feminist thought: Knowledge, consciousness and empowerment. Boston: Unwin Hyman. 
Council for Great City Schools (2010, October). A call for change: The social and educaiotnal factors contributing to the outcomes of black males in urban schools. A research report retrieved on November 20, 2010 at http://www.cges.org/cgcs/Call For Change.pdf

Cox, D.R. (1972). Regression models and life tables. Journal of Royal Statistical Society Series B34, 187-220.

Cox, S. (1999). An assessment of an alternative education program for at-risk delinquent youth. Journal of Research on Crime and Delinquency, 36(3), 323-336.

Cox, S., Davidson, W., \& Bynum, T. (1995). A meta-analytic assessment of delinquency related outcomes of alternative education students. Crime and Delinquency, 41(2), 219-234.

Denny, K., Gunter, P., Shores, R., \& Campbell, R. (1995). Educational placements of students with emotional and behavioral disorders: What do they indicate? In Issues in educational placement: students with emotional and behavioral disorders (pp. 119-144). Hillsdale, NJ: Lawrence Erlbaum.

Drum Major Institute for Policy. (2005, June). A look at the impact schools.

Dunbar, C. (2001). Alternative schooling for African American youth: Does anyone know we're here? New York: Peter Lang.

Education Commission of the State. (1999). Alternative schools for disruptive students.

Denver, CO: Information Clearinghouse.

Escobar-Chaves L., Tortolero, Kelder, S., and Kapadia, A. (2002). Violent behavior among urban youth attending alternative schools. Journal of School Health, 72(9). 
Eschool News report Retrieved on December 21, 2007 from

(http://www.eschoolnews.com/news/top-news/news-by-subject/budgetnews/?i=51244.

Ferguson, A. (2000). Bad boys: Public schools in the making of black masculinity. Michigan: University of Michigan Press.

Ferguson (2010). Proficiency of black students is found to be far lower than expected. New York Times, An article Retrieved on November $9^{\text {th }} 2010$ from http://www.nytimes.com/2010/11/09/education/09gap.html.

Franklin, C. (1992). Alternative school programs for at-risk youths. Social Work in Education. 14(4).

Garrison, R. W. (1987). Alternative schools for disruptive youth. California: National School Safety Center. Abstract obtained from Educational Management (ERIC Document Reproduction No. ED293198).

Gottfredson, G. D., Gottfredson, D. C., Czeh, E. R., Cantor, D., Crosse, S. B., \& Hantman, I. (2004). Toward safe and orderly schools-The National Study of Delinquency Prevention in Schools. Washington, DC: National Institute of Justice, U.S. Department of Justice.

Gold, M., \& Mann, D. W. (1984). Expelled to a friendlier place: A study of effective alternative schools. AnArbor, MI: University of Michigan Press.

Grieshop-Goodwin, T, Swann, A., \& Colwell, P. (2009). Opportunities Lost: Racial Disparities in Juvenile Justice in Kentucky and Identified Needs for System Change retrieved October 2010 from http://www.kyyouth.org/documents/09Brief_DMCFinal.pdf 
Grunbaum, J., Lowry, R, and Kann, L. (2001). Prevalence of health-related behaviors among alternative high school students as compared with students attending regular high schools. Journal of Adolescent Health, 29, 337-343.

Hadderman, M. (2002). Alternative schools: Trends and issues. Office of Educational Research and Improvement, Washington, D.C.

Hawkins, D. J., \& Wall, J. S. (1980). Alternative education: Exploring the delinquency prevention potential. Washington, D.C.: U.S. Department of Justice.

Hirschfield, P.J. (2008). Preparing for Prison?: The criminalization of school discipline in the USA. Theoretical Criminology, 12(1): 79-101

Huizinga, D., Loeber, R., Thornberry, T.P., and Cothern, L. (2000). Co-occurrence of Delinquency and Other Problem Behaviors. Bulletin. Washington, DC: U.S. Department of Justice, Office of Justice Programs, Office of Juvenile Justice and Delinquency Prevention.

Illback, R. J., \& Sanders, D. (2000). Kentucky 2000 safe schools data project: Statewide and regional data summary. Eastern Kentucky University: Kentucky Center for School Safety.

Imich, A. J. (1994). Exclusions from school: Current trends and issues. Educational Research, 36(1).

Jimerson, S. R., Anderson, G., \& Whipple, A. (2002). Winning the battle and losing the war: Examining the relation between grade retention and dropping out of high school. Psychology in the Schools, 39 (4), 441-457 
Orfield, G., Losen, D., Wald, J., \& Swanson, C., (2004). Losing our future: How minority the war: Examining the relation between grade retention and dropping out of high school. Psychology in the Schools, 39(4), 441-457.

Jones, I. (1999). Case studies of students transitioning from an alternative school back into high school. Unpublished doctoral dissertation, Virginia Polytech State University, Falls Church, Virginia.

Joseph, J. (1995). Juvenile Delinquency among African Americans. Journal of Black Studies, 25(4) 475-491.

Kaplan, E. L. \& Meier, P. (1958). Nonparametric estimation from incomplete data. Journal of the American Statistical Association 53: 457-481.

Katsiyannis, A., \& Williams, B. (1998). A national survey of state initiatives on alternative education. Remedial and Special Education, 19, 276-284.

Kentucky Youth Advocates (2008). Mulch, hoops and homemade pie: A report to the Kentucky State Board of Education on A5 and A6 programs in the commonwealth.

Kershaw, C. A., \& Blank, M. A. (1993, April). Student and educator perceptions of the impact of an alternative school structure. Paper presented at the annual meeting of the american educational research association. (ED No. 360729)

Kim, JH, \& Taylor, KA. (2008). Rethinking Alternative Education to break the cycle of educational inequality and inequity. The Journal of Educational Research, 101 (4) 207-219. 
Kliner, B., Porch, R., \& Farris, E. (2002). Public alternative schools and programs for students at risk of educational failure: 2000-2001. Washington, DC: National Center for Educational Statistics.

Kugelmass, J. (1987). Behavior, Bias, and Handicaps: Labeling the emotionally disturbed child. Transaction Books, New Brunswick, NJ.

Lange, C. M., \& Sleeten, S. J. (1995). Characteristics of alternative schools and programs serving at-risk students (Research Report No. 16). Minneapolis, MN: University of Minnisota, Enrollment Options for Students with Disabilities Project.

Lange, C. M., \& Sleeten, S. J. (2002). Alternative education: A brief history and research synthesis. Alexandria, VA: National Association of State Directors of Special Education. Retrieved November 1, 2005, from http://nasdse.org

Lange, C. \& Thomas, K. (2003, June 12). Accountability for alternative learning. USA Today, p. 8d.

Lehr, C., Soon Tan, C., \& Ysseldyke, J. (2009). Alternative Schools. A synthesis of state-level policy and research. Remedial and Special Education, 30(1), 19-32.

Lehr, C. A., \& Lange, C. M. (2003). Alternative schools and the students they serve: Perceptions of state directors of special education (Policy Research Brief No. 14). University of Minnesota: Institute on Community integration.

Lehr, C. A., \& Lange, C. M. (2003). Alternative schools serving students with and without disabilities. Preventing School Failure, 47(2), 59-66. 
Lehr, C. A., Lanners, E. J., \& Lange, C. M. (2003, October). Alternative schools: Policy and legislation across the united states (Research Report No. 1). University of Minnesota: Institute on Community Integration.

Lofflin, J. (2000). Alternative education's spoiled image: When it happened, how it happened, why it happened, and what to do about it. Indianapolis, IN: Indianapolis Public Schools \& University of Indianapolis.

Matson, J. and Niemien,G. (1987). Validity of measures of conduct disorder, depression and anxiety. Journal of Clinical Child Psychology, 16(2), 151-157.

Miller, Fitch \& Marshall (2003). Locus of control and at-risk youth: a comparison of regular education high school students and students in alternative schools. Education, 123(3). 548-552.

Morrison, G. M., Anthony, S., Storino, M. H., Cheng, J. F., Furlong, M. F., \& Morrison, R. L. (2001, Winter). School expulsion as a process and an event: Before and after effects on children at risk for school discipline. New Directions for Youth Development, 92, 45-71.

Morrison, G. M., \& D'Incau, B. (1997). The web of zero tolerance: Characteristics of students who are recommended for expulsion from school. Education and the treatment of children, 20,316-335.

National Center for Education Statistics, 2010 Alternative Schools and Programs for Public School Students At Risk of Educational Failure: 2007-08 http://nces.ed.gov/pubsearch/pubsinfo.asp?pubid=2010026

Nealis, L. (2003). Persistently dangerous schools and other problematic NCLB provisions. NASP Communique, 32(3). 
Noguera, P (2008). The trouble with black boys :and other reflections on race, equity, and the future of public education. San-Francisco: Josie-Bass.

youth are being left behind by the graduation rate crisis, Cambridge, MA: The Civil Rights Project at Harvard University.

Osborn, J. (2006). Bringing balance and technical accuracy to reporting odds ratios and the results of logistic regression analyses. Practical Assessment, Research \& Evaluation, 11 (7).

Paglin, C., and Fagler, J. (1997). Alternative schools: approaches for students at risk. Northwest Regional Educational Laboratory.

Pascopella, Angela (2005) 'Money Makes Security Go Around', District Administration 41(7), 47-53.

Poe-Yamagata, E., and Jones, M. 2000. And Justice for Some. Washington, DC: Prepared by The National Council on Crime and Delinquency for the Building Blocks for Youth Initiative.

Raywid, M. (1981). The first decade of public school alternatives. Phi Delta Kappan, $62(8), 551-553$.

Redding, R., \& Shalf, S. (2001, July). The legal context of school violence: The effectiveness of federal, state and local law enforcement efforts to reduce gun violence in schools. Law and Policy, 23(3), 297-342.

Reinke, W., \& Walker, H. M. (2005). Deviant peer contagion in education: Critical issues, current practices and potential solutions. University of Oregon: Executive taskforce on deviant peer contagion.

Ritzer, G. (2000). Modern sociological theory. Maryland: McGraw-Hill. 
Rozenkrantz, A. S. (1995). Alternative learning environments. Insights on Educaitonal Policy, Practice and Research, 6.

Sagor, R. (1997). Alternative programs for at-risk youth: Wolves in sheep's clothing? Reaching Today's Youth, 1(2), 18-22.

Schrenko, L. C. (2000). Evaluation of the Georgia crossroads alternative education program: July 1997-2000. Atlanta, GA: Georgia State Department of Education.

Sekayi, D. N. R. (2001). Intellectual indignation: Getting at the roots of student resistance in an alternative high school program. Education, 122(2).

Settles, D., \& Orwick, B. (2003). Alternative education: past, present and next steps. University of Kentucky: Kentucky Center for School Safety.

Shaw, C., Zorbaugh, F., McKay, H., and Cottrell, L. (1929). Delinquency Areas: A study of the geographic distribution of school truants, juvenile delinquents and adult offenders in Chicago. Chicago: University of Chicago Press

Singer, J \& Willett, J. (2003). Applied longitudinal data analysis. Modeling Change and Event Occurrence. Oxford: Oxford University Press.

Singer, J \& Willett, J. (1993) It's about Time: Using Discrete-Time Survival Analysis to Study Duration and the Timing of Events. Journal of Educational Statistics, 18 (2), 155-195.

Skiba, R., \& Peterson, R. L. (1999). The dark side of zero tolerance. Phi Delta Kappan, $80(5), 372-384$

Skiba, R. J., Peterson, R., \& Williams, T. (1997). Office referrals and suspension: Disciplinary intervention in middle schools. Education and Treatment of Children, 20 (3). 295-315. 
Solilei, G. (2005). Schools for disruptive students: A questionable alternative. Retrieved September 17, 2005, from http://www.ael.org

Stephens, S., \& Lakin, C. (1995). Where do students with emotional or behavioral disorders go to school. In Issues in educational placement: students with emotional and behavioral disorders (pp. 47-74). Hillsdale, NJ: Lawrence Erlbaum.

Swarts, L. (2002). A preliminary investigation of alternative education programs in kentucky (Report No. Phase I). Kentucky Department of Education.

Swarts, L. (2004). Alternative education accountability: Kentucky's approach [Special section]. Impact, 16(3), feature issue on achieving secondary education and transition results for students with disabilities.

Thomas, K. (2003, June 12). Accountability for alternative learning. USA Today, p. 8d.

Troyan, B. (2003). The silent treatment: Perpetual in-school suspension and the education rights of students. Texas Law Review, 81, 1637-1700.

Turpin, R. (2000). Academic success of at-risk students in an alternative school setting: An examination of students' academic success out of the mainstream school environment. Unpublished master's thesis, Campbellsville University, Campbellsville, Kentucky.

UCLA Academic Technology Services, Statistical Consulting Group Retrieved on February 20, 2010 from http://www.ats.ucla.edu/stat/mult_pkg/faq/general/citingats.htm

Wald, J. and Losen, D. (Eds.) (2003). Deconstructiong the School to Prison Pipeline: New. Directions for Youth Development. NJ: Jossey Bass 
Weissman, M., Wolf, E., Sowards, K., Abate, C., Weinberg, P., \& Marthia, C. (2005, April). School yard or prison yard: Improving outcomes for marginalized youth. Center for Community Alternatives.

Young, T. (1990). Public alternative education. New York, NY: Teachers College Verdugo, R \& Glenn,B (2006). Race and alternative schools: The new tracking. Washington, D.C. : Hamilton Fish Institute on School and Community Violence Van Belle, G (2002) Statistical Rules of Thumb. New York, NY: John Wiley \& Sons. 


\section{APPENDIX}

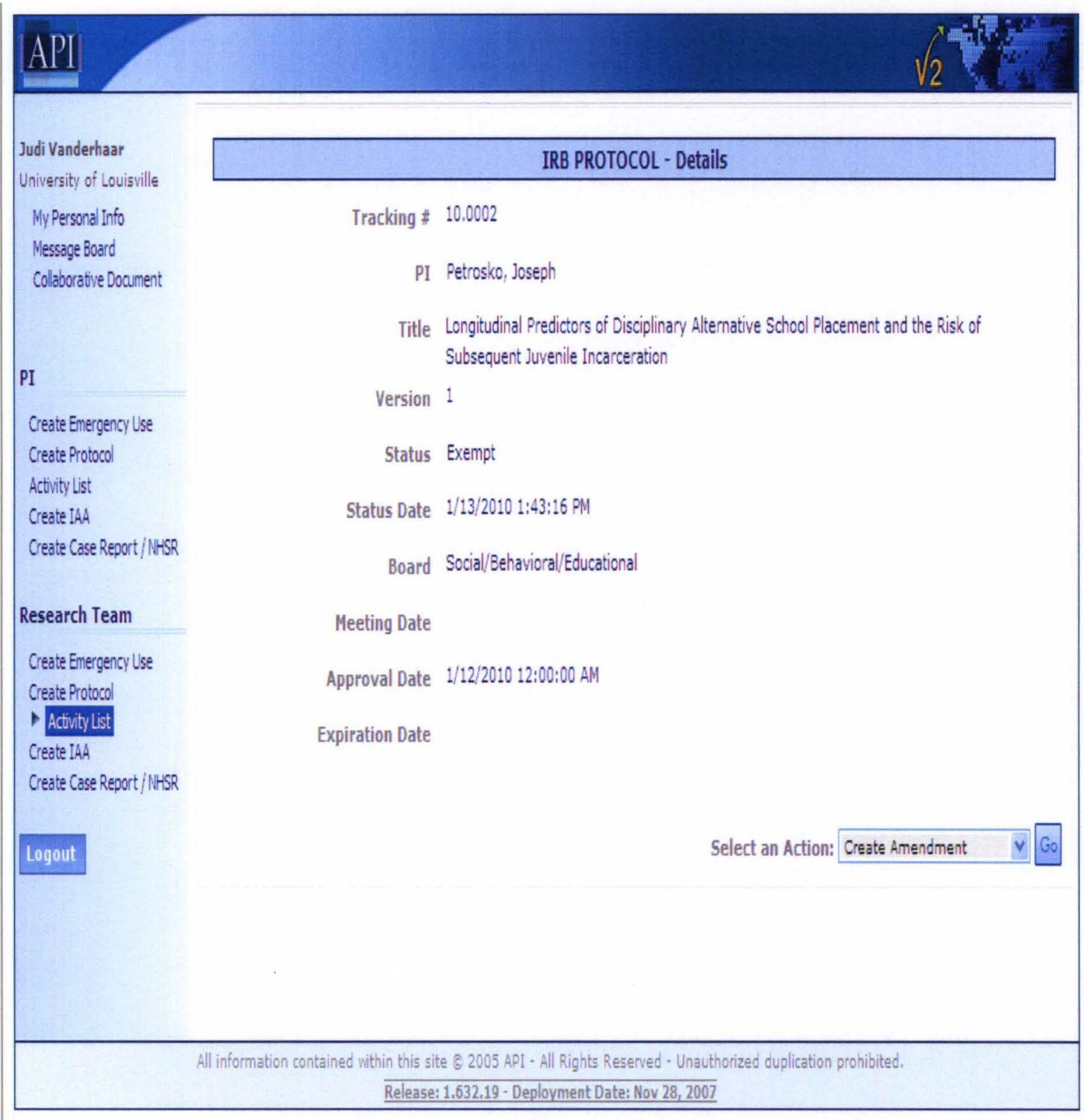




\title{
CURRICULUM VITAE
}

\author{
Judi Elisa Vanderhaar \\ Jefferson County Public Schools \\ Department of Accountability, Research \& Planning \\ Louisville, KY \\ Email: judi.vanderhaar@jefferson.kyschools.us \\ 502-485-3708
}

\section{EDUCATION}

2010 Ph.D. Candidate, Educational Leadership (Urban Educational Policy Analysis) Department of Educational Leadership, Foundations, and Human Resource Development; University of Louisville. Projected Graduation: May, 2010.

Dissertation: Longitudinal predictors of placement in disciplinary alternative school and the risk of subsequent juvenile detention.

2003 M.A., Sociology, with certification in Pan African Studies, University of Louisville. Master's Thesis: The shade cast over suspension: An investigation of racial disparities in out-of-school suspension among elementary school children.

1998 B.S., Sociology, University of Louisville.

\section{RESEARCH AND PROFESSIONAL EXPERIENCE}

Apr 2008-Present Evaluation Specialist, Jefferson County Public Schools:

Department of Accountability, Research \& Planning

- Collect quantitative and qualitative data; conduct mixed methods analyses for the evaluation of district-wide programs and initiatives.

- Research and evaluation design; survey development; write program evaluation reports for district, state and federal educational intervention programs; provide recommendations for program improvement; present findings to program directors and coordinators. 
Jan 2007-June 2008 Consultant, National Science Foundation Study: New Teacher Induction and Mentoring Study, Vanderbilt University / University of Pennsylvania with Dr. Laura Desimone, Dr. Tom Smith \& Dr. Andy Porter

- Collected quantitative and qualitative data at research sites in Kentucky (e.g., cognitive interviews for survey development, classroom observations, and interviews).

- Participated in instrument development, analyses, writing for presentations/ publications related to the study with team.

Jul 2007-Mar 2008 Graduate Research Assistant, University of Louisville, Department of Educational Leadership, Foundations, and Human Resource Education

- Conducted and analyzed data in four state experimental research design study (Effective Schools for the $21^{\text {st }}$ Century Grant) with Dr. Sam Stringfield and Dr. Sue Lasky:

- Assisted with protocol development, quantitative and qualitative analyses.

- Lead graduate student group research project to assess college-wide perceptions of diversity.

Jul 2005- Mar 2008 Evaluation Specialist Intern, Jefferson County Public Schools: Department of Accountability, Research \& Planning

- Collected quantitative and qualitative data; conducted mixed methods analysis for the evaluation of district-wide programs and projects.

- Designed research; developed surveys; wrotr program evaluation reports for district, state and federal educational intervention programs; provided recommendations for program improvement; presented findings to program directors and coordinators.

Jul 2006- Jul 2007 Graduate Research Assistant, University of Louisville, Department of Teaching and Learning

- Assisted faculty members with research and publications

- Conducted guest lecturers for faculty courses

\section{TEACHING EXPERIENCE}

Fall 2010 Guest Lecturer: Dissertation Research, Department of Educational Leadership, University of Louisville, College of Education and Human Development

Fall 2009 Guest Lecturer: Doctoral Course on Research Methods, Doctoral joint 
program:Jefferson County Public Schools and the University of Louisville, College of Education and Human Development.

Fall 2007 Guest Lecturer: Doctoral Student Seminar, Department of Educational Leadership, University of Louisville, College of Education and Human Development

Summer 2007 Co-Instructor: Developing Cross Cultural Competence, Department of

Teaching and Learning, University of Louisville, College of Education and Human Development

Spring 2007 Guest Lecturer: Action Research, Department of Educational Leadership,

University of Louisville, College of Education and Human Development

Spring 2007 Guest Lecturer: Developing Cross Cultural Competence, Department of

Teaching and Learning, University of Louisville College of

Education and Human Development

1999-2005 Substitute Teacher: All subject areas (K-12), Jefferson County Public

Schools, Louisville, KY.

\section{PUBLICATIONS}

\section{Peer Reviewed}

Clayton, C.D., Howell, P., Kapustka, K. M., Thomas, S., \& Vanderhaar, J. E. (2009). Understanding the scope of social justice in teacher education: The incidence of social justice in accreditation documents. Teacher Education and Practice, 22 (3), 302-322.

Thomas, S., \& Vanderhaar, J. E. (2008). The challenges of implementing and sustaining Multiculturalism in Teacher Education. The Teacher Educator, 43(3), 173-197.

Vanderhaar, J. E., Muñoz, M., \& Rodosky, R. (2007). Leadership as accountability for learning: The effects of school poverty, teacher experience, previous achievement and principal preparation programs on student achievement. Journal of Personnel Evaluation in Education, 19(1 \& 2), 17-33.

Muñoz, M. A., \& Vanderhaar, J. E. (2006). Literacy-embedded character education in a large urban district: Effects of the Child Development Project on elementary school students and teachers. Journal of Research on Character Education, 4(1 \& 2), 47-64.

\section{Book Reviews \& Non Peer-Reviewed}

Vanderhaar, J.E. (2008). Book Review: Merrell, Kenneth W.; Parisi, Danielle M. \& Whitcomb, Sara A. (2007). Strong Start: A Social and Emotional Learning 
Curriculum, Grades K- 2. Baltimore: Brookes Publishing. Education Review: A journal of book reviews.

Vanderhaar, J. E., \& Muñoz, M. A. (2006). Educating At-Risk African American Males: Formative and Summative Evaluation of the Street Academy Program. (ERIC Document Reproduction Service No. ED495958).

Vanderhaar, J. E., \& Muñoz, M. A. (2005). Limited English Proficient Intervention: Effects of a summer program in reading and mathematics. (ERIC Document Reproduction Service No. ED491400).

\section{Unpublished Manuscripts}

Vanderhaar, J. E., \& Chang, F. The (Ill) Logic of Exclusionary Discipline and Student Self-Regulation.

\section{EVALUATION REPORTS}

Vanderhaar, J.E. \& Weatherholt, T. (2010). Protecting You Protecting Me, Louisville

KY: Jefferson County Public Schools: Office of Safe and Drug Free Schools

Vanderhaar, J.E. (2010). Zeroing in on Alcohol Prevention (ZAP): End of grant evaluation report. Washington, DC: Office of Safe and Drug Free Schools.

Weatherholt, T., \& Vanderhaar, J.E. (2010). Steps to Respect, Louisville, KY: Jefferson County Public Schools: Office of Safe and Drug Free Schools

Vanderhaar, J.E. (2010) Learn and Serve Service Learning Program, Louisville, KY: Jefferson County Public Schools: Volunteer Talent Department.

Vanderhaar, J.E. (2009). Protecting You Protecting Me, Louisville KY: Jefferson County Public Schools: Office of Safe and Drug Free Schools

Vanderhaar, J.E. (2009). Whitney M. Young Scholars Program. Louisville, KY: Jefferson County Public School District: Lincoln Foundation.

Vanderhaar, J.E. (2009). Math \& Science Summer Program. Louisville, KY: Jefferson County Public School District: Lincoln Foundation.

Vanderhaar, J.E. (2009). MetroServe Service Learning Program. Louisville, KY: Jefferson County Public School District: Volunteer Talent Center

Vanderhaar, J.E. \& Chang, F. (2007). Project Business United in Leadership Development. Louisville, KY: Jefferson County Public School District: Lincoln Foundation 
Vanderhaar, J.E. \& Chang, F. (2007). Alternative School Evaluation: Breckenridge Metropolitan. Louisville, KY: Jefferson County Public School District, Department of Student Safety and Relations

Vanderhaar, J.E. \& Chang, F. (2007). Alternative School Evaluation: Kennedy Metropolitan. Louisville, KY: Jefferson County Public School District, Department of Student Safety and Relations

Vanderhaar, J.E. \& Chang, F. (2007). Alternative School Evaluation: Buechel Metropolitan. Louisville, KY: Jefferson County Public School District, Department of Student Safety and Relations

Vanderhaar, J.E. \& Chang, F. (2006). Project Business United in Leadership Development. Louisville, KY: Jefferson County Public School District: Lincoln Foundation.

Vanderhaar, J.E. \& Winsch, B. (2006). Project Science Match and the Right Technology. Washington, DC: Office of Innovations and Improvement: Women Educational Equity Program.

Vanderhaar, J.E. \& Munoz, M A. (2006). Street Academy. Louisville, KY: Jefferson County Public School District.

Vanderhaar, J.E. \& Dossett, D. (2006). Project Students in Alcohol Free Education (SAFE): End of grant evaluation report on life skills training. Washington, DC: Office of Safe and Drug Free Schools.

Vanderhaar, J.E. \& Munoz, M A. (2005). English as a Second Language Summer Reading and Math Program. Louisville, KY: Jefferson County Public School District.

Vanderhaar, J.E. \& Munoz, M A. (2005).Positive Outreach Program. Louisville, KY: Jefferson County Public School District.

Vanderhaar, J.E. \& Munoz, M A. (2005). Behavioral Coaches Program. Louisville, KY: Jefferson County Public School District. 


\section{PRESENTATIONS}

\section{National}

Lewis, T., Chang, F., Vanderhaar, J.E. \& Winsch, B. (2010). The Role of School Climate Data in Assessment and Accountability. Poster presented October 2010 at the National Evaluation Institute Conference, Williamsburg VA.

Vanderhaar, J.E. \& Carpenter, B. (2009). Responsiveness to Culture and Context in Evaluation. Poster presented October 2009 at the National Evaluation Institute Conference, Louisville, KY.

Vanderhaar, J. E. \& McGraner, K. (2008, March) Divergent Perceptions: New Teacher Challenges in Two Large Urban Districts. Paper presented March 2008 at the American Educational Research Association Conference, New York, NY.

Hulan, N, Ardashevak, Y, Vanderhaar, J.E. (2007, November). Culturally Responsive Teaching. Workshop presented at the National Kappa Delta Pi Bi-Annual Convocation, Louisville, KY

Bittner, J \& Vanderhaar, J.E. (2007, October) Preparing teen mothers for life after high school. Paper presented at the National Dropout Conference, Louisville, KY

Vanderhaar, J.E., Munoz, M.A., Burton, A. (2007, October). Using evaluation to guide a pilot program for African American males placed at risk. Paper presented the National Evaluation Institute conference, Orlando, FL.

Vanderhaar, J.E., Winsch, B. (2007, October). Doing SMART things for teenage mothers. Paper presented at the National Evaluation Institute conference, Orlando, FL.

Dossett, D., \& Vanderhaar, J. E. (2006, July). Evaluating the impact of Reading First in a large urban district: A mixed methodology design. Paper presented at the National Evaluation Institute conference, Dallas, TX.

Vanderhaar, J. E. Muñoz, M.,\& Rodosky, R.(2006, July). Leadership as accountability for learning. Paper presented at the National Evaluation Institute conference, Dallas, TX.

\section{Regional}

Vanderhaar, J.E. (2008, April) Documenting the journey from 3rd grade to alternative schoolplacement through survival analysis. Paper presented at the Regional Spring Research Conference, Cincinnati, $\mathrm{OH}$. 
Vanderhaar, J.E. (2007, April). Racial Disparities in Suspension Among Elementary School Children. Paper presented at the Regional Spring Research Conference, Lexington, $\mathrm{KY}$.

Vanderhaar, J.E., Crawford, F., Wyrik, A., White, J., Rollin, I. (2007, April). Assessing Perceptions of Diversity in a Metropolitan College of Education. Paper Presented at the Spring Research Conference, Lexington, KY.

\section{Invited}

Vanderhaar, J.E. \& Thomas, S. (2009, June).Cultural Competence and Substitute Teaching. Jefferson County Public Schools, Louisville, KY

Vanderhaar, J.E. \& Minnis, B. (2008, June). Cultural Competence and Substitute Teaching. Jefferson County Public Schools, Louisville, KY

Vanderhaar, J.E. (2006, May). Self-Esteem and Goal Setting during Teenage Motherhood. Keynote speaker, Teenage Parent Program (TAPP) schools, Louisville, KY.

\section{PROFESSIONAL SERVICE}

\section{National}

2007-2008

$2007-2008$

2006-2008

2006-2007

Local 2009-Present 2007- 2008

2007- 2008

2007-2008

2006- 2010

2004- 2006
Chair, American Educational Research Association (AERA) Division H Outstanding Publication Competition

Kappa Delta Pi Bi-Annual Convocation National Planning Committee member

Leadership Committee Member, American Educational Research Association (AERA) Division $\mathrm{H}$

Co-Chair, American Educational Research Association (AERA) Division H Outstanding Publication Competition

JCPS Service Learning Committee member

President, Kappa Delta Pi - Eta Omicron Chapter, University of Louisville

Diversity Committee: Graduate Student Representative/voting member, University of Louisville, College of Education and Human Development

Race Community \& Child Welfare Undoing Racism, Data and Research Committee member

Advisory Board, Project S.M.A.R.T. (Science, Math and the Right Technology)

Graduate Student Association: Departmental Representative, 
University of Louisville, College of Education and Human Development.

Standards and Admissions Committee: Graduate Student

Representative/voting member, University of Louisville, College of Education and Human Development

\section{NATIONAL EDITORIAL AND PROPOSAL REVIEW SERVICE}

2007

2007

$2007-2008$

2006-2007

2007

2006-2007

2006

2006
Ad Hoc Book Reviewer, Education Review, Mary Lou Fulton

College of Education, Arizona State University and Michigan State University

Ad-Hoc Reviewer, Journal for the Education of Students Placed At Risk, College of Education and Human Development, University of Louisville College of Education and Human Development American Educational Research Association (AERA) Division L, Proposal Reviewer

American Educational Research Association (AERA) Division H, Session Reviewer

Kappa Delta Pi, National Convocation Proposal Reviewer

American Educational Research Association (AERA) Division H, Session Reviewer

National Association for Multicultural Education (NAME) Proposal Reviewer

American Educational Research Association (AERA) Proposal Reviewer, Division G

\section{COMMUNITY SERVICE}

2005-Present

2005-Present

2007 (Oct)

2001-2002
EverylReads Book Buddy Reading Mentor, JCPS

Middle School Connection Volunteer, JCPS

Facilitator, Courageous Conversations about Racism, Joint

Conference of Louisville's Neighborhood Place System \& the KY

Cabinet for Health and Family Services on Race, Community and

Child Welfare, Louisville KY

Reading Tutor, Chenoweth Elementary, JCPS

\section{PROFESSIONAL DEVELOPMENT/ACTIVITIES}

2008

2006-2008

2007

2007

2007
Workshops on Quasi-Experimental Design and Analysis in Education with Tom Cook \& Will Shaddish, Northwestern University Inclusive Teaching Circle, University of Louisville, Louisville, KY Classroom Assessment and Grading that Works with Robert Marzano, Orlando, FL, October 6th

HLM workshop with Stephen Raudenbuch \& Tony Byrk, University of Chicago, September Undoing Racism, The Peoples Institute, Louisville, KY 
Negative Stereotyping in the Classroom, University of Louisville Culturally Responsive Behavior Management, Louisville Urban League

2006- 2007

2006 Future Faculty Program, University of Louisville, Louisville, KY

2006 Change Acceleration Process (CAP) Leadership Training, GE/JCPS Federal Grant Reporting Training, U.S. Department of Education, Washington, DC.

2006 National Association of Test Directors (NATD) annual meeting, SanFrancisco, CA.

2006 Instructionally Sensitive Assessments with James Popham, San Francisco, CA.

\section{HONORS/AWARDS}

March 2008 AERA Division H Service Award, Outstanding Publications Competition April 2007 Outstanding Volunteerism and Community Service, University of Louisville

2006-2008 Champions for Children, Jefferson County Public Schools

\section{PROFESSIONAL AFFILIATIONS}

American Educational Research Association

Social Context of Schooling (Division G)

Educational Evaluation (Division $\mathrm{H}$ )

Education Policy (Division L)

American Sociological Association

National Association of Multicultural Education

\section{RESEARCH INTERESTS}

School discipline policy and practice Culturally responsive research \& evaluation Use of survival analysis in education 